\title{
A comprehensive analysis of gene expression profiles in distal parts of the mouse renal
}

tubule.

Sylvain Pradervand ${ }^{2}$, Annie Mercier Zuber ${ }^{1}$, Gabriel Centeno ${ }^{1}$, Olivier Bonny ${ }^{1,3,4}$ and Dmitri Firsov $^{1,4}$

1 - Department of Pharmacology and Toxicology, University of Lausanne, 1005 Lausanne, Switzerland

2 - DNA Array Facility, University of Lausanne, 1015 Lausanne, Switzerland

3 - Service of Nephrology, Lausanne University Hospital, 1005 Lausanne, Switzerland

${ }^{4}$ - these two authors have equally contributed to the study

to whom correspondence should be addressed:

Dmitri FIRSOV

Department of Pharmacology and Toxicology, University of Lausanne, 27 rue du Bugnon, 1005 Lausanne, Switzerland

Phone: ++ 41-216925406 Fax: ++41-216925355ｅ-mail: dmitri.firsov@unil.ch

and

Olivier BONNY

Department of Pharmacology and Toxicology, University of Lausanne, 27 rue du Bugnon, 1005

Lausanne, Switzerland

Phone: ++ 41-216925417Ｆax: ++41-216925355ｅ-mail: olivier.bonny@,unil.ch 


\begin{abstract}
The distal parts of the renal tubule play a critical role in maintaining homeostasis of extracellular fluids. In this review, we present an in-depth analysis of microarray-based gene expression profiles available for microdissected mouse distal nephron segments, i.e., the distal convoluted tubule (DCT) and the connecting tubule (CNT), and for the cortical portion of the collecting duct (CCD) (Zuber et al., 2009). Classification of expressed transcripts in 14 major functional gene categories demonstrated that all principal proteins involved in maintaining of salt and water balance are represented by highly abundant transcripts. However, a significant number of transcripts belonging, for instance, to categories of G protein-coupled receptors (GPCR) or serine-threonine kinases exhibit high expression levels but remain unassigned to a specific renal function. We also established a list of genes differentially expressed between the DCT/CNT and the CCD. This list is enriched by genes related to segment-specific transport functions and by transcription factors directing the development of the distal nephron or collecting ducts. Collectively, this in silico analysis provides comprehensive information about relative abundance and tissue specificity of the DCT/CNT and the CCD expressed transcripts and identifies new candidate genes for renal homeostasis.
\end{abstract}




\section{Introduction}

The final adjustment of urine composition takes place in the distal parts of the renal tubule, i.e. in the distal nephron and in the collecting duct. Over the last decades, research efforts in the field allowed identification of many essential proteins (channels, transporters, receptors, etc.) involved in this process. The majority of these proteins were first discovered by expression cloning, an approach based on the a priori available information about function and tissue expression distribution of the candidate gene. The aquaporin-2 water channel (aqp-2), the $\mathrm{V}_{2}$-type of vasopressin receptor (Avpr2), the $\mathrm{Ca}^{2+}$-sensing receptor (CaSR), the thiazide-sensitive sodiumchloride co-transporter (NCC), the secretory potassium channel (ROMK), the amiloride-sensitive sodium channel $(\mathrm{ENaC})$ and the epithelial calcium channel (Trpv5) are just a few out of many examples of proteins identified by this approach. Moreover, a growing list of functionally important genes has been added from human genetic association studies. The latter includes WNK1 and WNK4 serine-threonine kinases [1], the FXYD2 subunit of the Na,K-ATPase [2], the KCNJ10 and KCNA1 potassium channels and the pro-EGF [3-5]. Significant progress in deciphering regulatory pathways in the distal nephron and/or collecting ducts has been made with the development of methods allowing global view of all expressed transcripts (transcriptome) or proteins (proteome) and their dynamics. For example, the aldosterone or vasopressin signaling pathways were extensively characterized by the serial analysis of gene expression (SAGE) and microarray hybridization [6, 7]. Various proteome tools were used for identification, of vasopressin-dependent phosphorylation sites within aqp-2 or for detection of lithium-induced changes in the proteome of the inner medullary collecting ducts (IMCD) $[8,9]$.

In order to identify new genes involved in renal homeostatic mechanisms we used an in silico approach based on the analysis of transcript abundance in several major functional gene categories most relevant to secretion/reabsorption processes in the distal nephron and/or the 
collecting duct. This analysis was performed on a recently obtained microarray-based dataset of gene expression profiles of the mouse distal convoluted tubule (DCT), the connecting tubule (CNT) and the cortical collecting duct (CCD) [10]. The principal characteristics of this dataset are the following: (i) the $\mathrm{DCT} / \mathrm{CNT}$ and the $\mathrm{CCD}$ samples were obtained by microdissection; the DCT and CNT were microdissected together because of the gradual transition between these two segments in mice; (ii) samples were prepared from animals sacrificed for microdissection every four hours throughout a $12 \mathrm{~h} / 12 \mathrm{~h}$ light-dark cycle (a total of 6 time-points); this protocol allows detection of all expressed transcripts independently of diurnal variations in their expression levels; (iii) a total of 30 animals were used for microdissection of DCT/CNT and CCD samples (5 animals/time-point); (iv) 12 microarray hybridizations were performed for both DCT/CNT and CCD (2 hybridizations/time-point). The quality of microdissection was validated by the analysis of expression levels of several nephron segment-enriched transcripts (see [10] and below). Altogether, this dataset represents a complete and reliable source of information on the genes expressed in the distal nephron and the CCD (see below).

Functional classification and analysis of transcript abundance allowed us to identify a new set of highly abundant transcripts encoding proteins potentially relevant to the homeostasis of water and/or electrolytes. Finally, comparison of the DCT/CNT and the CCD transcriptomes revealed a number of previously uncharacterized transcripts exhibiting significantly different expression levels between these parts of the renal tubule. These data could be further used for the functional characterization of the identified candidates.

1. Functional classification of DCT/CNT and CCD transcripts. Functional classification of DCT/CNT and CCD transcripts was performed using the PANTHER Classification System, a database allowing subdivision of proteins and mRNA transcripts into functionally related 
categories (www.pantherdb.org). A similar approach was previously used by Uawithya et al. for the transcriptional profiling of rat inner medullary collecting ducts (IMCD) [11]. The classification data are presented in tables in which only the 20 most abundant transcripts per category are listed for space purposes. If more than 20 transcripts per category fitted the cut-off criteria (see below), a full list of transcripts can be viewed in associated supplementary tables. The transcripts are ranked by their abundance calculated as $\log 2$ normalized microarray hybridization signal intensity (A-values) [12]. Hence, a difference in one unit of A_values corresponds to the 2-fold difference in the transcript expression levels. The median microarray signal intensity (5.8 units of A_value, for both the DCT/CNT and the CCD transcriptomes) was chosen as an arbitrary cut-off value above which expression of a transcript was assigned as significant. The data are discussed in terms of expression levels or transcripts abundance. However, we have to emphasize that microarray signal intensities and sequencing-based quantification of mRNA abundance have been shown to exhibit a correlation coefficient of $\sim 0.7$ [13]. To assess this correlation in the DCT/CNT and the CCD datasets we performed qPCR analysis of transcripts abundance in one of the selected gene categories, namely $\mathrm{G}$ proteincoupled receptors (GPCR). As shown in Figure 1A and 1B, both, DCT/CNT and CCD datasets exhibit a good correlation between microarray signal intensities and $\mathrm{Ct}$ values of $\mathrm{qPCR}$ amplification (correlation coefficients of 0.769 and 0.823 , respectively). These data also demonstrate that transcripts with A-values below the median cut-off level exhibit significantly lower correlation between microarray and qPCR data.

1.1. G protein-coupled receptors (GPCRs). Most GPCRs that have been previously identified in the DCT/CNT and/or the CCD are abundantly represented in the respective transcriptomes (Table 1 and Supplemental Table 1). These include vasopressin receptors type 1a (Avpr1a) and type 2 
(Avpr2), prostaglandin E receptors type 3 (Ptger3), type 1 (Ptger1) and type 4 (Ptger4), prostaglandin F receptor (Ptgfr), glucagon receptor (Gcgr), proteinase-activated receptor 2 (F2r11), calcium-sensing receptor (Casr), endothelin receptor type B (Ednrb), parathyroid hormone receptor 1 (Pth1r), adenosine A1 receptor (Adora1) and adrenergic receptors type beta 1 (Adrb1), beta 2 (Adrb2) and alpha 2a (Adra2a). This analysis also revealed the presence of a number of highly abundant GPCRs with yet unassigned function in the kidney. For instance, both, DCT/CNT and CCD exhibit high expression levels of several chemokine GPCRs, including Ccrl1, Cxcr4 and Gpr146. The Cxcr4 receptor has been shown to bind SDF-1, a chemokine involved in a multitude of functions, including epithelial patterning and renal morphogenesis [14]. However, the role of chemokine GPCRs in the adult kidney remains unknown. The DCT/CNT and the CCD transcriptomes are enriched by orphan receptors belonging to a subclass of adhesion-GPCRs (Celsr2, Gpr116, Gpr56 and Celsr1). Adhesion-GPCRs constitute a novel subclass of GPCRs characterized by the presence in their N-termini of cadherin-like cell adhesion modules. These receptors are critical for the normal development of the central nervous system and for the immune response. Several adhesion-GPCRs are involved in human diseases. For example, deletion of the Gpr56 gene in human causes the autosomal recessive bilateral frontoparietal polymicrogyria (BFP), a disease characterized by severe neurological dysfunction [15]. However, a renal phenotype in these patients, if any, has not yet been communicated. Both the DCT/CNT and the CCD transcriptomes revealed high expression levels of Gprc5C and Gprc5B, two receptors related to the family C of GPCRs, which also includes the metabotropic glutamate receptors, the GABA(B) receptors, several pheromone receptors and the calcium sensing receptor [16]. However, in contrast to other members of the family, both, Gprc5C and Gprc5B still remain orphan. Our analysis also revealed a high expression of three receptors belonging to the class A of the rhodopsin-like GPCRs, namely the oxoglutarate receptor 1 
(Oxgr1), the estrogen receptor (Gper or Gpr30) and the apelin receptor. Several pieces of evidence indicate that these receptors may have an important role in the regulation of tubular solute transport. Oxgr1 (also known as Gpr80 or Gpr99) is a specific receptor to $\alpha$-ketoglutarate, a citric acid cycle intermediate [17]. Interestingly, urinary concentration of $\alpha$-ketoglutarate varies significantly upon perturbation of systemic acid-base balance, being significantly increased in alkalosis and significantly decreased in acidosis [18]. This suggests a possible role for Oxgr1 in sensing acid-base disequilibrium. Gper is a recently identified plasma membrane estrogen receptor which mediates non-genomic effect of estrogen. As it was recently hypothesized, Gper may be involved in the rapid magnesiotropic effects of estrogen in the distal nephron [19]. Apelin is a recently discovered peptide which mediates a multitude of biological functions including vasoconstriction, cardiac myogenesis, glucose metabolism and vasopressin synthesis/release in the brain. Knockout of apelin receptor in mice leads to abnormal fluid homeostasis, resulting in disturbance of both, kidney urinary concentration capacity and drinking behaviour [20]. The role of this receptor in the renal tubules has not yet been elucidated.

1.2 Heterotrimeric G proteins. GPCRs transduce signals from extracellular stimuli by activating heterotrimeric $\mathrm{G}$ proteins. These latter can be grouped in four subfamilies Gas, Gai, $\mathrm{G \alpha q} / 11$ and Ga12/13, according to the structural and functional properties of their $\alpha$ subunits.

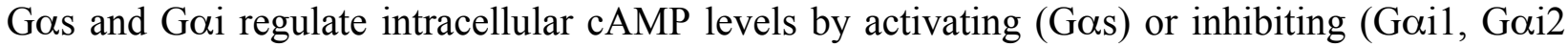

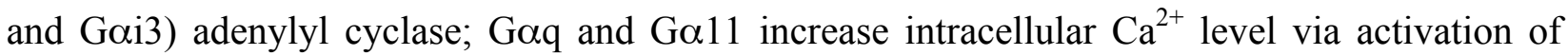
phospholipase C; and, Ga12 and Ga13 couple GPCRs to the small GTPases of the Rho family. As shown in Table 2, all $\alpha$ subunits, at the exception of Ga12, are well represented in both transcriptomes, thereby providing molecular basis for a variety of intracellular signalling pathways activated by GPCRs in these parts of the renal tubule. 
1.3 Nucleotide cyclases. Chabardès et al. have shown that cortical and outer medullary collecting ducts exhibit high expression levels of $\mathrm{Ca}^{2+}$-inhibitable adenylyl cyclases 6 (Adcy6) and 5 (Adcy5) [21]. Our data support these findings and extend the Adcy6 and Adcy5 distribution to the DCT/CNT (Table 3). Both the DCT/CNT and the CCD also show a high expression of Adcy9, a cyclase which can be either potentiated or inhibited by the intracellular $\mathrm{Ca}^{2+}[22]$. Collectively, these cyclases represent a point of cross-talk between the cAMP- and $\mathrm{Ca}^{2+}$-dependent signalling pathways. Similar to what was found in the IMCD, both, the DCT/CNT and the CCD exhibit low expression of guanylate cyclases (only Gucy1a3 fit the cutoff criteria) and none of the nitric acid synthase isoforms were detected (data not shown) [11].

1.4 Cyclic nucleotide phosphodiesterases. Cyclic nucleotide phosphodiesterases (Pde) participate in attenuation of GPCR signalling by degrading cellular cAMP and/or cGMP. As shown in Table 4, both, the DCT/CNT and the CCD exhibit high expression levels of several cAMP-specific phosphodiesterases, including $\mathrm{Ca}^{2+}$-activated Pde1a and cGMP-inhibited Pde3b. A significant expression of 3-isobutyl-1-methylxanthine (IBMX)-insensitive Pde8a and Pde8b provides a molecular basis for the IBMX-insensitive fraction of phosphodiesterase activity. The rolipram-sensitive cAMP-specific Pde4b and Pde4a have been proposed as important regulators of Avpr2-induced signalling cascade [23]. However, in the DCT/CNT and the CCD transcriptomes presented here they are expressed only at moderate levels.

1.5 Protein kinases. More than 350 protein kinases have been found in the transcriptomes of the DCT/CNT and the CCD (Table 5 and Supplemental Table 2). Most of them ( 300, Table 5A and Supplemental Table 2) belong to the class of serine/threonine protein kinases. Importantly, kinases that have been previously reported to strongly influence the secretion/reabsorption processes in DCT/CNT and/or the CCD are abundantly represented. WNK1, WNK4, SPAK (STK39) and Sgk1 have been involved in maintaining salt balance and are present within the 20 
most abundant serine-threonine kinases. Both, the DCT/CNT and the CCD also exhibit moderate to high expression levels of protein kinase A (Prkaa2, Prkacb, Prkaca and Prkaa1), protein kinase C (Prkcd, Prkci, Prkch, Prkca and Prkcz), casein kinases (Csnk1d, Csnk1a1, Csnk2a1, Csnk1g2 and Csnk2a2), Gsk3 $\beta$ and $\mathrm{G}$ protein-coupled receptor kinases 6, 5 and 4. Interestingly, several in vitro studies have demonstrated that the activity of the DCT-specific sodium-chloride cotransporter (NCC) is regulated by WNK3 [24], a kinase which is expressed at background levels in our data (A_values of 3.8 and 2.8 in DCT/CNT and CCD, respectively). Accordingly, WNK3 is also absent in microarray-based rat IMCD transcriptome [11]. Collectively, these results indicate that WNK3 distribution in the kidney requires a detailed re-evaluation. By contrast, both the DCT/CNT and the CCD exhibit strong expression of various serine-threonine kinases with yet unattributed function in the kidney. These include Pctk1, Pim3, Pak4, Aak1, Taok3, Rock1 and several MAP kinases. In the kidney, tyrosine kinases (Table 5B) and receptor tyrosine kinases (Table 5C) have been mostly involved in tubulogenesis, cell differentiation and in maintaining cell polarity. However, the fibroblast growth factor receptor 1 (Fgfr1), which is specifically expressed in the distal nephron and the collecting duct, has been recently shown as the predominant receptor for the hypophosphatemic action of FGF23 [25].

1.6 Protein phosphatases. Protein phosphatases participate in intracellular signalling by reversing protein kinases-dependent events. All protein phosphatases can be grouped into three subfamilies: serine/threonine phosphatases, phosphotyrosine-specific protein tyrosine phosphatases and dual specificity (serine/threonine/tyrosine) phosphatases. As shown in Table 6 and Supplemental Table 3, both, DCT/CNT and CCD express a variety of highly abundant phosphatases representing all three subfamilies. However, despite high expression levels and, presumably, significant functional role, only a limited number of phosphatases have been characterized in the kidney. Several studies have shown that calcineurin (Ppp3ca), a 
serine/threonine phosphatase with broad substrate specificity, is involved in the regulation of transport proteins, including the Na,K-ATPase, aqp-2, ROMK and acid-base transporters [26-29]. The ROMK has been also shown as a substrate of tyrosine phosphatases [30]. Dual specificity phosphatases are thought to participate in renal function mainly by dephosphorylating kinases involved in the stress response (e.g. MAP kinases).

1.7 A kinase anchoring proteins. A kinase anchoring proteins (AKAPs) constitute a family of scaffold proteins involved in the targeting of protein kinase A to its substrates. The AKAPs have been extensively studied for their role in the PKA-dependent regulation of aqp- 2 and ENaC activity. Henn et al., and Okutsu et al., have demonstrated that aqp-2 is co-localized with AKAP7 (AKAP18) and AKAP11 (AKAP220) in subapical vesicles of the principal cell [31, 32]. Bengrine et al., have shown that AKAP7 is also involved in the feedback inhibition of ENaC [33]. It has been proposed that these AKAPs are required for compartmentalization of cAMP signalling in the principal cell. As shown in Table 7, we found both AKAP7 and AKAP11 in the DCT/CNT and CCD transcriptomes. However, the role of the more abundant AKAPs 2, 9 and 8 has not yet been assessed.

1.8 Phospholipases. Phospholipases play important roles in transmembrane signaling processes activated by GPCRs and receptor tyrosine kinases. Receptor-mediated activation of phospholipases results in hydrolysis of membrane phospholipids and generation of phospholipidderived second messengers. Phospholipases C (PLC) is a family of enzymes which catalyses the hydrolysis of phosphatidylinositol 4,5-biphosphate to produce diacyglycerol (DAG) and inositol 1,4,5-trisphosphate (IP3). In the DCT/CNT and/or the CCD several targets of PLC/DAG/PKC cascade have been identified, including TRPV5 calcium channel, aqp-2, ROMK and ENaC [3437]. We found that the most abundant phospholipase in the DCT/CNT and the CCD is Plcg1, a PLC activated by a variety of growth factors including platelet-derived growth factor (PDGF), 
hepatocyte growth factor (HGF) and fibroblast growth factor (FGF) (Table 8). Recently, Irarrazabal et al., have shown that Plcg1 contributes to the osmoprotective effect of TonEBP/OREBP transcriptional factor in the kidney [38]. Analysis of both transcriptomes also revealed expression of $\mathrm{Ca}^{2+}$-sensitive PLC isoforms Plcd3 and Plcd1 but only a low amount of Gq-activated Plcb1. Phospholipases A2 (PLA2) catalyze the hydrolysis of phospholipids to generate free fatty acids and lysophospholipids. One of the principal products of PLA2 activity is the arachidonic acid, a precursor in the biosynthesis of prostaglandins and other eicosanoids. Prostaglandins are known to regulate water and solutes transport in an autocrine or paracrine manner by activating apical or basolateral GPCRs. According to our data, the principal PLA2 isoforms expressed in the DCT/CNT and the CCD are Pla2g4a, Pla2g15 and Pla2g6 (Table 8). Phospholipase D (PLD) isoforms which are also abundantly represented in both trancriptomes have been recently shown to be important regulators of endocytosis and endosomal recycling pathways [39].

1.9 Small GTP-binding proteins. Small GTP-binding proteins are low-molecular weight GTPases $(20-25 \mathrm{kDa})$ that control a variety of cellular processes including vesicle transport, cytoskeleton dynamics, cell division and immune response. All small GTPases can be divided in five subfamilies, namely the Rab subfamily, the Arf subfamily, the Rho/Rac/Cdc42 subfamily, the Ras/Ral/Rap subfamily and the Ran GTPase. More than 50 members of the Rab subfamily were found to be expressed at significant levels (Table 9A and Supplemental Table 4). The members of this family are implicated in the transport, docking and fusion of endocytotic vesicles. Van de Graaf et al. have shown that Rab11a is required for the intracellular trafficking of TRPV5 and TRPV6 calcium channels to the cell surface [40]. Curtis and Gluck have demonstrated that Rab11 and Rab20 are mainly expressed in V-ATPase expressing intercalated cells of the collecting duct, whereas principal cells of the collecting duct and of the distal nephron 
are enriched in Rab18 and Rab5a [41]. Several evidence indicate that Rab(s) could be involved in trafficking of CFTR, ENaC and aqp-2 [42]. However, functional role of many highly abundant Rab(s) in DCT/CNT and CCD remains unknown. ADP-ribosylating factors (Arfs) are participating in the formation of coated transport vesicles. El-Annan et al. have shown abundant expression of Arf1 and Arf6 in the distal nephron and the collecting duct and have demonstrated that Arf1 is mostly localized to the apical membrane whereas Arf6 appeared to be mainly expressed at the basolateral membrane [43]. Arf6 was further demonstrated as a factor promoting Avpr2 recycling [44]. Our data confirm high expression levels of Arf1 and Arf6 and reveal abundant expression of several Arf(s) (Arf3, Arl1, Arl3, etc., see Table 9B) with yet unassigned function in the renal tubule. As shown in Table 9C, both the DCT/CNT and the CCD also exhibit high expression levels of several Rho GTPases, including Cdc42, RhoA and Rac1. The main function of Rho GTPases consists in the control of cytoskeleton dynamics and assembly. Thus, it was logically proposed that Rho(s) could be involved in trafficking of aqp-2, a process which requires remodelling of microtubules and filaments. However, evidence that support this hypothesis remains limited to a few in vitro studies $[45,46]$. Members of Ras subfamily share the highest degree of homology with Ras, one of the most frequently mutated oncogenes in cancer. Ras, Ral and Rap have been shown to play an important role in cellular proliferation and differentiation by influencing a number of intracellular signalling pathways. Ras GTPases have been also shown to influence activity or expression of several important DCT/CNT and/or CCD transporters, including NCC (H-ras), H,K-ATPase (Rap1), ENaC (K-ras) and aqp-2 (Rap1) [4750]. As shown in Table 9D, H-ras, K-ras and Rap1 are present within the 10 most abundant members of the Ras subfamily. However, role of several other highly abundant Ras GTPases, including the most abundant Rragd, remain unknown. 
1.10 SNAREs and SNARE-related proteins. SNARE proteins participate in trafficking of renal transporters by mediating fusion of intracellular vesicles to the target membranes. Molecular composition of SNARE complexes has been extensively studied for aquaporins involved in renal urine concentration mechanism. Mistry et al., have shown that aqp-2 sorting to the apical membrane requires snapin (SNAPAP), SNAP23 and syntaxin-3, whereas syntaxin-4 is preferentially involved in cell surface expression of aqp-3 [51]. SNAP23/syntaxin-1a complex has been also proposed to regulate cell surface expression of ENaC. However, in our data, expression levels of syntaxin-1a are low (A_values of 4.7 and 5.0 in the DCT/CNT and the CCD, respectively). Accordingly, only a low signal intensity for syntaxin-1a was detected in the IMCD hybridization data [11]. As shown in Table 10 and Supplemental Table 5, both the DCT/CNT and the CCD exhibit high expression of SNAPAP, SNAP23, syntaxin-3 and syntaxin-4. High expression levels were also detected for vesicle associated membrane proteins (VAMP) $-2,8$ and 3. VAMP2 and VAMP3 proteins were previously identified in aqp-2-containing intracellular vesicles indicating their involvement in aqp-2 trafficking [52]. Recently, Wang et al. have shown that mice devoid of $V A M P 8$ gene exhibit a diabetes insipidus-like phenotype and a significantly reduced membrane expression of aqp-2 in collecting duct cells [53].

1.11 Clathrin, clathrin adaptors and dynamin-like GTPases. Clathrin-coated vesicles are major protein carriers in protein endocytotic pathways. Clathrin-coated vesicles mediate endocytosis of many essential DCT/CNT and/or CCD transporting proteins including ROMK, Na,K-ATPase, ENaC, aqp-2 and Trpv5 [54-58]. As shown in Table 11A, both the DCT/CNT and the CCD exhibit high expression levels of clathrin light and heavy chains (Clta, Cltb and, Cltc, respectively) as well as several clathrin adaptor subunits (Ap1s3, Ap2s1 and Ap3s1). Similar to the IMCD [11], our data show a high abundance of Picalm, a clathrin adaptor which was recently shown to direct VAMP2 trafficking during endocytosis [59]. Dynamins are high molecular 
weight GTPases $(\sim 100 \mathrm{kDa})$ that mediate the fission of clathrin-coated vesicles from the membrane. As shown in Figure 11B, both transcriptomes reveal a high expression of dynamin 2 (Dnm2) and dynamin 1-like (Dnm11) and low expression of dynamins 1 and 3 (Dnm1 and Dnm3, respectively). Interestingly, this distribution of dynamins differs significantly from that of IMCD in which only dynamin-like GTPases Mx1 and Mx2 demonstrated high signal intensities [11]. In the DCT/CNT and the CCD transcriptomes, both Mx1 and Mx2 exhibit low expression levels (Mx1: A_values of 4.3 and 3.8 in DCT/CNT and CCD, respectively; Mx2: A_values of 3.5 and 3.0 in DCT/CNT and CCD, respectively).

1.12 Cytoskeletal proteins and cytoskeletal regulators. Cytoskleletal proteins mediate a wide variety of essential renal functions. During foetal kidney development, the assembly and contraction of microtubules and microfilaments has been proposed as part of a mechanism that drives branching morphogenesis of the uteric bud [60]. In the adult kidney, cytoskeleton remodelling has been shown to influence cell surface expression and/or activity of a number of proteins involved in maintaining balance of water and electrolytes, including ENaC, aqp-2, Na,KATPase, secretory $\mathrm{K}$ channels and chloride channels [61-65]. A significant number of cytoskeletal proteins have been recently identified by a proteomic approach in the aqp-2containing vesicles in the IMCD [52]. As shown in Table 12 and Supplemental Table 6, 300 different transcripts encoding cytoskeletal and cytoskeletal-related proteins are present in our data. The overall distribution and abundance of cytoskeletal transcripts in the DCT/CNT and the CCD is largely similar to that identified in the IMCD. However, for several major transcripts a significant difference was observed. For instance, moesin, an actin-binding protein which has been shown to modulate activity of aqp-2, Na,K-ATPase and CFTR in different models of epithelial cells, was undetectable in IMCD transcriptome [11, 66-68]. In our study, moesin is abundantly present in both the DCT/CNT and the CCD (see subcategory actin and actin-binding 
proteins, Table 12A). Also our data reveal high expression of myosin VI (Myo6), a myosin which has been shown as a prerequisite for the clathrin-dependent endocytosis of CFTR in the intestine [69] (see subcategory myosin and myosin-like proteins, Table 12B). The role of Myo6 in the kidney has not yet been investigated. In subcategory microtubule and microtubule-related proteins (Table 12C) we found strong expression of tubulins $1 \mathrm{~b}$ and $1 \mathrm{a}$ (Tubalb and Tuba1a), two tubulins that were not detected in the IMCD. Again, despite a high abundance of these transcripts, their role in the kidney remains unknown. Finally, in subcategory intermediate filaments and related proteins (Table 12D), we detected several keratins not present in the IMCD transcriptome (Krt10, Krt80, Krt23 and Krt34).

1.13 Transporters and channels. As shown in Table 13 and Supplemental Table 7, more than 250 transcripts encoding water/solutes transporting proteins are expressed at significant levels in the DCT/CNT and/or the CCD, confirming the variety of solutes transported across the epithelium of these segments. In subcategory water channels (Table 13A), aquaporins are abundantly represented by plasma membrane expressed aquaporins 2,3 and 4 , as well as by the intracellular aquaporins 6 and 11. As expected, expression of aquaporins 2 and 4 is significantly lower in the DCT/CNT than in the CCD, whereas aquaporin-3 is equally represented in both transcriptomes. Surprisingly, our analysis also revealed a low, but significant, expression of aquaporin 1 , a channel which is present, according to immunohistochemical analyses, only in the proximal tubule and descending thin limb. Interestingly, the aquaporin 1 RNA has also been detected in human DCT, at levels of $\sim 10 \%$ of those in the proximal tubule [70]. However, in both, human and mouse transcriptomes, the expression levels of aquaporin 1 RNA in the distal nephron are significantly lower than those of other water channels. For instance, in mouse DCT/CNT the difference between the aquaporin 3 and aquaporin 1 RNA expression is $\sim 130$-fold (13.11 units of A-value vs. 6.09 units of A-value, respectively, Table 13A). 
In subcategory ion channels and transporters excluding SLC (Table 13B), all principal genes involved in maintaining ion balance are represented (e.g. Na,K-ATPase, $\alpha \beta \gamma \mathrm{ENaC}$ (Scnn1), ROMK (Kcnj1), Kir5.1 (Kcnj16), Kir 4.1 (Kcnj10), Clcnkb, Clc3, Trpv5, PMCA2 (ATP2b2), Trpm6 and various $\mathrm{H}^{+}$-ATPases). Analysis of the transcripts belonging to this subcategory also revealed a number of highly abundant transcripts with yet unassigned function in the kidney. For instance, both the DCT/CNT and the CCD exhibit high expression levels of Tmem16f, a functionally uncharacterized paralogue of a recently identified calcium-activated chloride channel Tmem16a [71]. Also, both transcriptomes reveal abundant expression of several voltage-gated ion channels, including Kcnq1, Kcne1, Kcnj10, Cacna1d, Cacnab4, Kcnh3 and Cacna2d1. Importantly, mutations in two voltage-gated potassium channels (Kcnj10 and Kcna1) have been recently shown to cause electrolyte imbalance in human $[3,4]$. To what extent other voltage-gated channels identified in our study can participate in the physiology/pathophysiology of distal nephron and/or collecting duct remains to be established.

In subcategory solute carrier proteins (SLC) (Table 13C), the most abundant transcript is pendrin (Slc26a4), a chloride/bicarbonate exchanger located at the apical membrane of the CNT and CCD cells. Also highly abundant is Slc2a9, a recently identified urate transporter [72]. Interestingly, analysis of the SLC(s) expressed in the DCT/CNT and/or the CCD revealed the presence of several transcripts whose expression was previously considered as restricted to the proximal tubule or to Henle's loop. For example, a high expression of the glucose transporter Glut1 (Slc2a1) and the sodium-glucose co-transporter Sglt2 (Slc2a5) and, a moderate expression of the sodium-potassium-chloride co-transporter NKCC2 (Slc12a1) and the sodium-phosphate co-transporter NaPi-IIa (Slc34a2) were detected in distal nephron. Glut1 and NKCC2 transcripts were also detected in the IMCD transcriptome [11]. Expression of NaPi-IIa, NKCC2 and Sglt2 in the DCT has been validated by RT-PCT analysis (D.Firsov, unpublished observations). The 
correlation between transcript and protein expression of these genes remains unknown. However, this information might be important for selection of tissue-specific promoters in transgenic experiments.

1.14 Transcription factors. More than 1'000 transcription factors are expressed in DCT/CNT and/or CCD above median levels (Table 14 and Supplemental Table 8). Only a small fraction of them has been assigned to a specific renal function. For instance, Homeobox-containing transcriptional factors (Hox) are largely involved in morphogenesis of different parts of the renal tubule (see below). Mineralocorticoid receptor $(\mathrm{Nr} 3 \mathrm{c} 2)$, glucocorticoid receptor $(\mathrm{Nr} 3 \mathrm{c} 2)$, vitamin D receptor (Vdr), cAMP response element-binding proteins ( $\mathrm{Creb}(\mathrm{s})$ and $\mathrm{Atf}(\mathrm{s}))$, peroxisome proliferator-activated receptors (PPARs), TonEBP (Nfat5), Jun, Fos, Edf1, Jag have been shown to participate in the regulation of secretion/reabsorption processes along the distal nephron and the collecting duct. Recently, we have shown that transcriptional factors of the circadian clock (arntl (bmal1), clock, npas2, dbp, hlf, tef) are playing a major role in DCT/CNT and CCD homeostatic function [10].

2. Comparison of DCT/CNT and CCD transcriptomes. To identify genes differentially expressed between the DCT/CNT and the CCD we performed a comparative analysis of the normalized DCT/CNT and CCD transcriptomes. A 3-fold difference in expression levels and a false discovery rate (FDR) of 5\% were used as cut-off criteria. Overall, 122 DCT/CNT transcripts (corresponding to 82 distinct genes) and $118 \mathrm{CCD}$ transcripts (corresponding to 91 distinct genes) met this criterion (Supplemental Figure 1).

2.1 Transcripts enriched in DCT/CNT. Analysis of differentially expressed transcripts revealed two major groups of genes enriched in DCT/CNT: (i) genes of the Homeobox (Hox) family of transcriptional factors that play an essential role during embryonic kidney development 
[73] and, (ii) genes involved in the secretion/reabsorption of different solutes along the nephron (Table 15 and Supplemental Table 8). The Hox genes have been shown to determine the segment identity of the renal tubule, being principal genes of formation and patterning of the uteric bud and the metanephric mesenchyme. However, their role in the adult kidney is less clear. Our data demonstrate that Hox genes which are specifically involved in the nephron formation during the embryogenesis (Hoxa9, Hoxd10, Hoxd11, Hoxa10, Hoxa3 and Hoxc9) remain enriched in the DCT/CNT of the adult kidney [74]. In contrast, analysis of the CCD enriched transcripts (Table 16) shows that Hox genes specifically involved in the development of the uteric bud are either not expressed in the CCD of the adult kidney (Hoxd1) or show comparable expression levels in the DCT/CNT and CCD (Hoxb7, Hoxd8) [74].

At least 15 out of $83 \mathrm{DCT} / \mathrm{CNT}$ enriched genes have been shown to participate in renal solute homeostasis. For instance, the thiazide-sensitive sodium-chloride cotransporter (NCC or Slc12a3) and the WNK1 (with-no-lysine (K)) serine-threonine kinase are critically involved in sodium/chloride reabsorption and potassium secretion in the distal nephron segments [75]. The Glut9 (Slc2a9) transporter has been recently shown as a principal transporter involved in the renal handling of urate in both human and mice [76]. A significant number of the DCT/CNT enriched genes are involved in the transepithelial reabsorption of calcium and magnesium. These latter include the genes coding for the sodium-calcium exchanger (Slc8a1), parvalbumin (Pvalb), the tissue kallikrein (Klk1), the parathyroid hormone 1 receptor (Pth1r), klotho $(\mathrm{Kl})$, the vitamin D receptor (Vdr), the calcium binding proteins calbindin-28K (Calb1) and S100 (S100g), the epidermal growth factor (Egf), the FXYD domain-containing ion transport regulator 2 (Fxyd2), the transient receptor potential cation channels Trpv5 and Trpm6 [77]. A secreted species of klotho has been shown to mediate the paracrine regulation of phosphate reabsorption in the proximal tubule [78]. 
This analysis also revealed several DCT/CNT-enriched transcripts potentially involved in renal solutes handling. For example, the Secreted Frizzled-Related Protein 1 (Sfrp1) belongs to a small family of secreted proteins acting as antagonist of the Wnt signaling pathway. Importantly, one of the Sfrp, namely Sfrp4, is one of the most potent tumor-derived antagonists of phosphate reabsorption in the proximal tubule As Sfrp1 strongly expressed in the kidney in normal physiological state, we believe that this gene might be an interesting candidate for maintaining phosphate balance by the kidney. Another interesting transcript is the cytochrome P450 2j11 (Cyp2j11) which shares a high degree of homology (80\%) with the human Cyp2j2 protein. Several studies have provided evidence for an association of Cyp $2 \mathrm{j} 2$ polymorphisms with a susceptibility to essential hypertension in man [79-81]. The Cyp2j2 has been proposed to regulate renal fluid-electrolyte transport by catalyzing production of cis-epoxyeicosatrienoic acids (EETs) from the arachidonic acid. In vitro, the EETs have been shown to inhibit the activity of ENaC [82]. However, other renal targets of EETs as well as the in vivo role of Cyp2j2/Cyp2j11 in the kidney remain unknown. Two other remarkable DCT/CNT enriched genes are the small GTPase Rab27a which is involved in the intracellular vesicle docking and membrane trafficking and, the Uscher syndrome 1C homolog (Ush1C), a ciliary protein which contributes to establishing the sensitivity to displacement of mechanotransduction channels in the hair cells [83, 84]. The functional relevance of these two proteins in the kidney remains unclear.

2.2 Transcripts enriched in $C C D$. The CCD transcriptome is also enriched in transcripts involved in different stages of tubulogenesis (Table 16 and Supplemental Table 9). These include an agonist of the frizzled receptors (Wnt9b), the enzymes of retinoic acid synthetic pathway (Aldh1a1 and Aldh1a7), the metallopeptidase inhibitor 2 (Timp2), the insulin-like growth factor 1 (Igf1), a ligand of the epidermal growth factor receptor (betacellulin), the arginase 2 (Arg2) and the axon guidance receptor homolog 1 (Robo1). Several enriched transcripts encode proteins 
participating in tubular water/solute transport (aqp-4, aqp-2, Fxyd4, Fxyd3, Slc26a7 and Ptger1). Interestingly, CCD cells exhibit significant expression of Gpr126, an orphan GPCR controlling the Gs/cAMP signaling pathway in Schwann cells [85]. In the kidney, neither function nor cellular localization of Gpr126 had been determined thus far. However, this receptor is expressed at high levels in mCCD cells, a model of principal cells of the collecting duct (Heidi Fodstad, unpublished microarray hybridization data, personal communication). This finding, if confirmed in human principal cells, raises an interesting possibility of using Gpr126 for bypassing malfunctioning V2R signaling pathway in X-linked nephrogenic diabetes insipidus (NDI). Both, the DCT/CNT and the CCD transcriptomes are enriched by enzymes involved in sulfation of glycoproteins (Sulf2 and Chst11 in DCT/CNT and, Chst9 and Hs3st3b1 in CCD). Sulfation is a posttranslational modification known to contribute to the functional heterogeneity of glycoproteins by modifying their binding capacities to glycans, glycolipids or to other glycoproteins. In the kidney, sulfation has been shown to affect many important biological processes including immune response, cell-cell adhesion and hormonal signaling. Yet, the specific targets of the above-mentioned enzymes along the nephron and in the collecting duct remain unknown.

Overall, this in-depth analysis of the mouse transcriptomes of the DCT/CNT and CCD opens new avenues in the comprehensive interpretation of molecular mechanisms underlying renal homeostasis. More studies are needed that will decipher the exact roles and interactions of the genes expressed in the distal part of the nephron and in the CCD.

\section{FIGURE LEGEND}

Figure 1. Correlation between qPCR- and microarray- based expression levels of GPCRs expressed in the DCT/CNT (A) and the CCD (B). Negative mean normalized Ct values (x-axis) are plotted against normalized expression values measured by Affymetrix microarrays (y-axis). 
Genes with the $\mathrm{Ct}$ values of 36 or above are not plotted. Loess curves are indicated with a red line. Genes considered as expressed from the microarray data are indicated with a red dot. Several genes discussed in the text are indicated with a green dot. Two outliers are Cxcr7 (a) and S1pr3 (b). The qPCR was performed on Mouse GPCR array from Applied Biosystems.

\section{Supplementary Figure 1}

A. Scatter plot of average expression value in the DCT/CNT samples versus average expression value in CCD samples. Dashed red lines: 2-fold change cut-off. Solid green line: loess curve. B. Density distribution of the moderated t-statistics for the expression in DCT/CNT versus CCD. Black line: t-statistics calculated on the normalized values not corrected for batch effect. Red line: t-statistics calculated on the normalized values after correction for batch effect.

Acknowledgments This work was supported by the Swiss National Science Foundation

Research Grant 3100A0-117824 (D.F.); and a bridge grant for young investigator from the Faculty of Biology and Medicine of the University of Lausanne and the Prof. Placide Nicod Foundation (O.B.) We would like to thank Dr. Hannes Richter from the Lausanne DNA Array Facility for the qPCR analysis of GPCRs expression levels.

\section{REFERENCES}

1. Kahle KT, Wilson FH, Lalioti M, Toka H, Qin H, Lifton RP (2004) WNK kinases: molecular regulators of integrated epithelial ion transport. Curr Opin Nephrol Hypertens 13:557-62 DOI Electronic Resource Number 2. Meij IC, Koenderink JB, van Bokhoven H, Assink KF, Groenestege WT, de Pont JJ, Bindels RJ, Monnens LA, van den Heuvel LP, Knoers NV (2000) Dominant isolated renal magnesium loss is caused by misrouting of the $\mathrm{Na}(+), \mathrm{K}(+)$-ATPase gamma-subunit. Nat Genet 26:265-6 DOI Electronic Resource Number 
3. Scholl UI, Choi M, Liu T, Ramaekers VT, Hausler MG, Grimmer J, Tobe SW, Farhi A, Nelson-Williams C, Lifton RP (2009) Seizures, sensorineural deafness, ataxia, mental retardation, and electrolyte imbalance (SeSAME syndrome) caused by mutations in KCNJ10. Proc Natl Acad Sci U S A 106:5842-7 DOI Electronic Resource Number

4. Glaudemans B, van der Wijst J, Scola RH, Lorenzoni PJ, Heister A, van der Kemp AW, Knoers NV, Hoenderop JG, Bindels RJ (2009) A missense mutation in the Kv1.1 voltage-gated potassium channel-encoding gene KCNA1 is linked to human autosomal dominant hypomagnesemia. J Clin Invest 119:936-42 DOI Electronic Resource Number 5. Groenestege WM, Thebault S, van der Wijst J, van den Berg D, Janssen R, Tejpar S, van den Heuvel LP, van Cutsem E, Hoenderop JG, Knoers NV, Bindels RJ (2007) Impaired basolateral sorting of pro-EGF causes isolated recessive renal hypomagnesemia. J Clin Invest 117:2260-7 DOI Electronic Resource Number

6. Robert-Nicoud M, Flahaut M, Elalouf JM, Nicod M, Salinas M, Bens M, Doucet A, Wincker P, Artiguenave F, Horisberger JD, Vandewalle A, Rossier BC, Firsov D (2001) Transcriptome of a mouse kidney cortical collecting duct cell line: effects of aldosterone and vasopressin. Proc Natl Acad Sci U S A 98:2712-6 DOI Electronic Resource Number

7. Fakitsas P, Adam G, Daidie D, van Bemmelen MX, Fouladkou F, Patrignani A, Wagner U, Warth R, Camargo SM, Staub O, Verrey F (2007) Early aldosterone-induced gene product regulates the epithelial sodium channel by deubiquitylation. J Am Soc Nephrol 18:1084-92 DOI Electronic Resource Number

8. Nielsen J, Hoffert JD, Knepper MA, Agre P, Nielsen S, Fenton RA (2008) Proteomic analysis of lithium-induced nephrogenic diabetes insipidus: mechanisms for aquaporin 2 down-regulation and cellular proliferation. Proc Natl Acad Sci U S A 105:3634-9 DOI Electronic Resource Number

9. Hoffert JD, Pisitkun T, Wang G, Shen RF, Knepper MA (2006) Quantitative phosphoproteomics of vasopressinsensitive renal cells: regulation of aquaporin-2 phosphorylation at two sites. Proc Natl Acad Sci U S A 103:7159-64 DOI Electronic Resource Number

10. Zuber AM, Centeno G, Pradervand S, Nikolaeva S, Maquelin L, Cardinaux L, Bonny O, Firsov D (2009) Molecular clock is involved in predictive circadian adjustment of renal function. Proc Natl Acad Sci U S A 106:16523-8 DOI Electronic Resource Number

11. Uawithya P, Pisitkun T, Ruttenberg BE, Knepper MA (2008) Transcriptional profiling of native inner medullary collecting duct cells from rat kidney. Physiol Genomics 32:229-53 DOI Electronic Resource Number

12. Irizarry RA, Hobbs B, Collin F, Beazer-Barclay YD, Antonellis KJ, Scherf U, Speed TP (2003) Exploration, normalization, and summaries of high density oligonucleotide array probe level data. Biostatistics 4:249-64 DOI Electronic Resource Number

13. Marioni JC, Mason CE, Mane SM, Stephens M, Gilad Y (2008) RNA-seq: an assessment of technical reproducibility and comparison with gene expression arrays. Genome Res 18:1509-17 DOI Electronic Resource Number

14. Ueland J, Yuan A, Marlier A, Gallagher AR, Karihaloo A (2009) A novel role for the chemokine receptor Cxcr4 in kidney morphogenesis: an in vitro study. Dev Dyn 238:1083-91 DOI Electronic Resource Number

15. Borgatti R, Marelli S, Bernardini L, Novelli A, Cavallini A, Tonelli A, Bassi MT, Dallapiccola B (2009) Bilateral frontoparietal polymicrogyria (BFPP) syndrome secondary to a 16q12.1-q21 chromosome deletion involving GPR56 gene. Clin Genet 76:573-6 DOI Electronic Resource Number

16. Robbins MJ, Michalovich D, Hill J, Calver AR, Medhurst AD, Gloger I, Sims M, Middlemiss DN, Pangalos MN (2000) Molecular cloning and characterization of two novel retinoic acid-inducible orphan G-protein-coupled receptors (GPRC5B and GPRC5C). Genomics 67:8-18 DOI Electronic Resource Number

17. He W, Miao FJ, Lin DC, Schwandner RT, Wang Z, Gao J, Chen JL, Tian H, Ling L (2004) Citric acid cycle intermediates as ligands for orphan G-protein-coupled receptors. Nature 429:188-93 DOI Electronic Resource Number

18. Packer RK, Curry CA, Brown KM (1995) Urinary organic anion excretion in response to dietary acid and base loading. J Am Soc Nephrol 5:1624-9 DOI Electronic Resource Number

19. van der Wijst J, Hoenderop JG, Bindels RJ (2009) Epithelial Mg2+ channel TRPM6: insight into the molecular regulation. Magnes Res 22:127-32 DOI Electronic Resource Number

20. Roberts EM, Newson MJ, Pope GR, Landgraf R, Lolait SJ, O'Carroll AM (2009) Abnormal fluid homeostasis in apelin receptor knockout mice. J Endocrinol 202:453-62 DOI Electronic Resource Number

21. Chabardes D, Firsov D, Aarab L, Clabecq A, Bellanger AC, Siaume-Perez S, Elalouf JM (1996) Localization of mRNAs encoding $\mathrm{Ca} 2+$-inhibitable adenylyl cyclases along the renal tubule. Functional consequences for regulation of the cAMP content. J Biol Chem 271:19264-71 DOI Electronic Resource Number

22. Cumbay MG, Watts VJ (2005) Galphaq potentiation of adenylate cyclase type 9 activity through a $\mathrm{Ca} 2+/$ calmodulin-dependent pathway. Biochem Pharmacol 69:1247-56 DOI Electronic Resource Number 
23. Takeda S, Lin CT, Morgano PG, McIntyre SJ, Dousa TP (1991) High activity of low-Michaelis-Menten constant 3', 5'-cyclic adenosine monophosphate-phosphodiesterase isozymes in renal inner medulla of mice with hereditary nephrogenic diabetes insipidus. Endocrinology 129:287-94 DOI Electronic Resource Number

24. Rinehart J, Kahle KT, de Los Heros P, Vazquez N, Meade P, Wilson FH, Hebert SC, Gimenez I, Gamba G, Lifton RP (2005) WNK3 kinase is a positive regulator of NKCC2 and NCC, renal cation-Cl- cotransporters required for normal blood pressure homeostasis. Proc Natl Acad Sci U S A 102:16777-82. Epub 2005 Nov 7. DOI Electronic Resource Number

25. Gattineni J, Bates C, Twombley K, Dwarakanath V, Robinson ML, Goetz R, Mohammadi M, Baum M (2009) FGF23 decreases renal NaPi-2a and NaPi-2c expression and induces hypophosphatemia in vivo predominantly via FGF receptor 1. Am J Physiol Renal Physiol 297:F282-91 DOI Electronic Resource Number

26. Lea JP, Sands JM, McMahon SJ, Tumlin JA (1994) Evidence that the inhibition of Na+/K(+)-ATPase activity by FK506 involves calcineurin. Kidney Int 46:647-52 DOI Electronic Resource Number

27. Jo I, Ward DT, Baum MA, Scott JD, Coghlan VM, Hammond TG, Harris HW (2001) AQP2 is a substrate for endogenous PP2B activity within an inner medullary AKAP-signaling complex. Am J Physiol Renal Physiol 281:F958-65 DOI Electronic Resource Number

28. Zhang Y, Lin DH, Wang ZJ, Jin Y, Yang B, Wang WH (2008) K restriction inhibits protein phosphatase 2B (PP2B) and suppression of PP2B decreases ROMK channel activity in the CCD. Am J Physiol Cell Physiol 294:C765-73 DOI Electronic Resource Number

29. Mohebbi N, Mihailova M, Wagner CA (2009) The calcineurin inhibitor FK506 (tacrolimus) is associated with transient metabolic acidosis and altered expression of renal acid-base transport proteins. Am J Physiol Renal Physiol 297:F499-509 DOI Electronic Resource Number

30. Wei Y, Bloom P, Gu R, Wang W (2000) Protein-tyrosine phosphatase reduces the number of apical small conductance $\mathrm{K}+$ channels in the rat cortical collecting duct. J Biol Chem 275:20502-7 DOI Electronic Resource Number

31. Henn V, Edemir B, Stefan E, Wiesner B, Lorenz D, Theilig F, Schmitt R, Vossebein L, Tamma G, Beyermann M, Krause E, Herberg FW, Valenti G, Bachmann S, Rosenthal W, Klussmann E (2004) Identification of a novel Akinase anchoring protein 18 isoform and evidence for its role in the vasopressin-induced aquaporin-2 shuttle in renal principal cells. J Biol Chem 279:26654-65 DOI Electronic Resource Number

32. Okutsu R, Rai T, Kikuchi A, Ohno M, Uchida K, Sasaki S, Uchida S (2008) AKAP220 colocalizes with AQP2 in the inner medullary collecting ducts. Kidney Int 74:1429-33 DOI Electronic Resource Number

33. Bengrine A, Li J, Awayda MS (2007) The A-kinase anchoring protein 15 regulates feedback inhibition of the epithelial Na+ channel. FASEB J 21:1189-201 DOI Electronic Resource Number

34. Gkika D, Topala CN, Chang Q, Picard N, Thebault S, Houillier P, Hoenderop JG, Bindels RJ (2006) Tissue kallikrein stimulates $\mathrm{Ca}(2+)$ reabsorption via PKC-dependent plasma membrane accumulation of TRPV5. EMBO J 25:4707-16 DOI Electronic Resource Number

35. van Balkom BW, Savelkoul PJ, Markovich D, Hofman E, Nielsen S, van der Sluijs P, Deen PM (2002) The role of putative phosphorylation sites in the targeting and shuttling of the aquaporin-2 water channel. J Biol Chem 277:41473-9 DOI Electronic Resource Number

36. Lin D, Sterling H, Lerea KM, Giebisch G, Wang WH (2002) Protein kinase C (PKC)-induced phosphorylation of ROMK1 is essential for the surface expression of ROMK1 channels. J Biol Chem 277:44278-84 DOI Electronic Resource Number

37. Stockand JD, Bao HF, Schenck J, Malik B, Middleton P, Schlanger LE, Eaton DC (2000) Differential effects of protein kinase $\mathrm{C}$ on the levels of epithelial Na+ channel subunit proteins. J Biol Chem 275:25760-5 DOI Electronic Resource Number

38. Irarrazabal CE, Gallazzini M, Schnetz MP, Kunin M, Simons BL, Williams CK, Burg MB, Ferraris JD (2009) Phospholipase $\mathrm{C}$-gamma1 is involved in signaling the activation by high $\mathrm{NaCl}$ of the osmoprotective transcription factor TonEBP/OREBP. Proc Natl Acad Sci U S A 107:906-11 DOI Electronic Resource Number

39. Donaldson JG (2009) Phospholipase D in endocytosis and endosomal recycling pathways. Biochim Biophys Acta 1791:845-9 DOI Electronic Resource Number

40. van de Graaf SF, Chang Q, Mensenkamp AR, Hoenderop JG, Bindels RJ (2006) Direct interaction with Rab11a targets the epithelial Ca2+ channels TRPV5 and TRPV6 to the plasma membrane. Mol Cell Biol 26:303-12 DOI Electronic Resource Number

41. Curtis LM, Gluck S (2005) Distribution of Rab GTPases in mouse kidney and comparison with vacuolar H+ATPase. Nephron Physiol 100:p31-42 DOI Electronic Resource Number

42. Saxena SK, Kaur S (2006) Regulation of epithelial ion channels by Rab GTPases. Biochem Biophys Res Commun 351:582-7 DOI Electronic Resource Number 
43. El-Annan J, Brown D, Breton S, Bourgoin S, Ausiello DA, Marshansky V (2004) Differential expression and targeting of endogenous Arf1 and Arf6 small GTPases in kidney epithelial cells in situ. Am J Physiol Cell Physiol 286:C768-78 DOI Electronic Resource Number

44. Madziva MT, Birnbaumer M (2006) A role for ADP-ribosylation factor 6 in the processing of G-protein-coupled receptors. J Biol Chem 281:12178-86 DOI Electronic Resource Number

45. Tamma G, Procino G, Strafino A, Bononi E, Meyer G, Paulmichl M, Formoso V, Svelto M, Valenti G (2007) Hypotonicity induces aquaporin-2 internalization and cytosol-to-membrane translocation of ICln in renal cells. Endocrinology 148:1118-30 DOI Electronic Resource Number

46. Klussmann E, Tamma G, Lorenz D, Wiesner B, Maric K, Hofmann F, Aktories K, Valenti G, Rosenthal W (2001) An inhibitory role of Rho in the vasopressin-mediated translocation of aquaporin-2 into cell membranes of renal principal cells. J Biol Chem 276:20451-7 DOI Electronic Resource Number

47. Ko B, Joshi LM, Cooke LL, Vazquez N, Musch MW, Hebert SC, Gamba G, Hoover RS (2007) Phorbol ester stimulation of RasGRP1 regulates the sodium-chloride cotransporter by a PKC-independent pathway. Proc Natl Acad Sci U S A 104:20120-5 DOI Electronic Resource Number

48. Laroche-Joubert N, Marsy S, Luriau S, Imbert-Teboul M, Doucet A (2003) Mechanism of activation of ERK and H-K-ATPase by isoproterenol in rat cortical collecting duct. Am J Physiol Renal Physiol 284:F948-54 DOI Electronic Resource Number

49. Mastroberardino L, Spindler B, Forster I, Loffing J, Assandri R, May A, Verrey F (1998) Ras pathway activates epithelial $\mathrm{Na}+$ channel and decreases its surface expression in Xenopus oocytes. Mol Biol Cell 9:3417-27 DOI Electronic Resource Number

50. Noda Y, Sasaki S (2006) Regulation of aquaporin-2 trafficking and its binding protein complex. Biochim Biophys Acta 1758:1117-25 DOI Electronic Resource Number

51. Mistry AC, Mallick R, Klein JD, Weimbs T, Sands JM, Frohlich O (2009) Syntaxin specificity of aquaporins in the inner medullary collecting duct. Am J Physiol Renal Physiol 297:F292-300 DOI Electronic Resource Number

52. Barile M, Pisitkun T, Yu MJ, Chou CL, Verbalis MJ, Shen RF, Knepper MA (2005) Large scale protein identification in intracellular aquaporin-2 vesicles from renal inner medullary collecting duct. Mol Cell Proteomics 4:1095-106 DOI Electronic Resource Number

53. Wang CC, Ng CP, Shi H, Liew HC, Guo K, Zeng Q, Hong W (2010) A role for VAMP8/endobrevin in surface deployment of the water channel aquaporin 2. Mol Cell Biol 30:333-43 DOI Electronic Resource Number

54. Zeng WZ, Babich V, Ortega B, Quigley R, White SJ, Welling PA, Huang CL (2002) Evidence for endocytosis of ROMK potassium channel via clathrin-coated vesicles. Am J Physiol Renal Physiol 283:F630-9 DOI Electronic Resource Number

55. Forgac M, Cantley L, Wiedenmann B, Altstiel L, Branton D (1983) Clathrin-coated vesicles contain an ATPdependent proton pump. Proc Natl Acad Sci U S A 80:1300-3 DOI Electronic Resource Number

56. Shimkets RA, Lifton RP, Canessa CM (1997) The activity of the epithelial sodium channel is regulated by clathrin-mediated endocytosis. J Biol Chem 272:25537-41 DOI Electronic Resource Number

57. Sun TX, Van Hoek A, Huang Y, Bouley R, McLaughlin M, Brown D (2002) Aquaporin-2 localization in clathrin-coated pits: inhibition of endocytosis by dominant-negative dynamin. Am J Physiol Renal Physiol 282:F998-1011 DOI Electronic Resource Number

58. van de Graaf SF, Rescher U, Hoenderop JG, Verkaart S, Bindels RJ, Gerke V (2008) TRPV5 is internalized via clathrin-dependent endocytosis to enter a Ca2+-controlled recycling pathway. J Biol Chem 283:4077-86 DOI Electronic Resource Number

59. Harel A, Wu F, Mattson MP, Morris CM, Yao PJ (2008) Evidence for CALM in directing VAMP2 trafficking. Traffic 9:417-29 DOI Electronic Resource Number

60. Michael L, Sweeney DE, Davies JA (2005) A role for microfilament-based contraction in branching morphogenesis of the ureteric bud. Kidney Int 68:2010-8 DOI Electronic Resource Number

61. Mazzochi C, Bubien JK, Smith PR, Benos DJ (2006) The carboxyl terminus of the alpha-subunit of the amiloride-sensitive epithelial sodium channel binds to F-actin. J Biol Chem 281:6528-38 DOI Electronic Resource Number

62. Sabolic I, Katsura T, Verbavatz JM, Brown D (1995) The AQP2 water channel: effect of vasopressin treatment, microtubule disruption, and distribution in neonatal rats. J Membr Biol 143:165-75 DOI Electronic Resource Number

63. Morrow JS, Cianci CD, Ardito T, Mann AS, Kashgarian M (1989) Ankyrin links fodrin to the alpha subunit of $\mathrm{Na}, \mathrm{K}-\mathrm{ATPase}$ in Madin-Darby canine kidney cells and in intact renal tubule cells. J Cell Biol 108:455-65 DOI Electronic Resource Number 
64. Wei Y, Wang WH (2002) Role of the cytoskeleton in mediating effect of vasopressin and herbimycin A on secretory K channels in CCD. Am J Physiol Renal Physiol 282:F680-6 DOI Electronic Resource Number

65. Schwiebert EM, Mills JW, Stanton BA (1994) Actin-based cytoskeleton regulates a chloride channel and cell volume in a renal cortical collecting duct cell line. J Biol Chem 269:7081-9 DOI Electronic Resource Number

66. Moyer BD, Denton J, Karlson KH, Reynolds D, Wang S, Mickle JE, Milewski M, Cutting GR, Guggino WB, Li M, Stanton BA (1999) A PDZ-interacting domain in CFTR is an apical membrane polarization signal. J Clin Invest 104:1353-61 DOI Electronic Resource Number

67. Kraemer DM, Strizek B, Meyer HE, Marcus K, Drenckhahn D (2003) Kidney $\mathrm{Na}^{+}, \mathrm{K}(+)$-ATPase is associated with moesin. Eur J Cell Biol 82:87-92 DOI Electronic Resource Number

68. Tamma G, Klussmann E, Oehlke J, Krause E, Rosenthal W, Svelto M, Valenti G (2005) Actin remodeling requires ERM function to facilitate AQP2 apical targeting. J Cell Sci 118:3623-30 DOI Electronic Resource Number 69. Ameen N, Apodaca G (2007) Defective CFTR apical endocytosis and enterocyte brush border in myosin VIdeficient mice. Traffic 8:998-1006 DOI Electronic Resource Number

70. Chabardes-Garonne D, Mejean A, Aude JC, Cheval L, Di Stefano A, Gaillard MC, Imbert-Teboul M, Wittner M, Balian C, Anthouard V, Robert C, Segurens B, Wincker P, Weissenbach J, Doucet A, Elalouf JM (2003) A panoramic view of gene expression in the human kidney. Proc Natl Acad Sci U S A 100:13710-5 DOI Electronic Resource Number

71. Schroeder BC, Cheng T, Jan YN, Jan LY (2008) Expression cloning of TMEM16A as a calcium-activated chloride channel subunit. Cell 134:1019-29 DOI Electronic Resource Number

72. Preitner F, Bonny O, Laverriere A, Rotman S, Firsov D, Da Costa A, Metref S, Thorens B (2009) Glut9 is a major regulator of urate homeostasis and its genetic inactivation induces hyperuricosuria and urate nephropathy. Proc Natl Acad Sci U S A 106:15501-6 DOI Electronic Resource Number

73. Patterson LT, Potter SS (2003) Hox genes and kidney patterning. Curr Opin Nephrol Hypertens 12:19-23 DOI Electronic Resource Number

74. Patterson LT, Potter SS (2004) Atlas of Hox gene expression in the developing kidney. Dev Dyn 229:771-9 DOI Electronic Resource Number

75. Yang CL, Angell J, Mitchell R, Ellison DH (2003) WNK kinases regulate thiazide-sensitive Na-Cl cotransport. J Clin Invest 111:1039-45 DOI Electronic Resource Number

76. Bibert S, Hess SK, Firsov D, Thorens B, Geering K, Horisberger JD, Bonny O (2009) Mouse GLUT9: evidences for a urate uniporter. Am J Physiol Renal Physiol 297:F612-9 DOI Electronic Resource Number

77. van de Graaf SF, Bindels RJ, Hoenderop JG (2007) Physiology of epithelial Ca2+ and Mg2+ transport. Rev Physiol Biochem Pharmacol 158:77-160 DOI Electronic Resource Number

78. Kuro OM (2009) Klotho. Pflugers Arch 4:4 DOI Electronic Resource Number

79. King LM, Gainer JV, David GL, Dai D, Goldstein JA, Brown NJ, Zeldin DC, Wu SN, Zhang Y, Gardner CO, Chen Q, Li Y, Wang GL, Gao PJ, Zhu DL, Polonikov AV, Ivanov VP, Solodilova MA, Khoroshaya IV, Kozhuhov MA, Ivakin VE, Katargina LN, Kolesnikova OE (2005) Single nucleotide polymorphisms in the CYP2J2 and CYP2C8 genes and the risk of hypertension

Evidence for association of polymorphisms in CYP2J2 and susceptibility to essential hypertension

A common polymorphism G-50T in cytochrome P450 $2 \mathrm{~J} 2$ gene is associated with increased risk of essential hypertension in a Russian population. Pharmacogenet Genomics 15:7-13 DOI Electronic Resource Number

80. Wu SN, Zhang Y, Gardner CO, Chen Q, Li Y, Wang GL, Gao PJ, Zhu DL, Polonikov AV, Ivanov VP, Solodilova MA, Khoroshaya IV, Kozhuhov MA, Ivakin VE, Katargina LN, Kolesnikova OE (2007) Evidence for association of polymorphisms in CYP2J2 and susceptibility to essential hypertension

A common polymorphism G-50T in cytochrome P450 2J2 gene is associated with increased risk of essential hypertension in a Russian population. Ann Hum Genet 71:519-25 DOI Electronic Resource Number

81. Polonikov AV, Ivanov VP, Solodilova MA, Khoroshaya IV, Kozhuhov MA, Ivakin VE, Katargina LN, Kolesnikova OE (2008) A common polymorphism G-50T in cytochrome P450 2J2 gene is associated with increased risk of essential hypertension in a Russian population. Dis Markers 24:119-26 DOI Electronic Resource Number

82. Wang S, Meng F, Xu J, Gu Y (2009) Effects of lipids on ENaC activity in cultured mouse cortical collecting duct cells. J Membr Biol 227:77-85 DOI Electronic Resource Number

83. Grillet N, Xiong W, Reynolds A, Kazmierczak P, Sato T, Lillo C, Dumont RA, Hintermann E, Sczaniecka A, Schwander M, Williams D, Kachar B, Gillespie PG, Muller U (2009) Harmonin mutations cause mechanotransduction defects in cochlear hair cells. Neuron 62:375-87 DOI Electronic Resource Number

84. Ullrich S (2008) Glucose-induced insulin secretion: is the small G-protein Rab27A the mediator of the K(ATP) channel-independent effect? J Physiol 586:5291 DOI Electronic Resource Number 
85. Monk KR, Naylor SG, Glenn TD, Mercurio S, Perlin JR, Dominguez C, Moens CB, Talbot WS (2009) A G protein-coupled receptor is essential for Schwann cells to initiate myelination. Science 325:1402-5 DOI Electronic Resource Number 

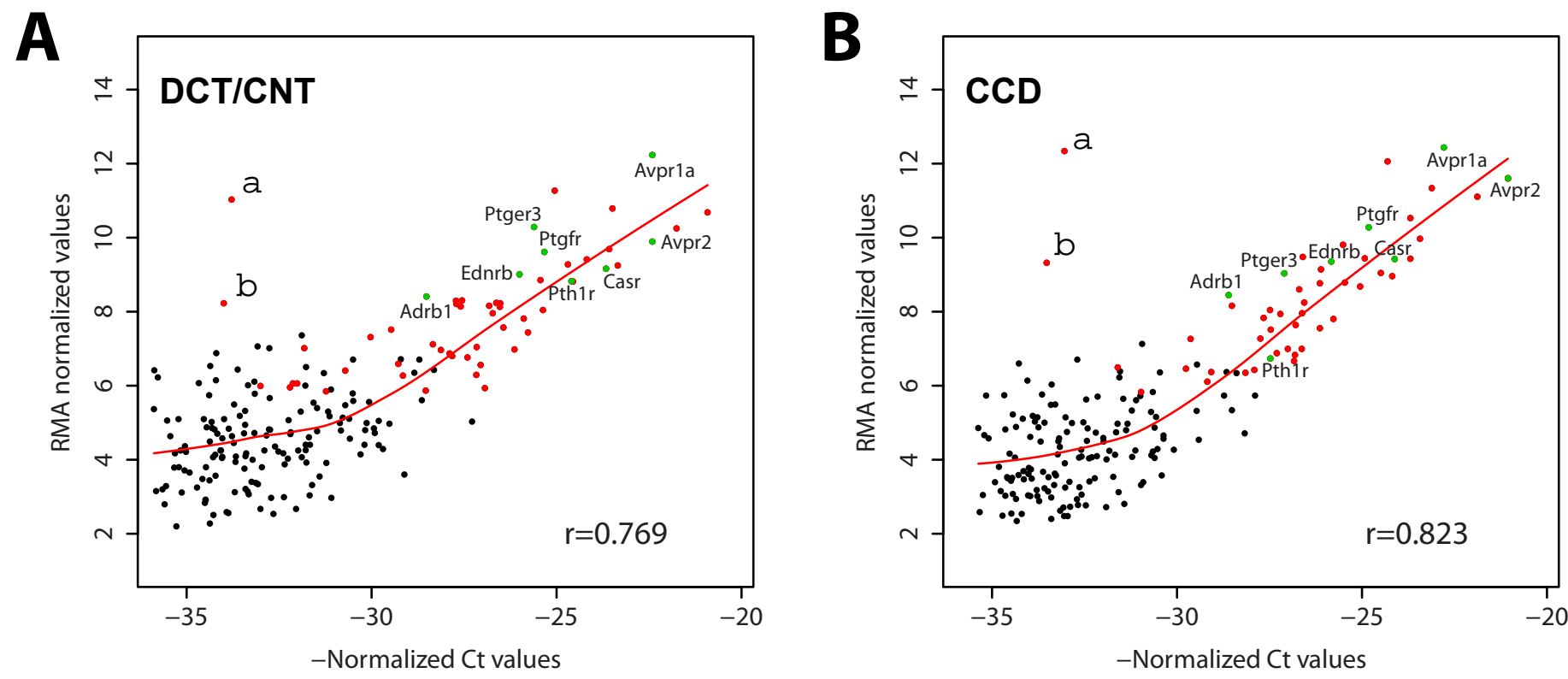
Supplemental Table 1. G protein-coupled receptors (GPCR)

\begin{tabular}{|c|c|c|c|}
\hline Gene Name & $\begin{array}{l}\text { Gene } \\
\text { Symbol }\end{array}$ & $\begin{array}{c}\text { DCT/CNT } \\
\text { A_Value }\end{array}$ & $\begin{array}{c}\text { CCD } \\
\text { A_Value }\end{array}$ \\
\hline arginine vasopressin receptor $1 \mathrm{~A}$ & Avpr1a & 12.23 & 12.44 \\
\hline cadherin, EGF LAG seven-pass G-type receptor 2 & Celsr2 & 11.27 & 12.06 \\
\hline chemokine (C-X-C motif) receptor 7 & Cxcr7 & 11.03 & 12.34 \\
\hline G protein-coupled receptor 116 & Gpr116 & 10.79 & 11.34 \\
\hline G protein-coupled receptor 56 & Gpr56 & 10.68 & 11.60 \\
\hline chemokine (C-X-C motif) receptor 4 & Cxcr4 & 10.39 & 10.65 \\
\hline prostaglandin E receptor 3 (subtype EP3) & Ptger3 & 10.29 & 9.04 \\
\hline G protein-coupled receptor, family C, group 5 , member C & Gprc5c & 10.25 & 11.11 \\
\hline arginine vasopressin receptor 2 & Avpr2 & 9.89 & 11.61 \\
\hline oxoglutarate (alpha-ketoglutarate) receptor 1 & Oxgr1 & 9.69 & 9.44 \\
\hline xenotropic and polytropic retrovirus receptor 1 & Xpr1 & 9.68 & 9.92 \\
\hline prostaglandin F receptor & Ptgfr & 9.61 & 10.28 \\
\hline G protein-coupled receptor, family C, group 5 , member B & Gprc5b & 9.41 & 10.53 \\
\hline glucagon receptor & Gcgr & 9.28 & 8.77 \\
\hline coagulation factor II (thrombin) receptor-like 1 & $\mathrm{~F} 2 \mathrm{rl1}$ & 9.25 & 9.97 \\
\hline calcium-sensing receptor & Casr & 9.16 & 9.42 \\
\hline endothelin receptor type B & Ednrb & 9.01 & 9.35 \\
\hline prostaglandin E receptor 1 (subtype EP1) & Ptger1 & 8.85 & 9.43 \\
\hline parathyroid hormone 1 receptor & Pth1r & 8.82 & 6.73 \\
\hline G protein-coupled receptor 108 & Gpr108 & 8.81 & 9.05 \\
\hline G protein-coupled estrogen receptor 1 & Gper & 8.43 & 8.64 \\
\hline adrenergic receptor, beta 1 & Adrb1 & 8.41 & 8.45 \\
\hline prostaglandin E receptor 4 (subtype EP4) & Ptger4 & 8.30 & 9.48 \\
\hline adrenergic receptor, beta 2 & Adrb2 & 8.29 & 8.16 \\
\hline adrenergic receptor, alpha $2 a$ & Adra2a & 8.24 & 8.79 \\
\hline apelin receptor & Aplnr & 8.24 & 7.45 \\
\hline sphingosine-1-phosphate receptor 3 & S1pr3 & 8.23 & 9.32 \\
\hline smoothened homolog (Drosophila) & Smo & 8.23 & 8.25 \\
\hline gamma-aminobutyric acid (GABA) B receptor, 1 & Gabbr1 & 8.21 & 7.83 \\
\hline coagulation factor II (thrombin) receptor & $\mathrm{F} 2 \mathrm{r}$ & 8.16 & 7.94 \\
\hline adenosine $A 1$ receptor & Adora1 & 8.14 & 9.81 \\
\hline G protein-coupled receptor 146 & Gpr146 & 8.13 & 9.14 \\
\hline RIKEN cDNA 2310046K01 gene & 2310046K01Rik & 8.09 & 9.51 \\
\hline G protein-coupled receptor 89 & Gpr89 & 8.09 & 8.50 \\
\hline cadherin, EGF LAG seven-pass G-type receptor 1 & Celsr1 & 8.04 & 8.68 \\
\hline G protein-coupled receptor 172B & Gpr172b & 8.03 & 7.91 \\
\hline latrophilin 1 & Lphn1 & 7.96 & 8.60 \\
\hline G protein-coupled receptor 107 & Gpr107 & 7.90 & 8.35 \\
\hline vomeronasal 2, receptor 29 & Vmn2r29 & 7.84 & 7.37 \\
\hline EGF, latrophilin seven transmembrane domain containing 1 & Eltd1 & 7.81 & 7.80 \\
\hline component of Sp100-rs /// predicted gene, EG665317 & Csprs & 7.59 & 7.04 \\
\hline G protein-coupled receptor 125 & Gpr125 & 7.57 & 7.64 \\
\hline complement component 5 a receptor 1 & C5ar1 & 7.51 & 7.26 \\
\hline neuropeptide $Y$ receptor Y6 & Npy6r & 7.44 & 8.96 \\
\hline vomeronasal 2, receptor 4 & Vmn2r4 & 7.33 & 6.10 \\
\hline adrenergic receptor, alpha 2c & Adra2c & 7.31 & 7.51 \\
\hline lysophosphatidic acid receptor 1 & Lpar1 & 7.30 & 9.04 \\
\hline transducin (beta)-like 3 & Tbl3 & 7.30 & 7.75 \\
\hline G protein-coupled receptor 126 & Gpr126 & 7.18 & 9.40 \\
\hline progestin and adipoQ receptor family member VIII & Paqr8 & 7.13 & 8.07 \\
\hline KISS1 receptor & Kiss1r & 7.12 & 6.37 \\
\hline CD97 antigen & Cd97 & 7.04 & 6.99 \\
\hline
\end{tabular}


histamine receptor $\mathrm{H} 2$

purinergic receptor P2Y, G-protein coupled, 5

$\mathrm{G}$ protein-coupled receptor 63

calcitonin receptor-like

lysophosphatidic acid receptor 2

secretin receptor

vomeronasal 1 receptor, D14

purinergic receptor P2Y, G-protein coupled, 14

calcitonin gene-related peptide-receptor component protein

sphingosine-1-phosphate receptor 4

$\mathrm{G}$ protein-coupled receptor 39

5-hydroxytryptamine (serotonin) receptor 1B

Melanin-concentrating hormone receptor 1 (Mchr1), mRNA

sphingosine-1-phosphate receptor 1

G protein-coupled receptor 135

opsin 3

chemokine (C-C motif) receptor 5

cannabinoid receptor 1 (brain)

$\mathrm{G}$ protein-coupled receptor 97

$\mathrm{G}$ protein-coupled receptor 37

Bradykinin receptor, beta 2 (Bdkrb2), mRNA

complement component 3a receptor 1

$\mathrm{G}$ protein-coupled receptor 110

$\mathrm{G}$ protein-coupled receptor 64

purinergic receptor P2Y, G-protein coupled 2
Hrh2

P2ry5

Gpr63

Calcrl

Lpar2

Sctr

V1rd14

P2ry14

Crcp

S1pr4

Gpr39

$\mathrm{Htr} 1 \mathrm{~b}$

Mchr1

S1pr1

Gpr135

Opn3

Ccr5

Cnr1

Gpr97

Gpr37

Bdkrb2

C3ar1

Gpr110

Gpr64

P2ry2
7.01

6.98

6.97

6.87

6.80

6.76

6.64

6.59

6.56

6.41

6.29

6.27

6.18

6.06

6.06

6.04

5.99

5.95

5.94

5.94

5.87

5.85

5.81

$5.15^{\star}$

$4.86^{*}$
6.49

7.55

7.96

6.35

7.27

6.11

5.41 *

8.04

6.83

5.83

6.88

6.99

6.21

$5.70^{*}$

$3.38^{\star}$

6.20

$4.76^{*}$

$5.03^{*}$

6.67

6.57

$5.73^{*}$

$5.64^{\star}$

$4.75^{\star}$

6.46

6.43

* - the A-value is below the cut-off level 


\begin{tabular}{|c|c|c|c|}
\hline Gene Name & $\begin{array}{l}\text { Gene } \\
\text { Symbol }\end{array}$ & $\begin{array}{l}\text { DCT/CNT } \\
\text { A_Value }\end{array}$ & $\begin{array}{c}\text { CCD } \\
\text { A_Value }\end{array}$ \\
\hline \multicolumn{4}{|l|}{ Table 5A. Serine/threonine kinases } \\
\hline calcium/calmodulin-dependent protein kinase II, beta & Camk2b & 12.95 & 13.41 \\
\hline PCTAIRE-motif protein kinase 1 & Pctk1 & 12.51 & 12.68 \\
\hline WNK lysine deficient protein kinase 1 & Wnk1 & 12.48 & 11.27 \\
\hline proviral integration site 3 & Pim3 & 12.43 & 12.20 \\
\hline serum/glucocorticoid regulated kinase 1 & Sgk1 & 11.98 & 12.86 \\
\hline mitogen-activated protein kinase kinase kinase 12 & Map3k12 & 11.85 & 11.90 \\
\hline MAP kinase-interacting serine/threonine kinase 2 & Mknk2 & 11.54 & 12.23 \\
\hline p21 (CDKN1A)-activated kinase 4 & Pak4 & 11.53 & 12.31 \\
\hline AP2 associated kinase 1 & Aak1 & 11.50 & 11.93 \\
\hline serum/glucocorticoid regulated kinase 2 & Sgk2 & 11.42 & 10.91 \\
\hline TAO kinase 3 & Taok3 & 11.34 & 10.85 \\
\hline glycogen synthase kinase 3 beta & Gsk3b & 11.28 & 12.04 \\
\hline casein kinase 1 , delta & Csnk1d & 11.20 & 11.79 \\
\hline Rho-associated coiled-coil containing protein kinase 1 & Rock1 & 11.13 & 11.28 \\
\hline mitogen-activated protein kinase-activated protein kinase 3 & Mapkapk3 & 11.07 & 11.40 \\
\hline NIMA (never in mitosis gene a)-related expressed kinase 7 & Nek7 & 11.02 & 11.20 \\
\hline casein kinase 1, alpha 1 & Csnk1a1 & 11.01 & 11.56 \\
\hline WNK lysine deficient protein kinase 4 & Wnk4 & 10.99 & 10.46 \\
\hline p21 (CDKN1A)-activated kinase 2 & Pak2 & 10.91 & 11.60 \\
\hline pyruvate dehydrogenase kinase, isoenzyme 2 & Pdk2 & 10.80 & 10.80 \\
\hline serine/threonine kinase 39, STE20/SPS1 homolog (yeast) & Stk39 & 10.75 & 11.46 \\
\hline homeodomain interacting protein kinase 2 & Hipk2 & 10.71 & 10.91 \\
\hline serine/threonine kinase 24 (STE20 homolog, yeast) & Stk24 & 10.58 & 11.01 \\
\hline mitogen-activated protein kinase 14 & Mapk14 & 10.53 & 11.07 \\
\hline calcium/calmodulin-dependent protein kinase kinase 2 , beta & Camkk2 & 10.40 & 11.59 \\
\hline mitogen-activated protein kinase kinase 7 & Map2k7 & 10.35 & 10.47 \\
\hline CDC like kinase 4 & Clk4 & 10.33 & 10.54 \\
\hline cyclin-dependent kinase-like 1 (CDC2-related kinase) & Cdkl1 & 10.29 & 11.16 \\
\hline STE20-like kinase (yeast) & Slk & 10.28 & 11.05 \\
\hline mitogen-activated protein kinase kinase kinase 5 & Map3k5 & 10.28 & 10.80 \\
\hline protein kinase N2 & Pkn2 & 10.27 & 10.50 \\
\hline nemo like kinase & Nlk & 10.26 & 10.87 \\
\hline bone morphogenetic protein receptor, type 1B & Bmpr1b & 10.22 & 11.13 \\
\hline CDC-like kinase 3 & Clk3 & 10.21 & 10.92 \\
\hline cyclin G associated kinase & Gak & 10.18 & 10.61 \\
\hline protein kinase, AMP-activated, alpha 2 catalytic subunit & Prkaa2 & 10.18 & 10.61 \\
\hline MAPK scaffold protein 1 & Mapksp1 & 10.10 & 10.30 \\
\hline protein $\mathrm{k}$ & Prkcd & 10.09 & 10.58 \\
\hline ase kinase, isoenzyme 1 & Pdk1 & 10.02 & 9.71 \\
\hline bone morphogenic protein receptor, type II (serine/threonine kinase) & Bmpr2 & 10.02 & 10.57 \\
\hline mitogen-activated protein kinase kinase kinase kinase 3 & Map4k3 & 10.01 & 10.76 \\
\hline serine/threonine kinase 17b (apoptosis-inducing) & Stk17b & 10.00 & 10.35 \\
\hline leucine-rich PPR-motif containing & Lrpprc & 9.99 & 9.98 \\
\hline CDC42 binding protein kinase gamma (DMPK-like) & Cdc42bpg & 9.96 & 10.60 \\
\hline tousled-like kinase 2 (Ara & Tlk2 & 9.89 & 10.60 \\
\hline NIMA (never in mitosis gene a)-related expressed kinase 9 & Nek9 & 9.88 & 10.46 \\
\hline CDC-like kinase 1 & Clk1 & 9.87 & 10.79 \\
\hline protein kinase, $\mathrm{X}$-linked & Prkx & 9.85 & 10.42 \\
\hline casein kinase 2 , alpha 1 polypeptide & Csnk2a1 & 9.83 & 10.37 \\
\hline homeodomain interacting protein kinase 3 & Hipk3 & 9.81 & 10.10 \\
\hline serine/threonine kinase 38 & Stk38 & 9.80 & 10.53 \\
\hline
\end{tabular}


large tumor suppressor 2

integrin linked kinase

mitogen-activated protein kinase kinase kinase 3

Lats2

9.76

10.35

nuclear receptor binding protein 2

Ilk

$9.74 \quad 10.27$

MAP/microtubule affinity-regulating kinase 2

Map3k3

9.88

Nrbp2

9.72

10.16

tousled-like kinase 1

Mark2

9.69

10.50

Tlk1

9.68

9.92

mitogen-activated protein kinase kinase kinase 7

Map3k7

9.68

9.97

Rous sarcoma oncogene

Src

activin receptor IIA

serine/arginine-rich protein specific kinase 1

Acvr2a

9.65

9.35

Srpk1

homeodomain interacting protein kinase 1

SNF related kinase

mitogen-activated protein kinase 3

Hipk1

Snrk

adrenergic receptor kinase, beta 2

Mapk3

9.65

10.01

similar to Yamaguchi sarcoma viral (v-yes-1) oncogene homolog

Adrbk2

9.63

9.89

transforming growth factor, beta receptor II

translocated promoter region

mitogen-activated protein kinase kinase kinase 1

CDC2-related kinase, arginine/serine-rich

serine/threonine kinase 3 (Ste20, yeast homolog)

serine/threonine kinase 11

Lyn

Tgfbr2

9.61

$\begin{array}{ll}9.58 & 10.66 \\ 9.55 & 10.13\end{array}$

mitogen-activated protein kinase kinase 2

protein kinase, CAMP dependent, catalytic, beta

mitogen-activated protein kinase 9

cyclin-dependent kinase 9 (CDC2-related kinase)

FK506 binding protein 12-rapamycin associated protein 1

serine/threonine kinase 4

protein kinase $\mathrm{C}$, iota

receptor-interacting serine-threonine kinase 4

3-phosphoinositide dependent protein kinase-1

eukaryotic translation initiation factor 2-alpha kinase 2

PRP4 pre-mRNA processing factor 4 homolog B (yeast)

kinase insert domain protein receptor

serine/threonine kinase 40

interleukin-1 receptor-associated kinase 1

oxidative-stress responsive 1

conserved helix-loop-helix ubiquitous kinase

v-erb-b2 erythroblastic leukemia viral oncogene homolog 3 (avian)

Tpr

Map3k1

Crkrs

Stk3

Stk11

Map2k2

9.54

9.97

$\begin{array}{rr}9.52 & 9.68 \\ 9.52 & 10.33\end{array}$

Prkacb

$9.50 \quad 10.89$

$9.47 \quad 10.48$

$9.45 \quad 10.45$

$9.42 \quad 9.95$

$9.41 \quad 9.38$

Mapk9

$9.40 \quad 10.54$

Cdk9

$9.35 \quad 9.68$

$9.33 \quad 9.32$

9.31

9.24

Frap1

9.29

9.82

Stk4

9.27

9.47

Prkci

9.27

9.70

$9.24-9.53$

$\begin{array}{lll}\text { Pdpk1 } & 9.22 & 9.94\end{array}$

$\begin{array}{lll}\text { Eif2ak2 } & 9.22 & 9.28\end{array}$

$\begin{array}{lll}\text { Prpf4b } & 9.22 & 9.57\end{array}$

$\begin{array}{lll}\text { Kdr } & 9.21 & 9.22\end{array}$

$\begin{array}{lll}\text { Stk40 } & 9.18 & 9.28\end{array}$

$\begin{array}{lll}\text { Irak1 } & 9.18 & 9.07\end{array}$

$\begin{array}{lll}\text { Oxsr1 } & 9.12 & 10.15\end{array}$

$\begin{array}{lll}\text { Chuk } & 9.12 & 9.97\end{array}$

$\begin{array}{lll}\text { Erbb3 } & 9.12 & 9.94\end{array}$

RIO kinase 2 (yeast)

Riok2

$9.12 \quad 9.45$

mitogen-activated protein kinase kinase kinase 2

Map3k2

$9.10 \quad 9.49$

plexin B1

casein kinase 1 , gamma 2

mitogen-activated protein kinase 6

protein kinase, cAMP dependent, catalytic, alpha

serum/glucocorticoid regulated kinase 3

cyclin-dependent kinase 7

Plxnb1

$9.06 \quad 10.17$

$\begin{array}{lll}\text { Csnk1g2 } & 9.02 & 9.31\end{array}$

Mapk6

$9.01 \quad 9.66$

$\begin{array}{lll}\text { Prkaca } & 9.01 & 9.51\end{array}$

$\begin{array}{lll}\text { Sgk3 } & 8.98 & 8.57\end{array}$

$\begin{array}{lll}\text { Cdk7 } & 8.97 & 9.02\end{array}$

$\begin{array}{lll}\text { Pdk4 } & 8.95 & 9.65\end{array}$

pyrute dehydrogenase kinase, isoenzyme 4

Mylk

$8.95 \quad 10.12$

mitogen-activated protein kinase kinase 1

Map2k1

8.94

9.34

protein kinase $\mathrm{C}$, eta

Unc-51 like kinase 1 (C. elegans)

Prkch

$8.94 \quad 10.04$

plexin B2

Ulk1

8.94

9.03

Plxnb2

8.93

10.28

Pik3r4

8.93

9.38

kit oncogene

Kit

8.91

9.80

CDC-like kinase 2 /// secretory carrier membrane protein 3

Clk2 IScamp:

8.86

9.21

RIO kinase 3 (yeast)

Riok3

8.86

9.31 
Braf transforming gene

activin A receptor, type 1B

Braf

8.86

9.44

large tumor suppressor

Acvr1b

8.85

9.04

TAO kinase 1

Lats1

8.85

9.49

testis-specific kinase 2

Taok1

8.85

9.61

eukaryotic elongation factor-2 kinase

Tesk2

8.84

8.95

protein kinase D3

Eef2k

$8.84 \quad 10.36$

microtubule associated serine/threonine kinase 2

Prkd3

8.78

9.31

dual serine/threonine and tyrosine protein kinase

Mast2

8.76

9.13

Dstyk

8.75

9.44

TAF1 RNA polymerase II

calcium/calmodulin-dependent protein kinase I

Taf1

8.75

9.37

CDC42 binding protein kinase alpha

protein kinase $\mathrm{C}$, alpha

NUAK family, SNF1-like kinase, 2

Camk1

8.74

9.21

$\begin{array}{lll}\text { Cdc42bpa } \quad 8.72 & 9.13\end{array}$

Prkca

8.71

9.10

Nuak2

8.71

10.00

protein kinase $\mathrm{C}$, zeta

NIMA (never in mitosis gene a)-related expressed kinase 4

Prkcz

8.68

9.20

eukaryotic translation initiation factor 2 alpha kinase 1

SH3-domain binding protein 4

doublecortin-like kinase 3

cyclin-dependent kinase 4

Yamaguchi sarcoma viral (v-yes) oncogene homolog 1

mitogen-activated protein kinase 1

cDNA sequence BC033915

TANK-binding kinase 1

serine/arginine-rich protein specific kinase 2

serine/threonine kinase 16

pyruvate dehydrogenase kinase, isoenzyme 3

casein kinase 2, alpha prime polypeptide

Fyn proto-oncogene

cyclin-dependent kinase (CDC2-like) 10

Nek4

Eif2ak1

Sh3bp4

Dclk3

Cdk4

Yes1

Mapk1

BC033915

8.68

8.76

8.67

8.97

8.66

9.12

8.64

9.84

$8.63 \quad 9.27$

$8.62 \quad 9.07$

Tbk1

$8.61 \quad 9.10$

Srpk2

8.61

8.75

Stk16

Pdk3

Csnk2a2

8.61

9.01

$8.60 \quad 8.97$

$8.59 \quad 8.90$

Fyn

8.59

8.86

Cdk10

8.59

9.20

cell division cycle 2-like 1

cyclin-dependent kinase 6

Cdc2l1

8.55

9.65

Cdk6
Dapk1

8.55

9.09

death associated protein kinase 1

colony stimulating factor 1 receptor

Csf1r

Endoplasmic reticulum (ER) to nucleus signalling 1 (Ern1), mRNA

cyclin-dependent kinase 8

MAP kinase-activated protein kinase 5

$\mathrm{G}$ protein-coupled receptor kinase 6

salt inducible kinase 2

mitogen-activated protein kinase kinase kinase kinase 4

ribosomal protein $\mathrm{S} 6$ kinase polypeptide 3

serine/threonine kinase 25 (yeast)

v-raf murine sarcoma 3611 viral oncogene homolog

v-raf-leukemia viral oncogene 1

RIKEN cDNA B230120H23 gene

mitogen-activated protein kinase kinase kinase 9

mitogen-activated protein kinase kinase kinase 4

Ern1

Cdk8

Mapkapk5

8.54

9.16

$8.53 \quad 8.98$

$8.50 \quad 7.62$

$8.48 \quad 8.46$

$8.48 \quad 8.49$

Grk6

8.42

8.45

$8.40 \quad 8.84$

Sik2

8.40

8.08

Map4k4

8.39

8.62

Rps6ka3

8.37

8.48

Stk25

8.37

8.97

Araf

8.35

9.60

Raf1

8.33

8.83

B230120H23

8.32

8.67

Map3k9

8.32

8.90

Map3k4

8.32

8.46

Gsk3a

8.32

8.89

glycogen synthase kinase 3 alpha

Cdk5

8.31

8.61

cyclin-dependent kinase 5

Pim1

8.30

8.76

Atm

8.28

9.18

ataxia telangiectasia mutated homolog (human)

mitogen-activated protein kinase kinase kinase kinase 5

protein serine kinase $\mathrm{H} 1$

microtubule associated serine/threonine kinase 3

Map4k5

8.27

9.11

Pskh1

8.24

8.59

Mast3

8.21

8.38

Vrk1

8.17

9.24

phosphorylase kinase, gamma 2 (testis)

Phkg2

8.14

8.50

8.14

8.37 
protein kinase $\mathrm{C}$, epsilon

adrenergic receptor kinase, beta 1

casein kinase 1 , gamma 3

receptor (TNFRSF)-interacting serine-threonine kinase 1

mitogen-activated protein kinase kinase 3

membrane protein, palmitoylated

NIMA (never in mitosis gene a)-related expressed kinase 1

WEE 1 homolog 1 (S. pombe)

Fas-activated serine/threonine kinase

inhibitor of kappaB kinase beta

v-erb-b2 erythroblastic leukemia viral oncogene homolog 2

plexin A1

serine/threonine kinase 38 like

tribbles homolog 3 (Drosophila)

cDNA sequence BC021891

interleukin-1 receptor-associated kinase 4

Rho-associated coiled-coil containing protein kinase 2

vaccinia related kinase 3

mitogen-activated protein kinase kinase kinase 10

mitogen-activated protein kinase kinase 4

thymoma viral proto-oncogene 3

Unc-51 like kinase 2 (C. elegans)

PCTAIRE-motif protein kinase 2

thymoma viral proto-oncogene 1

tribbles homolog 1 (Drosophila)

ribosomal protein S6 kinase polypeptide 1

v-abl Abelson murine leukemia viral oncogene homolog 2

cyclin-dependent kinase-like 2 (CDC2-related kinase)

protein kinase N3

leucine-rich repeat kinase 1

PFTAIRE protein kinase 1

CDC42 binding protein kinase beta

SMG1 homolog, phosphatidylinositol 3-kinase-related kinase

BMP2 inducible kinase

nuclear receptor binding protein 1

testis specific protein kinase 1

salt inducible kinase 1

branched chain ketoacid dehydrogenase kinase

LIM motif-containing protein kinase 2

misshapen-like kinase 1 (zebrafish)

ribosomal protein S6 kinase, polypeptide 1

thymoma viral proto-oncogene 2

NIMA (never in mitosis gene a)-related expressed kinase 8

calcium/calmodulin-dependent protein kinase II, delta

mitogen-activated protein kinase kinase kinase 11

serine/threonine kinase $32 \mathrm{~B}$

mitogen-activated protein kinase 13

RIKEN cDNA C230081A13 gene

$\mathrm{G}$ protein-coupled receptor kinase 5

tau tubulin kinase 2

cell division cycle 2-like 5

SPEG complex locus

mitogen-activated protein kinase kinase 6

mitogen-activated protein kinase kinase kinase kinase 2

vaccinia related kinase 2

MAP/microtubule affinity-regulating kinase 4

$\begin{array}{lll}\text { Prkce } & 8.14 & 8.00 \\ \text { Adrbk1 } & 8.14 & 8.39 \\ \text { Csnk1g3 } & 8.11 & 9.15 \\ \text { Ripk1 } & 8.06 & 8.45 \\ \text { Map2k3 } & 8.02 & 8.32 \\ \text { Mpp1 } & 8.01 & 8.17 \\ \text { Nek1 } & 8.01 & 8.68 \\ \text { Wee1 } & 8.00 & 7.63 \\ \text { Fastk } & 7.99 & 8.56 \\ \text { Ikbkb } & 7.98 & 8.73 \\ \text { Erbb2 } & 7.97 & 8.47 \\ \text { Plxna1 } & 7.97 & 8.50 \\ \text { Stk38I } & 7.97 & 8.58 \\ \text { Trib3 } & 7.97 & 7.93 \\ \text { BC021891 } & 7.95 & 8.84 \\ \text { Irak4 } & 7.95 & 8.97 \\ \text { Rock2 } & 7.94 & 8.76 \\ \text { Vrk3 } & 7.93 & 8.23 \\ \text { Map3k10 } & 7.93 & 8.75 \\ \text { Map2k4 } & 7.92 & 8.64 \\ \text { Akt3 } & 7.92 & 8.15 \\ \text { Ulk2 } & 7.92 & 8.23 \\ \text { Pctk2 } & 7.88 & 8.35 \\ \text { Akt1 } & 7.87 & 8.69 \\ \text { Trib1 } & 7.86 & 8.87 \\ \text { Rps6ka1 } & 7.82 & 8.69 \\ \text { Abl2 } & 7.80 & 8.30 \\ \text { Cdkl2 } & 7.79 & 8.11 \\ \text { Pkn3 } & 7.76 & 7.46 \\ \text { Lrrk1 } & 7.76 & 8.62 \\ \text { Pftk1 } & 7.75 & 8.38 \\ \text { Cdc42bpb } & 7.75 & 8.20 \\ \text { Smg1 } & 7.73 & 8.39 \\ \text { Bmp2k } & 7.73 & 7.78 \\ \text { Nrbp1 } & 7.65 & 8.00 \\ \text { Tesk1 } & 7.65 & 8.38 \\ \text { Sik1 } & 7.64 & 7.16 \\ \text { Bckdk } & 7.63 & 8.01 \\ \text { Limk2 } & 7.62 & 7.81 \\ \text { Mink1 } & 7.60 & 7.70 \\ \text { Rps6kb1 } & 7.60 & 8.16 \\ \text { Akt2 } & 7.59 & 8.29 \\ \text { Nek8 } & 7.53 & 8.34 \\ \text { Camk2d } & 7.52 & 8.15 \\ \text { Map3k11 } & 7.51 & 7.86 \\ \text { Stk32b } & 7.48 & 5.65 \\ \text { Mapk13 } & 7.46 & 8.18 \\ \text { C230081A13 } & 7.43 & 8.41 \\ \text { Grk5 } & 7.42 & 8.18 \\ \text { Ttbk2 } & 7.41 & 7.71 \\ \text { Cdc2l5 } & 7.39 & 7.99 \\ \text { Speg } & 7.38 & 6.90 \\ \text { Map2k6 } & 7.37 & 7.61 \\ \text { Map4k2 } & 7.36 & 8.01 \\ \text { Mark4 } & 7.34 & 8.10 \\ & 7.34 & 7.79 \\ \text { rk2 } & & \end{array}$


SH3-binding kinase 1

mitogen-activated protein kinase 8

p21 (CDKN1A)-activated kinase 6

Death-associated protein kinase 3 (Dapk3), mRNA

serine/threonine kinase 35

ribosomal protein S6 kinase polypeptide 1

renal tumor antigen

NIMA (never in mitosis gene a)-related expressed kinase 6

cell division cycle 2-like 6 (CDK8-like)

STE20-related kinase adaptor alpha

RIO kinase 1 (yeast)

protein kinase, AMP-activated, alpha 1 catalytic subunit

MAP kinase-interacting serine/threonine kinase 1

dystrophia myotonica-protein kinase

LIM-domain containing, protein kinase

ribosomal protein S6 kinase, polypeptide 2

MAP kinase-activated protein kinase 2

serine/threonine kinase 10

phosphorylase kinase gamma 1

PDLIM1 interacting kinase 1 like

polo-like kinase 4 (Drosophila)

casein kinase 1, gamma 1

ATM interactor

mitogen-activated protein kinase kinase 5

plexin A2

protein kinase $\mathrm{C}$, theta

STE20-related kinase adaptor beta

protein kinase D2

cell division cycle 2 homolog A (S. pombe)

activin $A$ receptor, type II-like 1

leucine-rich repeat kinase 2

pigeon homolog (Drosophila)

casein kinase 1, epsilon

cell division cycle 7 (S. cerevisiae)

unc-51-like kinase 3 (C. elegans)

MAP/microtubule affinity-regulating kinase 1

kinase suppressor of ras 1

PCTAIRE-motif protein kinase 3

calcium/calmodulin-dependent protein kinase II alpha

mitogen-activated protein kinase kinase kinase 14

mitogen-activated protein kinase kinase kinase kinase 1

ribosomal protein S6 kinase, polypeptide 4

tribbles homolog 2 (Drosophila)

mitogen-activated protein kinase 4

NUAK family, SNF1-like kinase, 1

protein kinase $\mathrm{N} 1$

microtubule associated serine/threonine kinase family member 4

eukaryotic translation initiation factor 2 alpha kinase 4

receptor-interacting serine-threonine kinase 3

cyclin-dependent kinase 2

activin receptor IIB

PDZ binding kinase

ribosomal protein S6 kinase, polypeptide 5

microtubule associated serine/threonine kinase-like

aurora kinase A

plexin D1
Sbk1

Mapk8

Pak6

Dapk3

Stk35

Rps6kc1

Rage

Nek6

Cdc2I6

Strada

Riok1

Prkaa1

Mknk1

Dmpk

Limk1

Rps6kb2

Mapkapk2

Stk10

Phkg1

Pdik1l

Plk4

Csnk1g1

Atmin

Map2k5

Plxna2

Prkcq

Stradb

Prkd2

Cdc2a

Acvrl1

Lrrk2

Pion

Csnk1e

Cdc7

Ulk3

Mark1

Ksr1

Pctk3

Camk2a

Map3k14

Map4k1

Rps6ka4

Trib2

Mapk4

Nuak1

Pkn1

Mast4

Eif2ak4

Ripk3

Cdk2

Acvr2b

Pbk

Rps6ka5

Mastl

Aurka

Plxnd1
7.28

7.27

7.26

7.23

7.21

7.21

7.21

7.19

7.19

7.18

7.17

7.17

7.16

7.14

7.12

7.09

7.09

7.08

7.08

7.08

7.04

6.99

6.99

6.94

6.92

6.90

6.86

6.80

6.80

6.79

6.77

6.76

6.69

6.69

6.67

6.67

6.66

6.58

6.56

6.54

6.51

6.51

6.50

6.50

6.50

6.49

6.48

6.46

6.43

6.36

6.35

6.35

6.34

6.33

6.30

6.25
7.06

7.97

8.86

7.40

7.24

8.05

7.51

7.13

7.87

7.70

7.54

7.27

7.67

6.75

6.71

7.50

7.69

7.61

8.63

7.82

6.75

7.54

7.62

7.37

6.12

8.32

7.08

7.49

6.65

6.80

7.15

6.24

7.31

6.12

6.14

6.41

6.25

7.46

5.99

6.50

6.85

7.53

6.28

6.71

6.67

6.29

6.86

7.40

6.09

7.03

6.41

6.15

6.73

6.09

6.21

6.49 
polo-like kinase 2 (Drosophila)

protein kinase, cGMP-dependent, type II

intestinal cell kinase

ribosomal protein S6 kinase, polypeptide 2

budding uninhibited by benzimidazoles 1 homolog, beta

DnaJ (Hsp40) homolog, subfamily C, member 6

mitogen-activated protein kinase 12

citron

p21 (CDKN1A)-activated kinase 1

anti-Mullerian hormone type 2 receptor

NIMA (never in mitosis gene a)-related expressed kinase 3

protein kinase, DNA activated, catalytic polypeptide

WNK lysine deficient protein kinase 2

PAS domain containing serine/threonine kinase

zeta-chain (TCR) associated protein kinase

testis-specific serine kinase 3

plexin A4

serine/threonine kinase 36 (fused homolog, Drosophila)

CHK2 checkpoint homolog (S. pombe)

$\mathrm{G}$ protein-coupled receptor kinase 4

calcium/calmodulin-dependent protein kinase IV

p21 (CDKN1A)-activated kinase 3

mitogen-activated protein kinase 11

Table 5B. Non-receptor tyrosine kinases

fyn-related kinase

dual-specificity tyrosine-(Y)-phosphorylation regulated kinase 1a

PTK2 protein tyrosine kinase 2

PTK2 protein tyrosine kinase 2 beta

lemur tyrosine kinase 2

fer (fms/fps related) protein kinase, testis specific 2

Janus kinase 2

Janus kinase 1

tyrosine kinase, non-receptor, 1

FMS-like tyrosine kinase 1

FMS-like tyrosine kinase 4

tyrosine kinase, non-receptor, 2

tec protein tyrosine kinase

tyrosine kinase 2

c-mer proto-oncogene tyrosine kinase

c-src tyrosine kinase

serine/threonine/tyrosine kinase 1

PTK7 protein tyrosine kinase 7

Aatyk3 mRNA for apoptosis-associated tyrosine kinase 3
Plk2

Prkg2

Ick

$\begin{array}{lll}\text { Rps6ka2 } & 6.07 & 5.76^{*}\end{array}$

Bub1b $\quad 6.06 \quad 5.99$

$\begin{array}{lll}\text { Dnajc6 } & 6.05 & 4.44^{\star}\end{array}$

$\begin{array}{lll}\text { Mapk12 } & 6.05 & 6.93\end{array}$

Cit

Pak1

Amhr2

Nek3

Prkdc

Wnk2

Pask

Zap70

Tssk3

Plxna4

Stk36

Chek2

Grk4

Camk4

Pak3

Mapk11

Frk

Dyrk1a

Ptk2

Ptk2b

Lmtk2

Fert2

Jak2

Jak1

Tnk1

Flt1

Flt4

Tnk2

Tec

Tyk2

Mertk

Csk

Styk1

Ptk7

Lmtk3

Met

11.36

Ddr1

Fgfr2

Insr

Insrr

$\operatorname{lgf} 1 \mathrm{r}$

Tek

Fgfr1

Ephb4

Ryk

10.1

10.91

$9.55 \quad 10.59$

$9.15 \quad 10.02$

$8.81 \quad 8.85$

$8.73 \quad 9.99$

$8.73 \quad 9.47$

$8.66 \quad 9.12$

$8.46 \quad 9.24$

$8.25 \quad 8.78$

$8.24 \quad 7.46$

$8.18 \quad 7.82$

$\begin{array}{ll}7.83 & 8.34\end{array}$

$\begin{array}{ll}7.76 & 7.94\end{array}$

$7.18 \quad 7.53$

$\begin{array}{ll}7.12 & 6.24\end{array}$

$\begin{array}{ll}7.02 & 7.59\end{array}$

$6.99 \quad 8.85$

$\begin{array}{ll}6.53 & 6.49\end{array}$

$6.29 \quad 6.04$

met proto-oncogene fibroblast growth factor receptor 2

insulin receptor

insulin-like growth factor I receptor

endothelial-specific receptor tyrosine kinase

fibroblast growth factor receptor 1

Eph receptor B4

receptor-like tyrosine kinase

\author{
receptor-like tyrosine kinase
}

$\begin{array}{lll}\text { Ryk } & 8.63 & 8.87 \\ & 8.21 & 8.45\end{array}$


tyrosine kinase with immunoglobulin-like and EGF-like domains 1

Tie1

Eph receptor B3

Ephb3

6.91

6.73

c-abl oncogene 1, receptor tyrosine kinase

Abl1

6.63

6.11

AXL receptor tyrosine kinase

Axl

6.62

7.24

receptor tyrosine kinase-like orphan receptor 1

Ror1

6.23

5.93

Eph receptor A4

Epha4

5.84

6.21

Eph receptor B6

Ephb6

$5.74^{*}$

6.31

TXK tyrosine kinase

Txk

* - the A-value is below the cut-off level 


\begin{tabular}{|c|c|c|c|}
\hline Gene Name & $\begin{array}{l}\text { Gene } \\
\text { Symbol }\end{array}$ & $\begin{array}{c}\text { DCT/CNT } \\
\text { A_Value }\end{array}$ & $\begin{array}{c}\text { CCD } \\
\text { A_Value }\end{array}$ \\
\hline \multicolumn{4}{|l|}{ Table 6A. Serine-threonine phosphatases } \\
\hline protein phosphatase 2 (formerly $2 \mathrm{~A}$ ), alpha isoform & Ppp2r1a & 12.51 & 12.72 \\
\hline protein phosphatase 1 , catalytic subunit, gamma isoform & Ppp1cc & 11.76 & 12.14 \\
\hline protein phosphatase 1 , catalytic subunit, beta isoform & Ppp1cb & 11.35 & 11.90 \\
\hline protein phosphatase 1 , catalytic subunit, alpha isoform & Ppp1ca & 11.17 & 11.79 \\
\hline protein phosphatase 1B, magnesium dependent, beta isoform & Ppm1b & 11.15 & 11.49 \\
\hline protein phosphatase $1 \mathrm{H}$ (PP2C domain containing) & Ppm1h & 10.87 & 11.35 \\
\hline protein phosphatase 2 , alpha isoform & Ppp2r5a & 10.85 & 11.19 \\
\hline protein phosphatase 2 (formerly $2 \mathrm{~A}$ ), catalytic subunit, alpha isoform & Рpp2ca & 10.68 & 10.96 \\
\hline PTC7 protein phosphatase homolog (S. cerevisiae) & Pptc7 & 10.37 & 10.32 \\
\hline protein phosphatase $1 \mathrm{~A}$, magnesium dependent, alpha isoform & Ppm1a & 10.20 & 10.66 \\
\hline protein phosphatase $1 \mathrm{~K}$ (PP2C domain containing) & Ppm1k & 10.13 & 10.67 \\
\hline protein phosphatase 2 , epsilon isoform & Ppp2r5e & 9.82 & 10.29 \\
\hline protein phosphatase 2 (formerly $2 \mathrm{~A}$ ), alpha isoform & Ppp2r2a & 9.80 & 10.36 \\
\hline protein phosphatase 2, gamma isoform & Ppp2r5c & 9.55 & 10.18 \\
\hline protein phosphatase 6 , catalytic subunit & Ppp6c & 9.55 & 9.76 \\
\hline protein phosphatase 2 , regulatory subunit $B$, delta isoform & Ppp2r2d & 9.44 & 9.41 \\
\hline protein phosphatase 3 , catalytic subunit, alpha isoform & Рpp3ca & 9.41 & 9.52 \\
\hline protein phosphatase $1 \mathrm{G}$ (formerly $2 \mathrm{C}$ ), magnesium-dependent, gamma is & Ppm1g & 9.37 & 10.02 \\
\hline protein phosphatase 2 (formerly $2 \mathrm{~A}$ ), beta isoform & Ppp2r1b & 9.25 & 9.58 \\
\hline protein phosphatase 5 , catalytic subunit & Ppp5c & 9.19 & 9.30 \\
\hline CTD (carboxy-terminal domain) phosphatase, subunit 1 & Ctdp1 & 9.02 & 9.52 \\
\hline integrin-linked kinase-associated serine/threonine phosphatase $2 \mathrm{C}$ & Ilkap & 8.94 & 9.78 \\
\hline protein phosphatase 3 , catalytic subunit, beta isoform & Ppp3cb & 8.89 & 9.20 \\
\hline protein phosphatase 1 (formerly $2 \mathrm{C}$ )-like & Ppm1l & 8.78 & 9.20 \\
\hline protein phosphatase 4 , regulator & Ppp4r1 & 8.50 & 9.01 \\
\hline protein phosphatase 3 , regulatory subunit $B$, (calcineurin $B$, type I) & Ppp3r1 & 7.86 & 8.20 \\
\hline cell division cycle 25 homolog A (S. pombe) & Cdc25a & 7.74 & 8.41 \\
\hline protein phosphatase $2 \mathrm{C}$, magnesium dependent, catalytic subunit & Ppm2c & 7.66 & 8.28 \\
\hline protein phosphatase 4 , catalytic subunit & Ppp4c & 7.42 & 8.27 \\
\hline cell division cycle 25 homolog B (S. pombe) & Cdc25b & 7.14 & 6.99 \\
\hline protein phosphatase 3 , catalytic subunit, gamma isoform & Ppp3cc & 7.11 & 6.82 \\
\hline protein phosphatase 2 , delta isoform & Ppp2r5d & 6.74 & 7.43 \\
\hline protein phosphatase 2 (formerly $2 \mathrm{~A}$ ), beta isoform & Ppp2r2b & 6.72 & 7.74 \\
\hline protein phosphatase $1 \mathrm{M}$ & Ppm1m & 6.55 & 6.90 \\
\hline protein phosphatase 2 (formerly $2 \mathrm{~A}$ ), alpha & Ppp2r3a & 6.10 & 7.20 \\
\hline protein phosphatase 2 , beta isoform & Ppp2r5b & 6.02 & 6.16 \\
\hline protein phosphatase $1 \mathrm{~F}$ (PP2C domain containing) & Ppm1f & 5.95 & 6.36 \\
\hline \multicolumn{4}{|l|}{ Table 6B. Tyrosine phosphatases } \\
\hline & $\mathrm{Ac}$ & 12.20 & 12.28 \\
\hline sine phosphatase $4 \mathrm{a} 2$ & Ptp4a2 & 11.67 & 12.30 \\
\hline protein tyrosine phosphatase, receptor type, $\mathrm{F}$ & Ptprf & 10.74 & 11.32 \\
\hline protein tyrosine phosphatase, receptor type, J & Ptprj & 10.60 & 11.51 \\
\hline protein tyrosine phosphatase, non-receptor type 11 & Ptpn11 & 10.44 & 10.73 \\
\hline protein tyrosine phosphatase, receptor type, S & Ptprs & 10.26 & 10.29 \\
\hline protein tyrosine phosphatase, non-receptor type 1 & Ptpn1 & 9.40 & 9.53 \\
\hline protein tyrosine phosphatase, non-receptor type 2 & Ptpn2 & 9.26 & 9.67 \\
\hline protein tyrosine phosphatase, receptor type, $\mathrm{K}$ & Ptprk & 9.11 & 9.22 \\
\hline protein tyrosine phosphatase, receptor type, $A$ & Ptpra & 8.96 & 9.64 \\
\hline protein tyrosine phosphatase, non-receptor type 9 & Ptpn9 & 8.95 & 9.38 \\
\hline protein tyrosine phosphatase, mitochondrial 1 & Ptpmt1 & 8.88 & 8.98 \\
\hline
\end{tabular}


protein tyrosine phosphatase, non-receptor type 13

protein tyrosine phosphatase, non-receptor type 14

$\begin{array}{lll}\text { Ptpn13 } & 8.83 & 9.61 \\ \text { Ptpn14 } & 8.75 & 9.59 \\ \text { Ptprg } & 8.53 & 7.55 \\ \text { Ptprd } & 8.48 & 8.11 \\ \text { Ptprc } & 8.36 & 8.46 \\ \text { Ptprm } & 8.36 & 8.97 \\ \text { Ptpn21 } & 8.13 & 8.83 \\ \text { Ptprg } & 7.91 & 8.01 \\ \text { Ptpn18 } & 7.86 & 8.59 \\ \text { Ptpn23 } & 7.62 & 8.04 \\ \text { Ptpn12 } & 7.35 & 7.75 \\ \text { Ptpn6 } & 7.28 & 7.21 \\ \text { Ptpru } & 6.86 & 6.92 \\ \text { Ptpdc1 } & 6.73 & 6.97 \\ \text { Ptp4a3 } & 6.10 & 6.19 \\ \text { Ptpre } & 5.90 & 6.32\end{array}$

similar to protein tyrosine phosphatase, receptor type, G

protein tyrosine phosphatase, receptor type, D

protein tyrosine phosphatase, receptor type, C

protein tyrosine phosphatase, receptor type, $\mathrm{M}$

protein tyrosine phosphatase, non-receptor type 21

protein tyrosine phosphatase, receptor type, $\mathrm{G}$

protein tyrosine phosphatase, non-receptor type 18

protein tyrosine phosphatase, non-receptor type 23

protein tyrosine phosphatase, non-receptor type 12

protein tyrosine phosphatase, non-receptor type 6

protein tyrosine phosphatase, receptor type, $U$

protein tyrosine phosphatase domain containing 1

protein tyrosine phosphatase $4 \mathrm{a} 3$

protein tyrosine phosphatase, receptor type, E

Ptpre

6.32

Table 6C. Dual-specificity phosphatases

dual specificity phosphatase 1

dual specificity phosphatase 3

slingshot homolog 1 (Drosophila)

Dusp1

11.46

11.73

Dusp3

10.47

11.73

Ssh1

9.19

9.73

dual specificity phosphatase 16

Dusp16 $\quad 8.91 \quad 9.64$

CDC14 cell division cycle 14 homolog A (S. cerevisiae)

Cdc14a

$8.68 \quad 9.04$

dual specificity phosphatase 19

Dusp19

$8.40 \quad 9.32$

dual specificity phosphatase 22

Dusp22

8.02

8.08

Dusp6

7.69

7.86

dual specificity phosphatase 7

Dusp7

7.49

8.11

CDC14 cell division cycle 14 homolog B (S. cerevisiae)

Cdc14b

7.41

8.17

Dusp23

7.40

7.18

dual specificity phosphatase 26 (putative)

Dusp26

7.30

Dusp12

7.28

6.08

dual specificity phosphatase 12

Ssh2

$\begin{array}{ll}7.06 & 7.57\end{array}$

dual specificity phosphatase 28

Dusp28

7.04

7.04

dual specificity phosphatase 18

Dusp18

slingshot homolog 2 (Drosophila)

Ssh2

dual specificity phosphatase 8

Dusp8

6.92

6.69

slingshot homolog 3 (Drosophila)

Ssh3

dual specificity phosphatase 4

Dusp4

6.41

7.73

epilepsy, progressive myoclonic epilepsy, type 2 gene alpha

Epm2a

6.39

6.54

dual specificity phosphatase 10

Dusp10

6.28

6.72

$5.61^{*}$

6.16

6.04

6.40

* - the A-value is below the cut-off level 


\begin{tabular}{|c|c|c|c|}
\hline Gene Name & $\begin{array}{l}\text { Gene } \\
\text { Symbol }\end{array}$ & $\begin{array}{c}\text { DCT/CNT } \\
\text { A_Value }\end{array}$ & $\begin{array}{c}\text { CCD } \\
\text { A_Value }\end{array}$ \\
\hline \multicolumn{4}{|l|}{ Table 9A. Rab small GTP-binding proteins } \\
\hline RAB1, member RAS oncogene family & Rab1 & 12.58 & 12.82 \\
\hline RAB14, member RAS oncogene family & Rab14 & 11.96 & 12.08 \\
\hline RAB7, member RAS oncogene family & Rab7 & 11.69 & 12.07 \\
\hline RAB10, member RAS oncogene family & Rab10 & 11.68 & 11.85 \\
\hline RAB2A, member RAS oncogene family & Rab2a & 11.67 & 11.90 \\
\hline RAB21, member RAS oncogene family & Rab21 & 11.29 & 11.53 \\
\hline RAB18, member RAS oncogene family & Rab18 & 10.68 & 11.30 \\
\hline RAB11a, member RAS oncogene family & Rab11a & 10.44 & 10.77 \\
\hline RAB28, member RAS oncogene family & Rab28 & 10.41 & 11.10 \\
\hline RAB22A, member RAS oncogene family & Rab22a & 10.23 & 10.42 \\
\hline RAB9, member RAS oncogene family & Rab9 & 9.98 & 10.24 \\
\hline RAB4A, member RAS oncogene family & Rab4a & 9.94 & 10.23 \\
\hline RAB11B, member RAS oncogene family & Rab11b & 9.83 & 10.88 \\
\hline RAB17, member RAS oncogene family & Rab17 & 9.74 & 10.19 \\
\hline RAB6B, member RAS oncogene family & Rab6b & 9.73 & 10.27 \\
\hline RAB25, member RAS oncogene family & Rab25 & 9.61 & 10.31 \\
\hline RAB6, member RAS oncogene family & Rab6 & 9.60 & 9.96 \\
\hline RAB20, member RAS oncogene family & Rab20 & 9.54 & 10.82 \\
\hline RAB5A, member RAS oncogene family & Rab5a & 9.48 & 10.06 \\
\hline RAB5B, member RAS oncogene family & Rab5b & 9.46 & 10.01 \\
\hline RAB15, member RAS oncogene family & Rab15 & 9.35 & 10.12 \\
\hline RAB3A, member RAS oncogene family & Rab3a & 9.16 & 8.83 \\
\hline RAB8A, member RAS oncogene family & Rab8a & 9.14 & 9.39 \\
\hline RAB33B, member of RAS oncogene family & Rab33b & 9.05 & 9.66 \\
\hline RAB35, member RAS oncogene family & Rab35 & 9.01 & 9.42 \\
\hline RAB24, member RAS oncogene family & Rab24 & 8.88 & 9.37 \\
\hline RAB, member of RAS oncogene family-like 3 & Rabl3 & 8.83 & 8.94 \\
\hline RAB8B, member RAS oncogene family & Rab8b & 8.80 & 9.40 \\
\hline RAB27A, member RAS oncogene family & Rab27a & 8.70 & 7.01 \\
\hline RAB12, member RAS oncogene family & Rab12 & 8.58 & 9.09 \\
\hline RAB, member of RAS oncogene family-like $2 \mathrm{~A}$ & Rabl2a & 8.33 & 8.47 \\
\hline Rab40c, member RAS oncogene family & Rab40c & 8.28 & 8.38 \\
\hline RAB5C, member RAS oncogene family & Rab5c & 8.23 & 8.05 \\
\hline RAB, member of RAS oncogene family-like 4 & Rabl4 & 8.08 & 8.41 \\
\hline RAB31, member RAS oncogene family & Rab31 & 8.02 & 8.04 \\
\hline RAB39B, member RAS oncogene family & Rab39b & 7.87 & 8.02 \\
\hline RAB34, member of RAS oncogene family & Rab34 & 7.85 & 7.66 \\
\hline RAB1B, member RAS oncogene family & Rab1b & 7.79 & 8.09 \\
\hline RAB23, member RAS oncogene family & Rab23 & 7.67 & 8.04 \\
\hline RAB13, member RAS oncogene family & Rab13 & 7.66 & 8.08 \\
\hline RAB7, member RAS oncogene family-like 1 & Rab7l1 & 7.46 & 8.09 \\
\hline RAB3D, member RAS oncogene family & Rab3d & 7.41 & 8.46 \\
\hline RAB4B, member RAS oncogene family & Rab4b & 7.38 & 7.85 \\
\hline RAB27b, member RAS oncogene family & Rab27b & 7.35 & 7.86 \\
\hline RAB19, member RAS oncogene family & Rab19 & 7.13 & 7.69 \\
\hline RAB43, member RAS oncogene family & Rab43 & 6.79 & 7.17 \\
\hline RAB2B, member RAS oncogene family & Rab2b & 6.63 & 7.24 \\
\hline RAB32, member RAS oncogene family & Rab32 & 6.55 & 7.45 \\
\hline RAB38, member of RAS oncogene family & Rab38 & 6.38 & 6.71 \\
\hline Rab40b, member RAS oncogene family & Rab40b & 6.33 & 6.98 \\
\hline TBC1 domain family, member 7 & Tbc1d7 & 6.30 & 6.73 \\
\hline
\end{tabular}


Table 9B. Arf small GTP-binding proteins

ADP-ribosylation factor 6

$\begin{array}{lrr}\text { Arf6 } & 12.58 & 13.00 \\ \text { Arf1 } & 11.89 & 11.93 \\ \text { Arf3 } & 11.64 & 12.25 \\ \text { Arl1 } & 11.61 & 11.94 \\ \text { Arl3 } & 11.46 & 11.73 \\ \text { Sar1a } & 11.46 & 12.09 \\ \text { Sar1b } & 10.69 & 11.12 \\ \text { Arf4 } & 10.48 & 10.99 \\ \text { Arl4c } & 10.07 & 9.25 \\ \text { Arl5a } & 9.72 & 10.22 \\ \text { Arl8b } & 9.53 & 10.18 \\ \text { Arl4a } & 9.18 & 9.27 \\ \text { Arfr11 } & 9.05 & 9.73 \\ \text { Arl6 } & 8.90 & 9.54 \\ \text { Arl8a } & 8.87 & 9.33 \\ \text { Arf2 } & 8.52 & 9.15 \\ \text { Arl2 } & 7.85 & 8.20 \\ \text { Arl4d } & 7.38 & 9.24 \\ \text { Arl5b } & 7.17 & 7.52 \\ \text { Trim23 } & 6.07 & 6.90 \\ \text { Arl10 } & 5.49^{\star} & 6.61\end{array}$

ADP-ribosylation factor 1

ADP-ribosylation factor 3

1.93

ADP-ribosylation factor-like 1

11.94

ADP-ribosylation factor-like 3

SAR1 gene homolog A (S. cerevisiae)

SAR1 gene homolog $B$ (S. cerevisiae)

ADP-ribosylation factor 4

ADP-ribosylation factor-like $4 C$

ADP-ribosylation factor-like $5 \mathrm{~A}$

ADP-ribosylation factor-like $8 \mathrm{~B}$

ADP-ribosylation factor-like $4 \mathrm{~A}$

ADP-ribosylation factor related protein 1

ADP-ribosylation factor-like 6

ADP-ribosylation factor-like $8 \mathrm{~A}$

ADP-ribosylation factor 2

ADP-ribosylation factor-like 2

ADP-ribosylation factor-like 4D

ADP-ribosylation factor-like 5B

tripartite motif-containing 23

ADP-ribosylation factor-like 10

Arl10

6.61

Table 9C. Rho small GTP-binding proteins

cell division cycle 42 homolog (S. cerevisiae)

ras homolog gene family, member $A$

RAS-related $C 3$ botulinum substrate 1

Cdc42

12.89

12.74

Rhoa

11.66

11.84

ras homolog gene family, member $B$

Rac1

11.32

11.81

Rhob

9.80

10.14

ras homolog gene family, member $U$

Rhou

9.77

10.58

ras homolog gene family, member $\mathrm{Q}$

Rhoq

8.74

9.34

Rho family GTPase 3

ras homolog gene family, member T2

ras homolog gene family, member $\mathrm{T} 1$

Rho-related BTB domain containing 1

Rnd3

8.16

9.13

Rhot2

8.06

8.88

Rhot1

8.05

8.84

Rhobtb1

7.44

8.02

$\begin{array}{lll}\text { Rhobtb2 } & 7.39 & 7.54\end{array}$

ras homolog gene family, member $C$

Rhoc

7.35

8.05

Rho family GTPase 2

Rnd2

7.18

7.67

ras homolog gene family, member $D$

Rhod

6.74

7.87

ras homolog gene family, member $\mathrm{J}$

Rho-related BTB domain containing 3

ras homolog gene family, member $G$

RAS-related $\mathrm{C} 3$ botulinum substrate 3

Rhoj

6.70

6.50

$\begin{array}{lll}\text { Rhobtb3 } & 6.63 & 7.56\end{array}$

Rhog

5.83

7.56
6.67

Rac3

$5.71^{*}$

6.03

Table 9D. Ras and Ras-related small GTP-binding proteins

Ras-related GTP binding $D$

Rragd $\quad 12.40 \quad 12.60$

RAS related protein $1 b$

Rap1b

10.75

11.28

RAS-related protein-1a

v-Ki-ras2 Kirsten rat sarcoma viral oncogene homolog

RAN, member RAS oncogene family

v-ral simian leukemia viral oncogene homolog A (ras related)

Harvey rat sarcoma virus oncogene 1

Rap1a

10.33

10.80

Kras

10.32

10.57

Ran

9.81

10.39

Rala

9.34

9.79

Hras1

9.18

Rragc

9.21

Ras-related GTP binding C

9.14

Ralb

9.08

9.67

v-ral simian leukemia viral oncogene homolog B (ras related)

Nras

9.02

10.30

neuroblastoma ras oncogene 
NFKB inhibitor interacting Ras-like protein 1

Ras-related GTP binding $A$

RAS related protein $2 \mathrm{a}$

RAP2B, member of RAS oncogene family

8.78

9.10

Harvey rat sarcoma oncogene, subgroup $\mathrm{R}$

Rraga

8.50

8.68

Rap2a

8.24

Rap2b

8.20

8.82

Rras

9.23

Ras-like without CAAX 1

Rit1

8.04

Rasl11b

7.79

8.51

RAS-like, family 11 , member $B$

muscle and microspikes RAS

NFKB inhibitor interacting Ras-like protein 2

Mras

7.73

8.31

Nkiras2

7.64

9.02

RAS, dexamethasone-induced 1

related RAS viral (r-ras) oncogene homolog 2

Rasd1

Rras2

7.60

7.79

Ras-related associated with diabetes

Rrad

7.40

7.79

RASD family, member 2

Rasd2

7.40

7.76

RAS and EF hand domain containing

Rasef

6.87

8.50

GTP binding protein (gene overexpressed in skeletal muscle)

Gem

6.59

8.55

RAS-like, family 2, locus 9

Rasl2-9

6.04

7.38

RAS-like, family 11 , member $A$

Rasl11a

5.96

6.66

6.32

* - the A-value is below the cut-off level 


\begin{tabular}{|c|c|c|c|}
\hline Gene Name & $\begin{array}{l}\text { Gene } \\
\text { Symbol }\end{array}$ & $\begin{array}{c}\text { DCT/CNT } \\
\text { A_Value }\end{array}$ & $\begin{array}{c}\text { CCD } \\
\text { A_Value }\end{array}$ \\
\hline \multicolumn{4}{|l|}{ Table 9A. Rab small GTP-binding proteins } \\
\hline RAB1, member RAS oncogene family & Rab1 & 12.58 & 12.82 \\
\hline RAB14, member RAS oncogene family & Rab14 & 11.96 & 12.08 \\
\hline RAB7, member RAS oncogene family & Rab7 & 11.69 & 12.07 \\
\hline RAB10, member RAS oncogene family & Rab10 & 11.68 & 11.85 \\
\hline RAB2A, member RAS oncogene family & Rab2a & 11.67 & 11.90 \\
\hline RAB21, member RAS oncogene family & Rab21 & 11.29 & 11.53 \\
\hline RAB18, member RAS oncogene family & Rab18 & 10.68 & 11.30 \\
\hline RAB11a, member RAS oncogene family & Rab11a & 10.44 & 10.77 \\
\hline RAB28, member RAS oncogene family & Rab28 & 10.41 & 11.10 \\
\hline RAB22A, member RAS oncogene family & Rab22a & 10.23 & 10.42 \\
\hline RAB9, member RAS oncogene family & Rab9 & 9.98 & 10.24 \\
\hline RAB4A, member RAS oncogene family & Rab4a & 9.94 & 10.23 \\
\hline RAB11B, member RAS oncogene family & Rab11b & 9.83 & 10.88 \\
\hline RAB17, member RAS oncogene family & Rab17 & 9.74 & 10.19 \\
\hline RAB6B, member RAS oncogene family & Rab6b & 9.73 & 10.27 \\
\hline RAB25, member RAS oncogene family & Rab25 & 9.61 & 10.31 \\
\hline RAB6, member RAS oncogene family & Rab6 & 9.60 & 9.96 \\
\hline RAB20, member RAS oncogene family & Rab20 & 9.54 & 10.82 \\
\hline RAB5A, member RAS oncogene family & Rab5a & 9.48 & 10.06 \\
\hline RAB5B, member RAS oncogene family & Rab5b & 9.46 & 10.01 \\
\hline RAB15, member RAS oncogene family & Rab15 & 9.35 & 10.12 \\
\hline RAB3A, member RAS oncogene family & Rab3a & 9.16 & 8.83 \\
\hline RAB8A, member RAS oncogene family & Rab8a & 9.14 & 9.39 \\
\hline RAB33B, member of RAS oncogene family & Rab33b & 9.05 & 9.66 \\
\hline RAB35, member RAS oncogene family & Rab35 & 9.01 & 9.42 \\
\hline RAB24, member RAS oncogene family & Rab24 & 8.88 & 9.37 \\
\hline RAB, member of RAS oncogene family-like 3 & Rabl3 & 8.83 & 8.94 \\
\hline RAB8B, member RAS oncogene family & Rab8b & 8.80 & 9.40 \\
\hline RAB27A, member RAS oncogene family & Rab27a & 8.70 & 7.01 \\
\hline RAB12, member RAS oncogene family & Rab12 & 8.58 & 9.09 \\
\hline RAB, member of RAS oncogene family-like $2 \mathrm{~A}$ & Rabl2a & 8.33 & 8.47 \\
\hline Rab40c, member RAS oncogene family & Rab40c & 8.28 & 8.38 \\
\hline RAB5C, member RAS oncogene family & Rab5c & 8.23 & 8.05 \\
\hline RAB, member of RAS oncogene family-like 4 & Rabl4 & 8.08 & 8.41 \\
\hline RAB31, member RAS oncogene family & Rab31 & 8.02 & 8.04 \\
\hline RAB39B, member RAS oncogene family & Rab39b & 7.87 & 8.02 \\
\hline RAB34, member of RAS oncogene family & Rab34 & 7.85 & 7.66 \\
\hline RAB1B, member RAS oncogene family & Rab1b & 7.79 & 8.09 \\
\hline RAB23, member RAS oncogene family & Rab23 & 7.67 & 8.04 \\
\hline RAB13, member RAS oncogene family & Rab13 & 7.66 & 8.08 \\
\hline RAB7, member RAS oncogene family-like 1 & Rab7l1 & 7.46 & 8.09 \\
\hline RAB3D, member RAS oncogene family & Rab3d & 7.41 & 8.46 \\
\hline RAB4B, member RAS oncogene family & Rab4b & 7.38 & 7.85 \\
\hline RAB27b, member RAS oncogene family & Rab27b & 7.35 & 7.86 \\
\hline RAB19, member RAS oncogene family & Rab19 & 7.13 & 7.69 \\
\hline RAB43, member RAS oncogene family & Rab43 & 6.79 & 7.17 \\
\hline RAB2B, member RAS oncogene family & Rab2b & 6.63 & 7.24 \\
\hline RAB32, member RAS oncogene family & Rab32 & 6.55 & 7.45 \\
\hline RAB38, member of RAS oncogene family & Rab38 & 6.38 & 6.71 \\
\hline Rab40b, member RAS oncogene family & Rab40b & 6.33 & 6.98 \\
\hline TBC1 domain family, member 7 & Tbc1d7 & 6.30 & 6.73 \\
\hline
\end{tabular}


Table 9B. Arf small GTP-binding proteins

ADP-ribosylation factor 6

$\begin{array}{lrr}\text { Arf6 } & 12.58 & 13.00 \\ \text { Arf1 } & 11.89 & 11.93 \\ \text { Arf3 } & 11.64 & 12.25 \\ \text { Arl1 } & 11.61 & 11.94 \\ \text { Arl3 } & 11.46 & 11.73 \\ \text { Sar1a } & 11.46 & 12.09 \\ \text { Sar1b } & 10.69 & 11.12 \\ \text { Arf4 } & 10.48 & 10.99 \\ \text { Arl4c } & 10.07 & 9.25 \\ \text { Arl5a } & 9.72 & 10.22 \\ \text { Arl8b } & 9.53 & 10.18 \\ \text { Arl4a } & 9.18 & 9.27 \\ \text { Arfr11 } & 9.05 & 9.73 \\ \text { Arl6 } & 8.90 & 9.54 \\ \text { Arl8a } & 8.87 & 9.33 \\ \text { Arf2 } & 8.52 & 9.15 \\ \text { Arl2 } & 7.85 & 8.20 \\ \text { Arl4d } & 7.38 & 9.24 \\ \text { Arl5b } & 7.17 & 7.52 \\ \text { Trim23 } & 6.07 & 6.90 \\ \text { Arl10 } & 5.49^{\star} & 6.61\end{array}$

ADP-ribosylation factor 1

ADP-ribosylation factor 3

1.93

ADP-ribosylation factor-like 1

11.94

ADP-ribosylation factor-like 3

SAR1 gene homolog A (S. cerevisiae)

SAR1 gene homolog $B$ (S. cerevisiae)

ADP-ribosylation factor 4

ADP-ribosylation factor-like $4 C$

ADP-ribosylation factor-like $5 \mathrm{~A}$

ADP-ribosylation factor-like $8 \mathrm{~B}$

ADP-ribosylation factor-like $4 \mathrm{~A}$

ADP-ribosylation factor related protein 1

ADP-ribosylation factor-like 6

ADP-ribosylation factor-like $8 \mathrm{~A}$

ADP-ribosylation factor 2

ADP-ribosylation factor-like 2

ADP-ribosylation factor-like 4D

ADP-ribosylation factor-like 5B

tripartite motif-containing 23

ADP-ribosylation factor-like 10

Arl10

6.61

Table 9C. Rho small GTP-binding proteins

cell division cycle 42 homolog (S. cerevisiae)

ras homolog gene family, member $A$

RAS-related $C 3$ botulinum substrate 1

Cdc42

12.89

12.74

Rhoa

11.66

11.84

ras homolog gene family, member $B$

Rac1

11.32

11.81

Rhob

9.80

10.14

ras homolog gene family, member $U$

Rhou

9.77

10.58

ras homolog gene family, member $\mathrm{Q}$

Rhoq

8.74

9.34

Rho family GTPase 3

ras homolog gene family, member T2

ras homolog gene family, member $\mathrm{T} 1$

Rho-related BTB domain containing 1

Rnd3

8.16

9.13

Rhot2

8.06

8.88

Rhot1

8.05

8.84

Rhobtb1

7.44

8.02

$\begin{array}{lll}\text { Rhobtb2 } & 7.39 & 7.54\end{array}$

ras homolog gene family, member $C$

Rhoc

7.35

8.05

Rho family GTPase 2

Rnd2

7.18

7.67

ras homolog gene family, member $D$

Rhod

6.74

7.87

ras homolog gene family, member $\mathrm{J}$

Rho-related BTB domain containing 3

ras homolog gene family, member $G$

RAS-related $\mathrm{C} 3$ botulinum substrate 3

Rhoj

6.70

6.50

$\begin{array}{lll}\text { Rhobtb3 } & 6.63 & 7.56\end{array}$

Rhog

5.83

7.56
6.67

Rac3

$5.71^{*}$

6.03

Table 9D. Ras and Ras-related small GTP-binding proteins

Ras-related GTP binding $D$

Rragd $\quad 12.40 \quad 12.60$

RAS related protein $1 b$

Rap1b

10.75

11.28

RAS-related protein-1a

v-Ki-ras2 Kirsten rat sarcoma viral oncogene homolog

RAN, member RAS oncogene family

v-ral simian leukemia viral oncogene homolog A (ras related)

Harvey rat sarcoma virus oncogene 1

Rap1a

10.33

10.80

Kras

10.32

10.57

Ran

9.81

10.39

Rala

9.34

9.79

Hras1

9.18

Rragc

9.21

Ras-related GTP binding C

9.14

Ralb

9.08

9.67

v-ral simian leukemia viral oncogene homolog B (ras related)

Nras

9.02

10.30

neuroblastoma ras oncogene 
NFKB inhibitor interacting Ras-like protein 1

Ras-related GTP binding $A$

RAS related protein $2 \mathrm{a}$

RAP2B, member of RAS oncogene family

8.78

9.10

Harvey rat sarcoma oncogene, subgroup $\mathrm{R}$

Rraga

8.50

8.68

Rap2a

8.24

Rap2b

8.20

8.82

Rras

9.23

Ras-like without CAAX 1

Rit1

8.04

Rasl11b

7.79

8.51

RAS-like, family 11 , member $B$

muscle and microspikes RAS

NFKB inhibitor interacting Ras-like protein 2

Mras

7.73

8.31

Nkiras2

7.64

9.02

RAS, dexamethasone-induced 1

related RAS viral (r-ras) oncogene homolog 2

Rasd1

Rras2

7.60

7.79

Ras-related associated with diabetes

Rrad

7.40

7.79

RASD family, member 2

Rasd2

7.40

7.76

RAS and EF hand domain containing

Rasef

6.87

8.50

GTP binding protein (gene overexpressed in skeletal muscle)

Gem

6.59

8.55

RAS-like, family 2, locus 9

Rasl2-9

6.04

7.38

RAS-like, family 11 , member $A$

Rasl11a

5.96

6.66

6.32

* - the A-value is below the cut-off level 


\begin{tabular}{llrr} 
Gene Name & Gene & DCT/CNT & \multicolumn{1}{c}{ CCD } \\
& Symbol & A_Value & A_Value \\
vesicle-associated membrane protein 2 & Vamp2 & 11.74 & 11.38 \\
vesicle-associated membrane protein 8 & Vamp8 & 11.66 & 12.03 \\
synaptosomal-associated protein 23 & Snap23 & 11.50 & 11.72 \\
synaptosomal-associated protein, 47 & Snap47 & 11.19 & 11.51 \\
vesicle transport through interaction with t-SNAREs 1B homolog & Vti1b & 10.68 & 10.94 \\
syntaxin 7 & Stx7 & 10.64 & 11.30 \\
vesicle-associated membrane protein 3 & Vamp3 & 10.55 & 10.89 \\
syntaxin 8 & Stx8 & 10.40 & 11.16 \\
SNAP-associated protein & Snapap & 10.18 & 10.61 \\
YKT6 homolog (S. Cerevisiae) & Ykt6 & 9.73 & 10.37 \\
syntaxin 3 & Stx3 & 9.60 & 10.30 \\
syntaxin 4A (placental) & Stx4a & 9.49 & 9.99 \\
syntaxin 12 & Stx12 & 9.47 & 10.30 \\
blocked early in transport 1 homolog (S. cerevisiae)-like & Bet1l & 9.38 & 9.35 \\
golgi SNAP receptor complex member 1 & Gosr1 & 9.37 & 9.75 \\
SEC22 vesicle trafficking protein homolog B (S. cerevisiae) & Sec22b & 9.35 & 9.73 \\
syntaxin 16 & Stx16 & 9.04 & 9.23 \\
blocked early in transport 1 homolog (S. cerevisiae) & Bet1 & 9.02 & 9.64 \\
golgi SNAP receptor complex member 2 & Gosr2 & 8.85 & 8.65 \\
vesicle-associated membrane protein 4 & Vamp4 & 8.63 & 8.80 \\
syntaxin 17 & Stx17 & 8.56 & 9.00 \\
vesicle transport through interaction with t-SNAREs homolog 1A (yeast) & Vti1a & 8.43 & 8.76 \\
syntaxin 5A & Stx5a & 8.39 & 9.16 \\
vesicle-associated membrane protein 7 & Vamp7 & 8.11 & 9.09 \\
syntaxin 6 & Stx6 & 7.77 & 8.33 \\
syntaxin 18 & Stx18 & 7.72 & 8.17 \\
syntaxin 6 & Stx6 & 7.69 & 8.65 \\
SEC22 vesicle trafficking protein homolog C (S. cerevisiae) & Sec22c & 7.55 & 8.30 \\
synaptosomal-associated protein 29 & Snap29 & 7.47 & 8.08 \\
vesicle-associated membrane protein 1 & Vamp1 & 6.75 & 6.64
\end{tabular}




\begin{tabular}{|c|c|c|c|}
\hline Gene Name & $\begin{array}{l}\text { Gene } \\
\text { Symbol }\end{array}$ & $\begin{array}{c}\text { DCT/CNT } \\
\text { A_Value }\end{array}$ & $\begin{array}{c}\text { CCD } \\
\text { A_Value }\end{array}$ \\
\hline \multicolumn{4}{|l|}{ Table 12A. Actin and actin-binding proteins } \\
\hline actin, beta & Actb & 13.35 & 13.80 \\
\hline cofilin 1, non-muscle & Cfl1 & 12.96 & 12.98 \\
\hline actin, gamma, cytoplasmic 1 & Actg1 & 12.93 & 13.06 \\
\hline catenin (cadherin associated protein), beta 1 & Ctnnb1 & 12.74 & 13.26 \\
\hline syndecan 4 & Sdc4 & 12.61 & 12.99 \\
\hline catenin (cadherin associated protein), alpha 1 & Ctnna1 & 12.59 & 13.02 \\
\hline tropomyosin 1, alpha & Tpm1 & 12.30 & 12.87 \\
\hline Wiskott-Aldrich syndrome-like (human) & Wasl & 11.90 & 12.81 \\
\hline spectrin beta 2 & Spnb2 & 11.76 & 12.23 \\
\hline LIM and SH3 protein 1 & Lasp1 & 11.67 & 11.83 \\
\hline cingulin-like 1 & Cgnl1 & 11.56 & 12.13 \\
\hline ARP2 actin-related protein 2 homolog (yeast) & Actr2 & 11.49 & 12.01 \\
\hline tensin 1 & Tns1 & 11.47 & 11.85 \\
\hline gelsolin & Gsn & 11.37 & 12.06 \\
\hline cortactin & Cttn & 11.33 & 12.17 \\
\hline cysteine and glycine-rich protein 1 & Csrp1 & 11.18 & 11.75 \\
\hline cofilin 2, muscle & $\mathrm{Cfl} 2$ & 11.13 & 11.49 \\
\hline utrophin & Utrn & 11.12 & 12.18 \\
\hline radixin & $\mathrm{Rdx}$ & 11.11 & 11.24 \\
\hline tensin 3 & Tns3 & 11.03 & 11.71 \\
\hline actin related protein $2 / 3$ complex, subunit 3 & Arpc3 & 10.96 & 11.35 \\
\hline adducin 1 (alpha) & Add1 & 10.85 & 11.48 \\
\hline ARP3 actin-related protein 3 homolog (yeast) & Actr3 & 10.84 & 11.50 \\
\hline tropomodulin 1 & Tmod1 & 10.80 & 10.99 \\
\hline shroom family member 3 & Shroom3 & 10.80 & 11.08 \\
\hline ezrin & Ezr & 10.69 & 11.19 \\
\hline capping protein (actin filament) muscle Z-line, beta & Capzb & 10.68 & 11.15 \\
\hline junction plakoglobin & Jup & 10.65 & 10.97 \\
\hline formin binding protein 1-like & Fnbp1l & 10.64 & 11.61 \\
\hline filamin, beta & Flnb & 10.62 & 10.73 \\
\hline cysteine and glycine-rich protein 2 & Csrp2 & 10.55 & 11.02 \\
\hline LIM domain and actin binding 1 & Lima1 & 10.51 & 10.67 \\
\hline Coronin, actin binding protein $1 \mathrm{C}, \mathrm{mRNA}$ & Coro1c & 10.49 & 10.96 \\
\hline spire homolog 1 (Drosophila) & Spire1 & 10.48 & 10.34 \\
\hline actin-binding LIM protein 1 & Ablim1 & 10.35 & 10.93 \\
\hline kelch domain containing $8 \mathrm{~A}$ & Klhdc8a & 10.34 & 11.75 \\
\hline PDZ and LIM domain 5 & Pdlim5 & 10.30 & 10.26 \\
\hline LIM domain containing preferred translocation partner in lipoma & Lpp & 10.27 & 11.27 \\
\hline huntingtin interacting protein 1 related & Hip1r & 10.22 & 10.43 \\
\hline tropomyosin 3, gamma & Tpm3 & 10.19 & 10.92 \\
\hline capping protein (actin filament) muscle Z-line, alpha 2 & Capza2 & 10.16 & 10.53 \\
\hline paxillin & Pxn & 10.16 & 11.18 \\
\hline actin related protein $2 / 3$ complex, subunit 5 -like & Arpc5I & 10.15 & 10.56 \\
\hline enabled homolog (Drosophila) & Enah & 10.11 & 11.08 \\
\hline microtubule-actin crosslinking factor 1 & Macf1 & 10.00 & 10.86 \\
\hline actin related protein $2 / 3$ complex, subunit 5 & Arpc5 & 9.96 & 10.56 \\
\hline ankyrin 3, epithelial & Ank3 & 9.92 & 9.74 \\
\hline sorbin and $\mathrm{SH} 3$ domain containing 2 & Sorbs2 & 9.91 & 10.94 \\
\hline dystrophin, muscular dystrophy & Dmd & 9.90 & 10.53 \\
\hline twinfilin, actin-binding protein, homolog 1 & Twf1 & 9.89 & 10.93 \\
\hline ARP10 actin-related protein 10 homolog (S. cerevisiae) & Actr10 & 9.81 & 10.22 \\
\hline
\end{tabular}


actin related protein $2 / 3$ complex, subunit 4

actin related protein $2 / 3$ complex, subunit $1 B$

kelch-like 2, Mayven (Drosophila)

ectodermal-neural cortex 1

syndecan 2

parvin, alpha

ARP1 actin-related protein 1 homolog A, centractin alpha (yeast)

vinculin

myeloid/lymphoid or mixed-lineage leukemia, translocated to, 4

capping protein (actin filament) muscle Z-line, alpha 1

talin 1

adducin 3 (gamma)

septin 10

actinin alpha 4

syndecan 1

ARP1 actin-related protein 1 homolog B, centractin beta (yeast)

stomatin (Epb7.2)-like 2

twinfilin, actin-binding protein, homolog 2 (Drosophila)

septin 7

catenin (cadherin associated protein), alpha-like 1

ARP8 actin-related protein 8 homolog (S. cerevisiae)

septin 9

tropomyosin 4

erythrocyte protein band 4.9

actin related protein $2 / 3$ complex, subunit $1 \mathrm{~A}$

drebrin-like

synaptopodin

actinin, alpha 1

spectrin beta 3

coronin, actin binding protein $2 \mathrm{~A}$

WAS protein family, member 2

plectin 1

moesin

caldesmon 1

tropomodulin 3

septin 2

spire homolog 2 (Drosophila)

PDZ and LIM domain 3

coronin, actin binding protein $1 \mathrm{~B}$

transgelin 2

septin 4

fascin homolog 1, actin bundling protein (Strongylocentrotus purpuratus)

tropomyosin 2, beta

formin binding protein 1

huntingtin interacting protein 1

coronin 7

septin 11

formin binding protein 4

calponin 2

talin 2

actin-like $6 \mathrm{~A}$

sorbin and SH3 domain containing 1

kelch-like 12 (Drosophila)

filamin, alpha

actin, alpha 2 , smooth muscle, aorta

drebrin 1

\begin{tabular}{|c|c|c|}
\hline Arpc4 & 9.81 & 10.97 \\
\hline Arpc1b & 9.75 & 10.80 \\
\hline Klhl2 & 9.70 & 10.26 \\
\hline Enc1 & 9.69 & 10.20 \\
\hline Sdc2 & 9.68 & 10.36 \\
\hline Parva & 9.58 & 10.30 \\
\hline Actr1a & 9.57 & 10.16 \\
\hline Vcl & 9.51 & 9.87 \\
\hline Mllt4 & 9.51 & 10.07 \\
\hline Capza1 & 9.48 & 9.87 \\
\hline TIn1 & 9.48 & 10.01 \\
\hline Add3 & 9.46 & 9.19 \\
\hline sept.10 & 9.41 & 9.60 \\
\hline Actn4 & 9.38 & 10.09 \\
\hline Sdc1 & 9.36 & 9.47 \\
\hline Actr1b & 9.30 & 9.45 \\
\hline Stoml2 & 9.23 & 9.55 \\
\hline Twf2 & 9.16 & 9.13 \\
\hline 07.sept & 9.15 & 9.67 \\
\hline Ctnnal1 & 9.11 & 9.79 \\
\hline Actr8 & 9.09 & 9.58 \\
\hline septin 9 & 9.08 & 9.74 \\
\hline Tpm4 & 9.07 & 9.80 \\
\hline Epb4.9 & 8.99 & 9.10 \\
\hline Arpc1a & 8.92 & 10.23 \\
\hline Dbnl & 8.89 & 9.21 \\
\hline Synpo & 8.84 & 9.01 \\
\hline Actn1 & 8.81 & 9.52 \\
\hline Spnb3 & 8.79 & 10.27 \\
\hline Coro2a & 8.75 & 8.91 \\
\hline Wasf2 & 8.71 & 9.64 \\
\hline Plec1 & 8.71 & 9.47 \\
\hline Msn & 8.64 & 8.03 \\
\hline Cald1 & 8.60 & 9.18 \\
\hline Tmod3 & 8.55 & 9.06 \\
\hline septin 2 & 8.53 & 9.58 \\
\hline Spire2 & 8.41 & 8.88 \\
\hline Pdlim3 & 8.34 & 8.33 \\
\hline Coro1b & 8.30 & 9.52 \\
\hline Tagln2 & 8.22 & 8.76 \\
\hline septin 4 & 8.16 & 8.42 \\
\hline Fscn1 & 8.06 & 8.45 \\
\hline Tpm2 & 7.99 & 6.42 \\
\hline Fnbp1 & 7.96 & $8.5 \varepsilon$ \\
\hline Hip1 & 7.87 & 8.31 \\
\hline Coro7 & 7.86 & 8.5 \\
\hline septin 11 & 7.82 & 8.6 \\
\hline Fnbp4 & 7.77 & 8.38 \\
\hline Cnn2 & 7.77 & 9.10 \\
\hline Tln2 & 7.76 & $7.7 \varepsilon$ \\
\hline Actl6a & 7.75 & 8.1 \\
\hline Sorbs1 & 7.69 & 7.7 \\
\hline Klhl12 & 7.66 & 7.9 \\
\hline FIna & 7.62 & 8.4 \\
\hline Acta2 & 7.59 & 6.1 \\
\hline $\mathrm{Db}$ & 7.5 & \\
\hline
\end{tabular}


actin-binding LIM protein 2

septin 6

kelch-like 17 (Drosophila)

kelch-like 18 (Drosophila)

transgelin

nebulin-related anchoring protein

septin 8

formin-like 2

synaptopodin 2-like

coronin, actin binding protein $1 \mathrm{~A}$

espin

kelch-like 20 (Drosophila)

kelch-like 25 (Drosophila)

syntrophin, acidic 1

zyxin

actinin alpha 2

kelch-like 7 (Drosophila)

sorbin and $\mathrm{SH} 3$ domain containing 3

capping protein (actin filament), gelsolin-like

whirlin

villin-like

kelch-like 8 (Drosophila)

palladin, cytoskeletal associated protein

stomatin

WAS protein family, member 3 (Wasf3), mRNA

PDZ domain containing 2

stomatin-like 1

syntrophin, basic 2

Rho GTPase activating protein 6

giant axonal neuropathy

septin 1

multiple PDZ domain protein

PDZ and LIM domain 7

formin-like 3

syndecan 3

spectrin beta 1

ARP6 actin-related protein 6 homolog (yeast)

septin 3

actinin alpha 3

villin 1

filamin binding LIM protein 1

Table 12B. Myosin and myosin-like proteins

myosin, heavy polypeptide 9, non-muscle

myosin, light chain $12 \mathrm{~B}$, regulatory

myosin $\mathrm{X}$

myosin IC

myosin VI

myosin, heavy polypeptide 10 , non-muscle

myosin $1 \mathrm{H}$

myosin XVIIIA

myosin VB

myosin IXb

myosin IE

myosin, light polypeptide 9 , regulatory

myosin ID

$\begin{array}{lrr}\text { Ablim2 } & 7.48 & 7.16 \\ \text { septin 6 } & 7.47 & 6.87 \\ \text { KIhl17 } & 7.43 & 7.62 \\ \text { KIhl18 } & 7.38 & 7.17 \\ \text { Tagln } & 7.36 & 6.92 \\ \text { Nrap } & 7.32 & 6.81 \\ \text { septin 8 } & 7.29 & 8.11 \\ \text { Fmnl2 } & 7.22 & 8.48 \\ \text { Synpo2l } & 7.18 & 7.11 \\ \text { Coro1a } & 7.16 & 7.30 \\ \text { Espn } & 7.12 & 7.11 \\ \text { KIhl20 } & 7.10 & 7.60 \\ \text { KIhl25 } & 7.10 & 7.54 \\ \text { Snta1 } & 7.08 & 7.62 \\ \text { Zyx } & 6.97 & 7.90 \\ \text { Actn2 } & 6.96 & 7.30 \\ \text { KIhl7 } & 6.96 & 8.00 \\ \text { Sorbs3 } & 6.95 & 7.58 \\ \text { Capg } & 6.91 & 9.04 \\ \text { Whrn } & 6.89 & 6.36 \\ \text { Vill } & 6.86 & 6.46 \\ \text { Klhl8 } & 6.82 & 7.42 \\ \text { Palld } & 6.73 & 6.35 \\ \text { Stom } & 6.71 & 6.53 \\ \text { Wasf3 } & 6.71 & 7.48 \\ \text { Pdzd2 } & 6.70 & 6.95 \\ \text { Stoml1 } & 6.69 & 7.17 \\ \text { Sntb2 } & 6.68 & 6.84 \\ \text { Arhgap6 } & 6.60 & 7.16 \\ \text { Gan } & 6.51 & 6.49 \\ \text { septin 1 } & 6.34 & 5.94 \\ \text { Mpdz } & 6.23 & 7.01 \\ \text { Pdlim7 } & 6.22 & 6.06 \\ \text { Fmnl3 } & 6.17 & 8.22 \\ \text { Sdc3 } & 6.15 & 5.98 \\ \text { Spnb1 } & 5.75^{\star} & 5.86 \\ \text { Actr6 } & 5.73^{\star} & 5.32 * \\ \text { septin 3 } & 5.53^{\star} & 6.32 \\ \text { Actn3 } & 5.41^{\star} & 6.19 \\ \text { Vil1 } & 5.40^{\star} & 6.07 \\ \text { Fblim1 } & 5.24^{\star} & 6.16\end{array}$

$\begin{array}{lrr}\text { Myh9 } & 12.12 & 12.56 \\ \text { Myl12b } & 11.80 & 12.55 \\ \text { Myo10 } & 10.70 & 10.60 \\ \text { Myo1c } & 10.64 & 10.58 \\ \text { Myo6 } & 10.21 & 10.93 \\ \text { Myh10 } & 10.14 & 11.43 \\ \text { Myo1h } & 9.23 & 10.17 \\ \text { Myo18a } & 9.14 & 9.71 \\ \text { Myo5b } & 8.56 & 9.06 \\ \text { Myo9b } & 8.52 & 9.12 \\ \text { Myo1e } & 8.32 & 8.95 \\ \text { Myl9 } & 8.26 & 6.85 \\ \text { Myo1d } & 7.95 & 8.73\end{array}$


myosin IXa

Myo9a

Myo5a

myosin VA

Myo5c

myosin, heavy polypeptide 11 , smooth muscle

$\begin{array}{lll}\text { Myh11 } & 7.43 \quad 5.61\end{array}$

myosin, heavy polypeptide 6 , cardiac muscle, alpha

Myh6

Myh7

myosin, heavy polypeptide 7 , cardiac muscle, beta

Myo7b

Myl6b

myosin, light polypeptide $6 \mathrm{~B}$

Myl4

myosin, light polypeptide 4

myosin IB

myosin VIIA

myosin IB

myosin, heavy polypeptide 14

myosin light chain, phosphorylatable, fast skeletal muscle

myosin VIIA and Rab interacting protein

myomesin 1

myosin IIIB

Myo1b

Myo7a

Myo1b

Myh14

Mylpf

Myrip

Myom1

Table 12C. Microtubule and microtubule-related proteins

tubulin, alpha $4 \mathrm{~A}$

tubulin, alpha 1B

Myo3b

$6.85 \quad 6.53$

$\begin{array}{ll}6.84 & 6.57\end{array}$

$\begin{array}{ll}6.75 & 6.47\end{array}$

$6.72 \quad 6.77$

$6.68 \quad 6.99$

$6.51 \quad 7.07$

$6.49 \quad 6.65$

$6.43 \quad 7.64$

$6.36 \quad 6.21$

$6.31 \quad 6.85$

6.14 4.94*

$5.875 .66^{*}$

$5.46^{\star} \quad 6.08$

tubulin, alpha $1 \mathrm{~A}$

tubulin, beta $2 \mathrm{~A}$

$\begin{array}{lrr}\text { Tuba4a } & 13.63 & 13.51 \\ \text { Tuba1b } & 12.88 & 13.17 \\ \text { Tuba1a } & 12.61 & 12.89 \\ \text { Tubb2a } & 12.32 & 12.64 \\ \text { Gabarapl1 } & 12.28 & 12.39 \\ \text { Map1lc3b } & 11.89 & 12.01 \\ \text { Dynlrb1 } & 11.87 & 11.89 \\ \text { Dynll1 } & 11.86 & 12.45 \\ \text { Dynll1 I/I E } & 11.75 & 12.50 \\ \text { Gabarap } & 11.50 & 11.62 \\ \text { Dynlt3 } & 11.49 & 11.85 \\ \text { Dynll2 } & 11.17 & 11.69 \\ \text { Tubb2b } & 11.03 & 11.27 \\ \text { Kif5b } & 11.00 & 11.06 \\ \text { Mapre1 } & 10.77 & 11.28 \\ \text { Dctn6 } & 10.76 & 11.35 \\ \text { Tbcb } & 10.62 & 11.38 \\ \text { Dctn4 } & 10.58 & 11.20 \\ \text { Kif13b } & 10.53 & 10.89 \\ \text { Dync1i2 } & 10.36 & 10.55 \\ \text { Map1lc3a } & 10.26 & 10.35 \\ \text { Mapre2 } & 10.26 & 10.24 \\ \text { Dstn } & 10.25 & 10.99 \\ \text { Kif21a } & 10.23 & 10.07 \\ \text { Nefl } & 10.21 & 8.28 \\ \text { Kif1c } & 10.19 & 10.94 \\ \text { Dctn5 } & 10.15 & 11.03 \\ \text { Kif26b } & 10.13 & 10.96 \\ \text { Kif1b } & 10.12 & 10.97 \\ \text { Tubb5 } & 10.01 & 10.60 \\ \text { Dync1li2 } & 9.97 & 10.63 \\ \text { Dync1h1 } & 9.91 & 10.72 \\ \text { Wdr1 } & 9.87 & 9.62 \\ \text { Dnalc1 } & 9.71 & 10.19 \\ \text { Kifap3 } & 9.68 & 10.03 \\ \text { Mark2 } & 9.68 & 10.50 \\ \text { Clip1 } & 9.38 & 9.94\end{array}$

gamma-aminobutyric acid (GABA(A)) receptor-associated protein-like 1 microtubule-associated protein 1 light chain 3 beta

dynein light chain roadblock-type 1

dynein light chain LC8-type 1

dynein light chain LC8-type 1 /// predicted gene, EG627788

gamma-aminobutyric acid receptor associated protein

dynein light chain Tctex-type 3

dynein light chain LC8-type 2

tubulin, beta $2 \mathrm{~B}$

kinesin family member $5 B$

microtubule-associated protein, RP/EB family, member 1

dynactin 6

tubulin folding cofactor $B$

dynactin 4

kinesin family member $13 \mathrm{~B}$

dynein cytoplasmic 1 intermediate chain 2

microtubule-associated protein 1 light chain 3 alpha

microtubule-associated protein, RP/EB family, member 2

destrin

kinesin family member $21 \mathrm{~A}$

neurofilament, light polypeptide

kinesin family member $1 \mathrm{C}$

dynactin 5

kinesin family member $26 \mathrm{~B}$

kinesin family member $1 \mathrm{~B}$

tubulin, beta 5

dynein, cytoplasmic 1 light intermediate chain 2

dynein cytoplasmic 1 heavy chain 1

WD repeat domain 1

dynein, axonemal, light chain 1

kinesin-associated protein 3

MAP/microtubule affinity-regulating kinase 2

CAP-GLY domain containing linker protein 1

Clip1 
tubulin, gamma complex associated protein 4

microtubule-associated protein 4

microtubule-associated protein 7

formin 1

tubulin, beta $2 \mathrm{C}$

kinesin family member $16 \mathrm{~B}$

dynactin 2

kinesin light chain 4

microtubule-associated protein 2

katanin p60 (ATPase-containing) subunit A1

tubulin tyrosine ligase

KIF13A

kinesin family member $3 \mathrm{~A}$

kinesin family member $\mathrm{C} 3$

kinesin family member $2 \mathrm{~A}$

kinectin 1

tubulin tyrosine ligase-like family, member 4

microtubule-associated protein 7 domain containing 1

tubulin tyrosine ligase-like family, member 5

kinesin family member $3 \mathrm{~B}$

kinesin family member 12

kinesin family member $3 \mathrm{C}$

kinesin family member 22

Dynein light chain Tctex-type 1 (Dynlt1), mRNA

dynactin 1

Tubulin, beta 6, mRNA (cDNA clone MGC:6469 IMAGE:2631779)

tubulin tyrosine ligase-like 1

kinesin family member 23

kinesin family member $20 \mathrm{~A}$

kinesin light chain 2

dynein, axonemal, light chain 4

WD repeat domain 78

kinesin light chain 3

$\mathrm{MAP} / \mathrm{microtubule}$ affinity-regulating kinase 4

CAP-GLY domain containing linker protein 2

microtubule-associated protein, RP/EB family, member 3

microtubule-associated protein tau

tubulin tyrosine ligase-like family, member 10

dynein, axonemal, heavy chain 11

dynein cytoplasmic 1 light intermediate chain 1

kinesin light chain 1

dynein, axonemal, heavy chain 7B

WD repeat domain 34

kinesin family member $5 \mathrm{C}$

tubulin, gamma complex associated protein 5

tubulin, gamma 1

tubulin, gamma complex associated protein 2

WD repeat domain 60

tubulin polymerization-promoting protein family member 3

microtubule-associated protein $1 \mathrm{~A}$

kinesin family member $\mathrm{C} 2$

CAP-GLY domain containing linker protein family, member 4

tubulin, gamma complex associated protein 3

tubulin, beta 4

tubulin tyrosine ligase-like family, member 11

kinesin family member 11

\begin{tabular}{|c|c|c|}
\hline Tubgcp4 & 9.32 & 9.83 \\
\hline Mtap4 & 9.27 & 9.51 \\
\hline Mtap7 & 9.26 & 9.29 \\
\hline Fmn1 & 9.19 & 9.45 \\
\hline Tubb2c & 9.04 & 10.03 \\
\hline Kif16b & 9.02 & 9.28 \\
\hline Dctn2 & 8.92 & 10.25 \\
\hline Klc4 & 8.88 & 9.82 \\
\hline Mtap2 & 8.84 & 9.77 \\
\hline Katna1 & 8.77 & 9.22 \\
\hline Ttl & 8.72 & 8.75 \\
\hline Kif13a & 8.68 & 9.77 \\
\hline Kif3a & 8.52 & 8.47 \\
\hline Kifc3 & 8.29 & 9.22 \\
\hline Kif2a & 8.23 & 8.91 \\
\hline Ktn1 & 8.21 & 8.76 \\
\hline Ttlll4 & 8.15 & 8.41 \\
\hline Mtap7d1 & 8.13 & 8.14 \\
\hline Ttll5 & 8.02 & 8.56 \\
\hline Kif3b & 7.99 & 8.38 \\
\hline Kif12 & 7.91 & 8.72 \\
\hline Kif3c & 7.85 & 8.29 \\
\hline Kif22 & 7.82 & 7.02 \\
\hline Dynlt1 & 7.79 & 7.98 \\
\hline Dctn1 & 7.74 & 8.27 \\
\hline Tubb6 & 7.70 & 8.44 \\
\hline Ttll1 & 7.56 & 8.12 \\
\hline Kif23 & 7.54 & 7.66 \\
\hline Kif20a & 7.48 & 7.39 \\
\hline Klc2 & 7.44 & 7.45 \\
\hline Dnalc4 & 7.36 & 8.05 \\
\hline Wdr78 & 7.35 & 7.74 \\
\hline Klc3 & 7.34 & 7.35 \\
\hline Mark4 & 7.34 & 7.79 \\
\hline Clip2 & 7.32 & 7.50 \\
\hline Mapre3 & 7.30 & 7.07 \\
\hline Mapt & 7.12 & 8.73 \\
\hline Ttll10 & 7.03 & 7.58 \\
\hline Dnahc11 & 6.92 & 7.54 \\
\hline Dync1li1 & 6.89 & 7.16 \\
\hline Klc1 & 6.87 & 7.23 \\
\hline Dnahc7b & 6.79 & 7.47 \\
\hline Wdr34 & 6.73 & 8.05 \\
\hline Kif5c & 6.64 & 6.89 \\
\hline Tubgcp5 & 6.56 & 7.09 \\
\hline Tubg1 & 6.55 & 7.20 \\
\hline Tubgcp2 & 6.54 & 6.93 \\
\hline Wdr60 & 6.50 & 7.04 \\
\hline Трpр3 & 6.48 & 6.60 \\
\hline Mtap1a & 6.40 & 6.54 \\
\hline Kifc2 & 6.37 & 6.61 \\
\hline Clip4 & 6.37 & 5.92 \\
\hline Tubgcp3 & 6.14 & 6.43 \\
\hline Tubb4 & 6.11 & $5.55^{\star}$ \\
\hline Ttll11 & 5.99 & 6.14 \\
\hline Kif11 & 5.9 & 6.02 \\
\hline
\end{tabular}


midline 2

kinesin family member $20 \mathrm{~B}$

midline 1

dynein cytoplasmic 2 heavy chain 1

dynein light chain roadblock-type 2

MAP/microtubule affinity-regulating kinase 1

Table 12D. Intermediate filaments and related proteins

keratin 7

plakophilin 4

keratin 18

keratin 8

lamin A

plastin 3 (T-isoform)

plakophilin 2

keratin 10

keratin 80

vimentin

keratin 23

lamin B2

keratin 24

lamin B1

keratin 34

keratin 19

plakophilin 3

plastin 1 (I-isoform)

$\begin{array}{lrr}\text { Mid2 } & 5.85 & 6.57 \\ \text { Kif2Ob } & 5.75^{\star} & 5.86 \\ \text { Mid1 } & 5.75^{\star} & 5.86 \\ \text { Dync2h1 } & 5.00^{*} & 6.21 \\ \text { Dynlrb2 } & 4.90^{\star} & 5.91 \\ \text { Mark1 } & 4.90^{*} & 6.41\end{array}$

Krt7

Pkp4

$12.42 \quad 12.89$

Krt18

11.75

11.73

Krt8

11.13

12.45

Lmna

0.92

11.84

Pls3

10.75

Pkp2

10.38

11.37

Krt10

9.51

9.39

10.12

Krt80

8.25

8.17

9.68

Vim

7.98

Krt23

7.07

Krt24

6.95

Lmnb1

6.95

6.72

6.64

6.36

6.10

8.54

7.54

9.95

7.40

6.00

Krt34

7.02

Krt19

6.52

Pkp3

7.51

Pls1

6.71

6.00

* - the A-value is below the cut-off level 
Supplemental Table 7. Transporters and channels.

\author{
Gene Name \\ Table 13A. Water channels \\ aquaporin 3 \\ aquaporin 6 \\ aquaporin 4 \\ aquaporin 11 \\ aquaporin 2 \\ aquaporin 5 \\ aquaporin 1
}

Table 13B. Ion channels and transporters excluding SLC proteins.

ATPase, $\mathrm{Na}+/ \mathrm{K}+$ transporting, beta 1 polypeptide voltage-dependent anion channel 1

ATPase, $\mathrm{H}+$ transporting, lysosomal V1 subunit A ATPase, $\mathrm{H}+$ transporting, lysosomal V0 subunit $\mathrm{C}$ ATPase, $\mathrm{H}+$ transporting, lysosomal V1 subunit D ATPase, $\mathrm{Na}+/ \mathrm{K}+$ transporting, alpha 1 polypeptide VATPase, $\mathrm{H}+$ transporting, lysosomal V1 subunit E1 ATPase, $\mathrm{H}+$ transporting, lysosomal V0 subunit D2 voltage-dependent anion channel 2

potassium inwardly-rectifying channel, subfamily J, member 16

potassium inwardly-rectifying channel, subfamily $\mathrm{J}$, member 1

FXYD domain-containing ion transport regulator 2

ATPase, $\mathrm{H}+$ transporting, lysosomal V1 subunit $\mathrm{F}$

ATPase, $\mathrm{H}+$ transporting, lysosomal V0 subunit $\mathrm{B}$

ATPase, $\mathrm{H}+$ transporting, lysosomal V0 subunit $\mathrm{E}$

sodium channel, nonvoltage-gated 1 gamma

potassium voltage-gated channel, subfamily Q, member 1

potassium voltage-gated channel, Isk-related subfamily, member 1

ATPase, Ca++ transporting, cardiac muscle, slow twitch 2

chloride channel $\mathrm{Kb}$

ATPase, $\mathrm{H}+$ transporting, lysosomal V1 subunit $\mathrm{H}$

ATPase, $\mathrm{H}+$ transporting, lysosomal V1 subunit $\mathrm{C} 1$

ATPase, $\mathrm{H}+$ transporting, lysosomal accessory protein 1

FXYD domain-containing ion transport regulator 4

expressed sequence BF642829

chloride channel 5

vacuolar protein sorting 25 (yeast)

sodium channel, type IV, beta

transmembrane protein $16 \mathrm{~F}$

potassium inwardly-rectifying channel, subfamily J, member 10

sodium channel, nonvoltage-gated 1 beta

ATPase, $\mathrm{H}+$ transporting, lysosomal V0 subunit D1

voltage-dependent anion channel 3

ATPase, $\mathrm{Na}+/ \mathrm{K}+$ transporting, beta 3 polypeptide

ATPase, $\mathrm{H}+$ transporting, lysosomal V1 subunit G1

polycystic kidney disease 2

ATPase, $\mathrm{H}+$ transporting, lysosomal V1 subunit B1

inositol 1,4,5-triphosphate receptor 2

chloride channel 3

two pore channel 1

ATPase, $\mathrm{H}+/ \mathrm{K}+$ exchanging, gastric, alpha polypeptide

inositol 1,4,5-triphosphate receptor 1

\begin{tabular}{|c|c|c|}
\hline $\begin{array}{l}\text { Gene } \\
\text { Symbol }\end{array}$ & $\begin{array}{c}\text { DCT/CNT } \\
\text { A_value }\end{array}$ & $\begin{array}{c}\text { CCD } \\
\text { A_Value }\end{array}$ \\
\hline Aqp3 & 13.11 & 13.45 \\
\hline Aqp6 & 11.53 & 12.84 \\
\hline Aqp4 & 8.16 & 11.63 \\
\hline Aqp11 & 8.11 & 6.90 \\
\hline Aqp2 & 7.95 & 10.25 \\
\hline Aqp5 & 6.51 & 6.20 \\
\hline Aqp1 & 6.09 & 6.57 \\
\hline
\end{tabular}

\begin{tabular}{lrr} 
Atp1b1 & 13.86 & 13.87 \\
Vdac1 & 13.73 & 13.74 \\
Atp6v1a & 13.11 & 13.10 \\
Atp6v0c & 12.99 & 12.66 \\
Atp6v1d & 12.99 & 13.17 \\
Atp1a1 & 12.76 & 12.12 \\
Atp6v1e1 & 12.71 & 12.61 \\
Atp6v0d2 & 12.58 & 12.78 \\
Vdac2 & 12.54 & 12.63 \\
Kcnj16 & 12.44 & 12.63 \\
Kcnj1 & 12.41 & 12.69 \\
Fxyd2 & 12.40 & 11.11 \\
Atp6v1f & 12.25 & 12.36 \\
Atp6v0b & 12.01 & 11.93 \\
Atp6v0e & 11.90 & 11.97 \\
Scnn1g & 11.54 & 11.88 \\
Kcnq1 & 11.51 & 11.68 \\
Kcne1 & 11.47 & 11.68 \\
Atp2a2 & 11.45 & 11.61 \\
Clcnkb & 11.33 & 11.70 \\
Atp6v1h & 11.32 & 11.64 \\
Atp6v1c1 & 11.27 & 11.48 \\
Atp6ap1 & 11.14 & 11.33 \\
Fxyd4 & 11.09 & 13.27 \\
BF642829 & 11.09 & 11.73 \\
Clcn5 & 11.06 & 10.81 \\
Vps25 & 10.97 & 11.32 \\
Scn4b & 10.92 & 8.47 \\
Tmem16f & 10.91 & 11.18 \\
Kcnj10 & 10.85 & 10.68 \\
Scnn1b & 10.84 & 11.39 \\
Atp6v0d1 & 10.80 & 11.52 \\
Vdac3 & 10.78 & 11.15 \\
Atp1b3 & 10.60 & 11.51 \\
Atp6v1g1 & 10.59 & 11.16 \\
Pkd2 & 10.43 & 11.00 \\
Atp6v1b1 & 10.43 & 10.16 \\
Itpr2 & 10.40 & 10.98 \\
Clcn3 & 10.40 & 10.75 \\
Tpcn1 & 10.22 & 10.39 \\
\hline Atp4a & 10.15 & 10.33 \\
\hline At & 10.02 & 10.62
\end{tabular}


ATPase, $\mathrm{H}+$ transporting, lysosomal $\mathrm{V} 1$ subunit $\mathrm{B} 2$

ATPase, $\mathrm{Ca}++$ transporting, plasma membrane 2

calcium channel, voltage-dependent, $L$ type, alpha 1D subunit

ATPase, $\mathrm{Cu}++$ transporting, alpha polypeptide

chloride intracellular channel 1

chloride intracellular channel 4 (mitochondrial)

potassium channel, subfamily K, member 1 (TWIK-1)

ATPase, Ca++-sequestering

sodium channel, nonvoltage-gated, type I, alpha

ATPase, $\mathrm{H}+$ transporting, lysosomal V0 subunit A4

purinergic receptor $P 2 X$, ligand-gated ion channel 4

ATX1 (antioxidant protein 1) homolog 1 (yeast)

transient receptor potential cation channel, subfamily $\mathrm{M}$, member 6

chloride channel 4-2

transient receptor potential cation channel, subfamily $\mathrm{C}$, member 2

ATPase, $\mathrm{H}+$ transporting, lysosomal V1 subunit $\mathrm{C} 2$

transient receptor potential cation channel, subfamily $\mathrm{M}$, member 7

ATPase, $\mathrm{H}+$ transporting, lysosomal V0 subunit A1

ATPase, $\mathrm{H}+$ transporting, lysosomal V0 subunit A2

chloride channel 7

transient receptor potential cation channel, subfamily $\mathrm{M}$, member 4

calcium channel, voltage-dependent, beta 4 subunit

potassium inwardly rectifying channel, subfamily J, member 11

transmembrane protein 37

chloride channel 6

mucolipin 1

MRS2-like, magnesium homeostasis factor (S. cerevisiae)

transient receptor potential cation channel, subfamily $\mathrm{V}$, member 6

ATP-binding cassette, sub-family C (CFTR/MRP), member 4

transient receptor potential cation channel, subfamily $\mathrm{V}$, member 5

transmembrane and coiled-coil domains 3

stromal interaction molecule 1

cholinergic receptor, nicotinic, alpha polypeptide 4

potassium voltage-gated channel, subfamily $\mathrm{H}$ (eag-related), member 3

calcium channel, voltage-dependent, alpha2/delta subunit 1

B-box and SPRY domain containing

potassium voltage gated channel, Shaw-related subfamily, member 2

glutamate receptor, ionotropic, NMDA3B

RIKEN cDNA 2010001E11 gene /// expressed sequence AI317395

calcium channel, voltage-dependent, gamma subunit 8

polycystic kidney disease 2-like 2

stromal interaction molecule 2

potassium voltage-gated channel, subfamily $Q$, member 2

potassium voltage gated channel, Shaw-related subfamily, member 3

calcium channel, voltage-dependent, beta 3 subunit

chloride intracellular channel 5

transient receptor potential cation channel, subfamily $\mathrm{V}$, member 4

gamma-aminobutyric acid (GABA-A) receptor, subunit gamma 1

calcium channel, voltage-dependent, $\mathrm{P} / \mathrm{Q}$ type, alpha $1 \mathrm{~A}$ subunit

potassium voltage gated channel, Shaw-related subfamily, member 4

potassium intermediate/small conductance calcium-activated channel

subfamily $\mathrm{N}$, member 3

ATPase, $\mathrm{H}+/ \mathrm{K}+$ exchanging, beta polypeptide

transmembrane protein $142 \mathrm{~A}$

calcium channel, voltage-dependent, gamma subunit 2

FXYD domain-containing ion transport regulator 1

\begin{tabular}{|c|c|c|}
\hline Atp6v1b2 & 9.97 & 10.36 \\
\hline Atp2b2 & 9.83 & 10.17 \\
\hline Cacna1d & 9.77 & 10.66 \\
\hline Atp7a & 9.75 & 10.49 \\
\hline Clic1 & 9.64 & 10.71 \\
\hline Clic4 & 9.62 & 9.55 \\
\hline Kcnk1 & 9.45 & 10.45 \\
\hline Atp2c1 & 9.38 & 10.25 \\
\hline Scnn1a & 9.37 & 9.54 \\
\hline Atp6v0a4 & 9.27 & 9.03 \\
\hline P2rx4 & 9.19 & 9.29 \\
\hline Atox1 & 9.09 & 9.82 \\
\hline Trpm6 & 9.09 & 7.39 \\
\hline Clcn4-2 & 8.97 & 9.67 \\
\hline Trpc2 & 8.91 & 9.87 \\
\hline Atp6v1c2 & 8.82 & 8.91 \\
\hline Trpm7 & 8.75 & 9.29 \\
\hline Atp6v0a1 & 8.69 & 9.13 \\
\hline Atp6v0a2 & 8.41 & 8.49 \\
\hline Clcn7 & 8.41 & 9.02 \\
\hline Trpm4 & 8.36 & 9.32 \\
\hline Cacnb4 & 8.23 & 7.89 \\
\hline Kcnj11 & 8.16 & 8.44 \\
\hline Tmem37 & 8.10 & 7.69 \\
\hline Clcn6 & 8.04 & 8.29 \\
\hline Mcoln1 & 7.90 & 8.66 \\
\hline Mrs2l & 7.88 & 8.34 \\
\hline Trpv6 & 7.86 & 8.90 \\
\hline Abcc4 & 7.80 & 8.56 \\
\hline Trpv5 & 7.68 & $5.58^{\star}$ \\
\hline Tmco3 & 7.66 & 8.32 \\
\hline Stim1 & 7.65 & 7.83 \\
\hline Chrna4 & 7.58 & $5.12^{\star}$ \\
\hline Kcnh3 & 7.57 & 7.17 \\
\hline Cacna2d1 & 7.55 & 6.24 \\
\hline Bspry & 7.44 & 8.37 \\
\hline Kcnc2 & 7.43 & 8.08 \\
\hline Grin3b & 7.40 & 7.25 \\
\hline 2010001E & 7.32 & 6.92 \\
\hline Cacng8 & 7.31 & 6.72 \\
\hline Pkd2/2 & 7.24 & 7.78 \\
\hline Stim2 & 7.20 & 8.06 \\
\hline Kcnq2 & 7.13 & 6.87 \\
\hline Kcnc3 & 7.12 & 7.50 \\
\hline Cacnb3 & 7.10 & 7.52 \\
\hline Clic5 & 7.06 & 6.39 \\
\hline Trpv4 & 6.91 & 7.55 \\
\hline Gabrg1 & 6.77 & 9.07 \\
\hline Cacna1a & 6.74 & 6.61 \\
\hline Kcnc4 & 6.72 & 6.43 \\
\hline Kcnn3 & 6.69 & 7.36 \\
\hline Atp4b & 6.67 & 6.22 \\
\hline Tmem142i & 6.66 & 6.81 \\
\hline Cacng2 & 6.63 & 6.00 \\
\hline & 6.6 & \\
\hline
\end{tabular}


potassium intermediate/small conductance calcium-activated channel

Kcnn1

subfamily $\mathrm{N}$, member 1

transient receptor potential cation channel, subfamily $\mathrm{C}$, member 5

Trpc5

Kcnk3

FXYD domain-containing ion transport regulator 5

glutamate receptor, ionotropic, kainate 4

expressed sequence AI317395

chloride channel $\mathrm{Ka}$

cholinergic receptor, nicotinic, gamma polypeptide

claudin 16

glutamate receptor, ionotropic, kainate 5 (gamma 2)

transient receptor potential cation channel, subfamily $\mathrm{C}$, member 4

antigen p97 (melanoma associated)

sodium channel, voltage-gated, type VIII, alpha

two pore segment channel 2

transient receptor potential cation channel, subfamily $\mathrm{C}$, member 7

ATPase, $\mathrm{H}+$ transporting, lysosomal V1 subunit G2

potassium inwardly-rectifying channel, subfamily $\mathrm{J}$, member 4

potassium channel, subfamily $\mathrm{T}$, member 1

potassium inwardly-rectifying channel, subfamily J, member 15

expressed sequence Al118078

sodium channel, voltage-gated, type I, beta

calcium channel, voltage-dependent, beta 1 subunit

sodium channel, voltage-gated, type II, beta

ATPase, $\mathrm{Na}+/ \mathrm{K}+$ transporting, beta 2 polypeptide

amiloride-sensitive cation channel 5 , intestinal

potassium voltage-gated channel, delayed-rectifier, subfamily $\mathrm{S}$, member 3

purinergic receptor $\mathrm{P} 2 \mathrm{X}$, ligand-gated ion channel, 5

calcium channel, voltage-dependent, beta 2 subunit

purinergic receptor $\mathrm{P} 2 \mathrm{X}$-like 1 , orphan receptor

transient receptor potential cation channel, subfamily $\mathrm{V}$, member 2

amiloride-sensitive cation channel 4, pituitary

transient receptor potential cation channel, subfamily $\mathrm{M}$, member 3

ATPase, Ca++ transporting, cardiac muscle, fast twitch 1

chloride intracellular channel 3

potassium voltage-gated channel, subfamily G, member 2

potassium voltage gated channel, Shab-related subfamily, member 1

transient receptor potential cation channel, subfamily M, member 2

bestrophin 1

potassium voltage gated channel, Shaw-related subfamily, member 1

cation channel, sperm associated 2

calcium channel, voltage-dependent, gamma subunit 4

Kv channel-interacting protein 1

gamma-aminobutyric acid (GABA-A) receptor, pi

calcium channel, voltage-dependent, gamma subunit 1

glutamate receptor, ionotropic, NMDA2B (epsilon 2)

potassium voltage-gated channel, shaker-related subfamily, member 7

hydrogen voltage-gated channel 1

cholinergic receptor, nicotinic, beta polypeptide 4

amiloride-sensitive cation channel 2 , neuronal

ATPase, $\mathrm{H}+/ \mathrm{K}+$ transporting, nongastric, alpha polypeptide

purinergic receptor $\mathrm{P} 2 \mathrm{X}$, ligand-gated ion channel, 7

cholinergic receptor, nicotinic, beta polypeptide 1 (muscle)

FXYD domain-containing ion transport regulator 3

gamma-aminobutyric acid (GABA-A) receptor, subunit epsilon
Fxyd5 $\quad 6.59 \quad 6.96$

Grik4 $\quad 6.59 \quad 6.65$

Al317395 $6.59 \quad 5.64^{*}$

$\begin{array}{lll}\text { Clcnka } \quad 6.59 & 6.28\end{array}$

Chrng $\quad 6.56 \quad 6.20$

Cldn16 $6.52 \quad 5.79 *$

Grik5 $\quad 6.52 \quad 6.61$

Trpc4 $6.45 \quad 5.23^{*}$

$\begin{array}{lll}\text { Mfi2 } & 6.43 & 5.91\end{array}$

$\begin{array}{lll}\text { Scn8a } & 6.40 & 6.01\end{array}$

$\begin{array}{lll}\text { Tpcn2 } & 6.36 & 6.71\end{array}$

$\begin{array}{lll}\text { Trpc7 } & 6.36 & 5.78 *\end{array}$

$\begin{array}{lll}\text { Atp6v1g2 } \quad 6.33 & 6.33\end{array}$

$\begin{array}{lll}\text { Kcnj4 } & 6.33 & 6.45\end{array}$

$\begin{array}{lll}\text { Kcnt1 } & 6.32 & 6.17\end{array}$

$\begin{array}{lll}\text { Kcnj15 } & 6.29 & 6.37\end{array}$

$\begin{array}{lll}\text { Al118078 } & 6.29 & 6.23\end{array}$

Scn1b 6.24 5.69*

$\begin{array}{lll}\text { Cacnb1 } & 6.23 & 6.72\end{array}$

$\begin{array}{lll}\text { Scn2b } & 6.20 \quad 5.80\end{array}$

$\begin{array}{lll}\text { Atp1b2 } & 6.19 & 5.43^{*}\end{array}$

$\begin{array}{lll}\text { Accn5 } & 6.19 & 5.84\end{array}$

$\begin{array}{lll}\text { Kcns3 } & 6.19 & 7.58\end{array}$

$\begin{array}{lll}\mathrm{P} 2 \mathrm{rx} 5 & 6.15 & 6.13\end{array}$

$\begin{array}{lll}\text { Cacnb2 } \quad 6.13 & 6.96\end{array}$

P2rxl1 6.11 5.70*

$\begin{array}{lll}\text { Trpv2 } & 6.08 & 5.49 *\end{array}$

$\begin{array}{lll}\text { Accn4 } & 6.07 & 5.93\end{array}$

$\begin{array}{lll}\text { Trpm3 } & 6.07 & 5.93\end{array}$

$\begin{array}{lll}\text { Atp2a1 } & 6.05 & 6.20\end{array}$

$\begin{array}{lll}\text { Clic3 } & 6.05 & 5.69 *\end{array}$

$\begin{array}{lll}\text { Kcng2 } & 6.03 \quad 5.98\end{array}$

Kcnb1 $6.00 \quad 5.74^{*}$

Trpm2 $5.97 \quad 5.50$ *

$\begin{array}{lll}\text { Best1 } & 5.96 \quad 6.06\end{array}$

Kcnc1 $5.93 \quad 5.47^{*}$

Catsper2 $\quad 5.93 \quad 5.89$

Cacng4 $5.93 \quad 5.21^{*}$

Kcnip1 $\quad 5.90 \quad 5.74^{*}$

Gabrp $\quad 5.88 \quad 4.75^{*}$

Cacng1 5.88 4.94*

Grin2b $\quad 5.82 \quad 5.54^{*}$

Kcna7 $5.81 \quad 5.59^{*}$

Hven1 5.75* 6.39

Chrnb4 5.69* 6.86

Accn2 $5.47^{\star} \quad 5.82$

Atp12a $\quad 5.41^{\star} \quad 5.89$

$\begin{array}{lll}\text { P2rx7 5.30* } & 5.82\end{array}$

Chrnb1 5.01* 6.93

Fxyd3 4.97* 6.55

Gabre 4.68* 6.27 
Table 13C. Solute carrier proteins (SLC).

solute carrier family 26 , member 4 (pendrin)

solute carrier family 25 (mitochondrial carrier, adenine nucleotide

Slc26a4

13.43

Slc25a5

12.88

translocator), member 5

solute carrier family 2 (urate transporter), member 9

solute carrier family 25 (mitochondrial carrier, adenine nucleotide

translocator), member 4

solute carrier family 16 (monocarboxylic acid transporters), member 7

solute carrier family 2 (facilitated glucose transporter), member 1 (GLUT1)

solute carrier family 12 , member 3 (NCC)

solute carrier family 25 (mitochondrial carrier oxoglutarate carrier),

member 11

solute carrier family 27 (fatty acid transporter), member 1

solute carrier family 25 (mitochondrial carnitine/acylcarnitine translocase), member 20

solute carrier family 25 (mitochondrial carrier; phosphate carrier),

member 23

solute carrier family 25 (mitochondrial carrier, Aralar), member 12

solute carrier family 5 (sodium/glucose cotransporter), member 2 (SGLT2)

solute carrier family 25 (mitochondrial thiamine pyrophosphate carrier),

member 19

solute carrier family 40 (iron-regulated transporter), member 1

solute carrier family 2 (facilitated glucose transporter), member 4 (GLUT4)

solute carrier family 25 (mitochondrial carrier ornithine transporter),

member 15

solute carrier family 25 , member 36

solute carrier family 25 , member 30

solute carrier family 11 (proton-coupled divalent metal ion transporters),

member 2

solute carrier family 25 (mitochondrial carrier, brain), member 14

solute carrier family 16 (monocarboxylic acid transporters), member 10

solute carrier family 5 (inositol transporters), member 3

solute carrier family 25 , member 32

solute carrier family 12 , member 7 (KCC4)

solute carrier family 25 (mitochondrial carrier, phosphate carrier),

member 25

solute carrier organic anion transporter family, member 4a1

solute carrier family $15(\mathrm{H}+$ /peptide transporter), member 2 (PEPT2)

solute carrier family 22 (organic cation transporter), member 5

solute carrier family 22 (organic anion/cation transporter), member 12

solute carrier family 25 , member 44

solute carrier family 12 , member 2 (NKCC1)

solute carrier organic anion transporter family, member 3a1

solute carrier family 37 (glucose-6-phosphate transporter), member 4

solute carrier family 37 (glycerol-3-phosphate transporter), member 3

solute carrier family 2 (facilitated glucose transporter), member 12

solute carrier family 25 (mitochondrial carrier, adenine nucleotide

translocator), member 13

solute carrier family 16 (monocarboxylic acid transporters), member 9

solute carrier family 16 (monocarboxylic acid transporters), member 13

solute carrier family 25 (mitochondrial carrier, citrate transporter),

member 1

solute carrier family 13 (sodium-dependent dicarboxylate transporter),

member 3

solute carrier family 16 (monocarboxylic acid transporters), member 11

solute carrier family 18 (vesicular monoamine), member 1
Slc2a9 $\quad 12.42 \quad 10.74$

Slc25a4 $12.42 \quad 12.54$

Slc16a7 $\quad 12.12 \quad 11.52$

Slc2a1 $\quad 12.10 \quad 12.73$

Slc12a3 $\quad 10.77 \quad 5.28^{*}$

Slc25a11 $10.13 \quad 10.66$

Slc27a1 $\quad 10.12 \quad 10.46$

Slc25a20 $\quad 10.07 \quad 10.59$

Slc25a23 $\quad 9.76 \quad 9.59$

Slc25a12 $\quad 9.48 \quad 9.66$

Slc5a2 $\quad 9.48 \quad 9.52$

Slc25a19 $\quad 9.48 \quad 9.66$

Slc40a1 $\quad 9.46 \quad 9.10$

Slc2a4 $\quad 9.32 \quad 8.67$

Slc25a15 $\quad 9.25 \quad 9.27$

Slc25a36 $\quad 9.16 \quad 9.84$

Slc25a30 $\quad 9.10 \quad 8.66$

Slc1la2 $\quad 8.97 \quad 9.46$

Slc25a14 $\quad 8.95 \quad 9.60$

Slc16a10 $\quad 8.85 \quad 9.08$

$\begin{array}{lll}\text { Slc5a3 } & 8.72 \quad 9.03\end{array}$

Slc25a32 $\quad 8.69 \quad 9.14$

Slc12a7 $\quad 8.61 \quad 8.97$

Slc25a25 $\quad 8.52 \quad 9.07$

$\begin{array}{lll}\text { Slco4a1 } & 8.44 & 9.03\end{array}$

Slc15a2 $\quad 8.43 \quad 8.65$

$\begin{array}{lll}\text { Slc22a5 } & 8.42 \quad 8.77\end{array}$

Slc22a12 $\quad 8.33 \quad 7.89$

Slc25a44 $\quad 8.30 \quad 8.56$

Slc12a2 $\quad 8.28 \quad 8.96$

Slco3a1 $\quad 8.24 \quad 9.10$

$\begin{array}{lll}\text { Slc37a4 } & 8.20 & 8.05\end{array}$

$\begin{array}{lll}\text { Slc37a3 } & 8.19 & 8.81\end{array}$

Slc2a12 $\quad 8.13 \quad 7.88$

Slc25a13 $\quad 8.09 \quad 8.76$

$\begin{array}{lll}\text { Slc16a9 } & 7.98 \quad 8.37\end{array}$

Slc16a13 $\quad 7.95 \quad 8.06$

Slc25a1 $\quad 7.91 \quad 8.49$

$\begin{array}{lll}\text { Slc13a3 } & 7.78 \quad 7.54\end{array}$

$\begin{array}{lll}\text { Slc16a11 } & 7.71 & 7.30\end{array}$

$\begin{array}{lll}\text { Slc18a1 } & 7.71 \quad 7.84\end{array}$ 
solute carrier family 27 (fatty acid transporter), member 4

solute carrier family 34 (sodium phosphate), member 1

solute carrier family 2, (facilitated glucose transporter), member 8

solute carrier family 12 , member 1 (NKCC2)

solute carrier family 25 (mitochondrial carrier, peroxisomal membrane

protein), member 17

solute carrier family 15 , member 4

solute carrier family 25 , member 34

solute carrier family 23 (nucleobase transporters), member 2

solute carrier family 46 , member 1

solute carrier family 17 (anion/sugar transporter), member 5

solute carrier family 22 (organic anion transporter), member 6

solute carrier family 16 (monocarboxylic acid transporters), member 8

solute carrier family 12 , member 6 (KCC3)

solute carrier family 5 (sodium/glucose cotransporter), member 1 (SGLT1)

solute carrier family 17 (sodium phosphate), member 1 (NPT1)

solute carrier family 17 (sodium phosphate), member 3 (NPT4)

solute carrier family 25 (mitochondrial carrier, palmitoylcarnitine

transporter), member 29

solute carrier family 22 (organic cation transporter), member 17

solute carrier family 15 (oligopeptide transporter), member 1

solute carrier family 26 (sulfate transporter), member 2

solute carrier family 16 (monocarboxylic acid transporters), member 6

solute carrier family 16 (monocarboxylic acid transporters), member 14

solute carrier organic anion transporter family, member 1a1

solute carrier family 18 (vesicular monoamine), member 2

solute carrier family 25 , member 45

solute carrier family 37 (glycerol-3-phosphate transporter), member 1

solute carrier family 22 (organic anion transporter), member 8

solute carrier family 22 (organic cation transporter), member 13

solute carrier family 6 (neurotransmitter transporter), member 18

solute carrier organic anion transporter family, member $2 \mathrm{~b} 1$

solute carrier organic anion transporter family, member $4 \mathrm{C} 1$

solute carrier family 22 (organic cation transporter), member 2

solute carrier family 5 (sodium/glucose cotransporter), member 10

solute carrier family 37 (glycerol-3-phosphate transporter), member 2

solute carrier family 22 (organic cation transporter), member 18

solute carrier family 16 (monocarboxylic acid transporters), member 2

solute carrier family 22 (organic cation transporter), member 3

solute carrier family 22 (organic cation transporter), member 1

solute carrier family 22 (organic anion transporter), member 7

solute carrier family 26 , member 11

solute carrier family 22 (organic anion/cation transporter), member 15

solute carrier family 2 (facilitated glucose transporter), member 5

solute carrier family 15 , member 3

solute carrier family 25 (mitochondrial carrier, glutamate), member 22

solute carrier family 12 , member 4

solute carrier family 25 , member 27

solute carrier family 16 (monocarboxylic acid transporters), member 4

solute carrier organic anion transporter family, member 2a1

solute carrier family 23 (nucleobase transporters), member 1

solute carrier family 5 (sodium-dependent vitamin transporter), member 6

solute carrier family 22 (organic cation transporter), member 4

solute carrier family 16 (monocarboxylic acid transporters), member 12

solute carrier family 6 (neurotransmitter transporter), member 20

solute carrier family 26 , member 7

\begin{tabular}{|c|c|c|}
\hline Slc27a4 & 7.71 & 8.17 \\
\hline Slc34a1 & 7.68 & 7.72 \\
\hline Slc2a8 & 7.64 & 8.29 \\
\hline Slc12a1 & 7.64 & 6.83 \\
\hline Slc25a17 & 7.50 & 8.11 \\
\hline Slc15a4 & 7.46 & 8.45 \\
\hline Slc25a34 & 7.36 & 7.62 \\
\hline Slc23a2 & 7.34 & 7.72 \\
\hline Slc46a1 & 7.28 & 7.79 \\
\hline Slc17a5 & 7.25 & 7.79 \\
\hline Slc22a6 & 7.21 & 7.72 \\
\hline Slc16a8 & 7.08 & 7.01 \\
\hline Slc12a6 & 7.07 & 7.75 \\
\hline Slc5a1 & 6.94 & 6.42 \\
\hline Slc17a1 & 6.90 & 7.08 \\
\hline Slc17a3 & 6.90 & 7.47 \\
\hline Slc25a29 & 6.86 & 7.47 \\
\hline Slc22a17 & 6.84 & 8.13 \\
\hline Slc15a1 & 6.81 & $4.73^{\star}$ \\
\hline Slc26a2 & 6.81 & 8.09 \\
\hline Slc16a6 & 6.73 & 7.52 \\
\hline Slc16a14 & 6.71 & 6.16 \\
\hline Slco1a1 & 6.70 & 6.74 \\
\hline Slc18a2 & 6.67 & 6.64 \\
\hline Slc25a45 & 6.59 & 7.21 \\
\hline Slc37a1 & 6.59 & 7.00 \\
\hline Slc22a8 & 6.56 & 6.43 \\
\hline Slc22a13 & 6.50 & 6.60 \\
\hline Slc6a18 & 6.49 & 6.63 \\
\hline Slco2b1 & 6.41 & 6.49 \\
\hline Slco4c1 & 6.40 & 7.78 \\
\hline Slc22a2 & 6.39 & 6.47 \\
\hline Slc5a10 & 6.30 & 6.42 \\
\hline Slc37a2 & 6.25 & 5.98 \\
\hline Slc22a18 & 6.24 & 6.34 \\
\hline Slc16a2 & 6.24 & 6.41 \\
\hline Slc22a3 & 6.24 & 5.14 \\
\hline Slc22a1 & 6.21 & 6.31 \\
\hline Slc22a7 & 6.20 & 6.40 \\
\hline Slc26a11 & 6.16 & 6.30 \\
\hline Slc22a15 & 6.13 & 6.16 \\
\hline Slc2a5 & 6.10 & $5.56^{*}$ \\
\hline Slc15a3 & 6.06 & $5.30^{*}$ \\
\hline Slc25a22 & 6.06 & 5.85 \\
\hline Slc12a4 & 5.91 & 6.32 \\
\hline Slc25a27 & 5.91 & 6.09 \\
\hline Slc16a4 & 5.89 & 6.79 \\
\hline Slco2a1 & 5.88 & $5.28^{\star}$ \\
\hline Slc23a1 & 5.88 & 6.31 \\
\hline Slc5a6 & 5.84 & 6.05 \\
\hline Slc22a4 & $5.72^{\star}$ & 5.88 \\
\hline Slc16a12 & $5.63^{*}$ & 5.92 \\
\hline Slc6a20 & $5.59^{*}$ & 6.33 \\
\hline & $5.29 *$ & 7 \\
\hline
\end{tabular}


* - the A-value is below the cut-off level 


\begin{tabular}{|c|c|c|c|}
\hline Gene Name & $\begin{array}{l}\text { Gene } \\
\text { Symbol }\end{array}$ & $\begin{array}{l}\text { DCT/CNT } \\
\text { A_Value }\end{array}$ & $\begin{array}{c}\text { CCD } \\
\text { A_Value }\end{array}$ \\
\hline zinc finger protein 526 & Zfp526 & 13.23 & 13.31 \\
\hline ring-box 1 & $\mathrm{Rbx} 1$ & 13.04 & 13.19 \\
\hline pituitary tumor-transforming gene 1 & Pttg1 & 12.79 & 12.76 \\
\hline mortality factor 4 like 1 & Morf4I1 & 12.76 & 13.05 \\
\hline Jun proto-oncogene related gene $d$ & Jund & 12.74 & 12.75 \\
\hline homeo box D8 & Hoxd8 & 12.66 & 12.80 \\
\hline early growth response 1 & Egr1 & 12.64 & 13.46 \\
\hline TSC22 domain family, member 1 & Tsc22d1 & 12.38 & 12.51 \\
\hline homeo box D9 & Hoxd9 & 12.37 & 12.50 \\
\hline Jun oncogene & Jun & 12.28 & 12.83 \\
\hline FBJ osteosarcoma oncogene & Fos & 12.25 & 12.85 \\
\hline nascent polypeptide-associated complex alpha polypeptide & Naca & 12.17 & 12.64 \\
\hline endothelial differentiation-related factor 1 & Edf1 & 12.14 & 12.37 \\
\hline SUB1 homolog (S. cerevisiae) & Sub1 & 11.81 & 12.28 \\
\hline ring finger protein 7 & Rnf7 & 11.67 & 12.20 \\
\hline ecotropic viral integration site 1 & Evi1 & 11.64 & 12.07 \\
\hline pleiomorphic adenoma gene-like 1 & Plagl1 & 11.62 & 11.83 \\
\hline MPN domain containing & Mpnd & 11.57 & 11.89 \\
\hline peroxisome proliferative activated receptor, gamma, coactivator $1 \mathrm{a}$ & Ppargc1a & 11.55 & 11.37 \\
\hline Kruppel-like factor 9 & Klf9 & 11.52 & 11.44 \\
\hline CAMP responsive element binding protein 3 & Creb3 & 11.45 & 11.92 \\
\hline fusion, derived from t(12;16) malignant liposarcoma (human) & Fus & 11.43 & 11.79 \\
\hline eukaryotic translation initiation factor 3 , subunit $\mathrm{H}$ & Eif3h & 11.42 & 11.79 \\
\hline transcription factor CP2-like 1 & Tcfcp2l1 & 11.41 & 11.91 \\
\hline thyroid hormone receptor associated protein 3 & Thrap3 & 11.40 & 11.56 \\
\hline mortality factor 4 like 2 & Morf4l2 & 11.35 & 11.61 \\
\hline transcriptional regulator, SIN3B (yeast) & $\sin 3 b$ & 11.32 & 11.44 \\
\hline vitamin $\mathrm{D}$ receptor & Vdr & 11.31 & 9.46 \\
\hline proliferation-associated $2 \mathrm{G} 4$ & $\mathrm{~Pa} 2 \mathrm{~g} 4$ & 11.31 & 11.85 \\
\hline hypoxia inducible factor 1 , alpha subunit & Hif1a & 11.30 & 11.95 \\
\hline PR domain containing 16 & Prdm16 & 11.29 & 11.71 \\
\hline POU domain, class 3 , transcription factor 3 & Pou3f3 & 11.27 & 12.11 \\
\hline zinc finger, HIT domain containing 1 & Znhit1 & 11.22 & 11.52 \\
\hline nuclear receptor co-repressor 1 & Ncor1 & 11.21 & 11.55 \\
\hline amino-terminal enhancer of split & Aes & 11.13 & 11.49 \\
\hline transformation related protein 53 binding protein 1 & Trp53bp1 & 11.13 & 11.76 \\
\hline zinc finger, matrin type 2 & Zmat2 & 11.11 & 11.42 \\
\hline leucine rich repeat (in FLII) interacting protein 1 & Lrrfip1 & 11.11 & 11.66 \\
\hline BUD31 homolog (yeast) & Bud31 & 11.09 & 10.85 \\
\hline GATA binding protein 2 & Gata2 & 11.08 & 12.22 \\
\hline estrogen-related receptor gamma & Esrrg & 11.08 & 11.05 \\
\hline transcription elongation factor $\mathrm{A}(\mathrm{SII}) 1$ & Tcea1 & 11.07 & 11.37 \\
\hline zinc finger, MYND domain containing 11 & Zmynd11 & 11.06 & 11.35 \\
\hline zinc finger $\mathrm{CCCH}$-type containing 15 & Zc3h15 & 11.04 & 10.95 \\
\hline endothelial PAS domain protein 1 & Epas1 & 11.02 & 11.08 \\
\hline jagged 1 & Jag1 & 11.01 & 11.47 \\
\hline Cbp/p300-interacting transactivator & Cited2 & 10.95 & 11.44 \\
\hline LPS-induced TN factor & Litaf & 10.91 & 11.85 \\
\hline forkhead box I1 & Foxi1 & 10.89 & 11.54 \\
\hline ring finger protein 11 & Rnf11 & 10.89 & 11.22 \\
\hline nuclear factor, erythroid derived 2, like 2 & $\mathrm{Nfe} 2 \mathrm{l} 2$ & 10.88 & 11.28 \\
\hline AF4/FMR2 family, member 1 & Aff1 & 10.88 & 11.58 \\
\hline
\end{tabular}


Kruppel-like factor 6

GATA zinc finger domain containing 1

Klf6

$10.88 \quad 11.73$

AT rich interactive domain 4B (RBP1-like)

Gatad1

$10.84 \quad 11.01$

WW domain binding protein 5

10.84

11.22

replication initiator 1

$10.84 \quad 11.84$

BCL2-associated transcription factor 1

Arid4b

$10.81 \quad 10.87$

activating transcription factor 4

Repin

$10.80 \quad 10.99$

ets homologous factor

Bclaf1

$10.78 \quad 10.78$

serum deprivation response

Atf4

$10.78 \quad 11.84$

forkhead box $\mathrm{O} 3$

leucine rich repeat (in FLII) interacting protein 2

Ehf

$10.73 \quad 10.56$

Sdpr

$10.73 \quad 10.93$

SNW domain containing 1

Foxo3

$10.73 \quad 10.83$

PHD finger protein 17

$10.72 \quad 10.81$

purine rich element binding protein $B$

10.71

10.70

forkhead box J3

Snw1

Phf17

$10.70 \quad 11.04$

TAF13 RNA polymerase II

Foxi3

$10.68 \quad 11.23$

general transcription factor II I

male-specific lethal 3 homolog (Drosophila)

TAR DNA binding protein

homeo box D10

CCAAT/enhancer binding protein zeta

Taf13

$10.67 \quad 10.69$

Gtf2i

$10.65 \quad 11.14$

Msl3

Tardbp

10.63

11.01

Hoxd10

10.62

11.03

Cebpz

10.59

biogenesis of lysosome-related organelles complex-1, subunit 1

Bloc1s1

10.58

yes-associated protein 1

nuclear receptor subfamily 2 , group F, member 6

Yap1

10.57

7.40

11.12

Nr2f6

10.55

10.74

homeo box A9

E26 avian leukemia oncogene 2, 3' domain

cold shock domain protein $A$

praja 2, RING-H2 motif containing

general transcription factor IIF, polypeptide 1

Hoxa9

10.54

10.63

Ets2

Csda

Pja2

Gtf2f1

Ctcf

ELK4, member of ETS oncogene family

Elk4

10.53

10.72

10.43

10.42

10.37

10.36

forkhead box N3

YY1 transcription factor

activating transcription factor 2

forkhead box K1

leucine-zipper-like transcriptional regulator, 1

basic helix-loop-helix family, member e40

Foxn3

10.34

10.33

Yy1

Atf2

Foxk1

Lztr1

Bhlhe40

10.32

10.32

10.32

10.32

nuclear factor, erythroid derived 2,-like 1

Nfe2l1

10.29

MAD homolog 1 (Drosophila)

Smad1

10.28

TAF10 RNA polymerase II

Taf10

10.28

10.28

zinc finger, $\mathrm{CCHC}$ domain containing 3

nuclear factor $\mathrm{I} / \mathrm{C}$

interferon-induced protein 35

c-myc binding protein

$D$ site albumin promoter binding protein

Zcchc3

10.27

$\mathrm{Nfic}$

Ifi35

Mycbp

Dbp

prefoldin 1

CAMP responsive element binding protein 3-like 2

Pfdn1

Creb312

10.27

10.27

10.26

10.25

10.23

Rnf185

10.23

Ring finger protein 185 (Rnf185), mRNA

AF4/FMR2 family, member 4

zinc finger protein 422

Aff4

10.22

10.21

Zfp422

10.21

Phf14

10.21

11.01

PHD finger protein 14

Gabpa

10.18

10.78

10.72

10.92

10.59

11.04

10.85

10.67

11.15

10.93

10.36

11.37

10.77

10.99

10.76

11.21

GA repeat binding protein, alpha

Hoxd11

10.16

Foxp1

10.15

forkhead box $\mathrm{P} 1$

zinc finger and BTB domain containing $7 a$

Zbtb7a

10.15

nuclear receptor coactivator 2

Ncoa2

10.14

10.17

10.94

10.36

10.62

10.70

10.88

10.68

11.04

10.65

10.87

10.32

6.59

10.79

10.81

10.69 
forkhead box $\mathrm{O} 1$

polyglutamine binding protein 1

Foxo1

$10.13 \quad 10.01$

HLA-B associated transcript 2

Pqbp1

$10.13 \quad 10.60$

RIKEN cDNA 9030612M13 gene

Bat2

$10.13 \quad 10.81$

CREB binding protein

transcription elongation factor B (SIII), polypeptide 2

9030612M13Rik $\quad 10.13 \quad 10.45$

$\begin{array}{lll}\text { Crebbp } & 10.13 & 11.11\end{array}$

COP9 (constitutive photomorphogenic) homolog, subunit 5

Tceb2

$10.12 \quad 10.70$

inhibitor of DNA binding 2

zinc finger protein 238

aryl hydrocarbon receptor nuclear translocator

FBJ osteosarcoma oncogene $B$

nuclear receptor coactivator 4

signal transducer and activator of transcription 3

Cops5

$10.12 \quad 10.77$

Id2

$10.11 \quad 10.77$

$\begin{array}{lll}\text { Zfp238 } & 10.10 & 10.62\end{array}$

$\begin{array}{lll}\text { Arnt } & 10.10 \quad 10.61\end{array}$

Fosb $\quad 10.08 \quad 10.24$

$\begin{array}{lll}\text { Ncoa4 } & 10.08 & 10.74\end{array}$

ring finger protein 114

$\begin{array}{lll}\text { Stat3 } & 10.06 & 10.75\end{array}$

$\begin{array}{lll}\text { Rnf114 } & 10.06 & 10.99\end{array}$

zinc finger and BTB domain containing 4

scaffold attachment factor $B$

zinc finger and BTB domain containing 20

homeo box B7 I// homeo box B8

zinc finger homeobox 3

Ngfi-A binding protein 1

CCR4-NOT transcription complex, subunit 4

zinc finger protein 251

GLIS family zinc finger 2

Zbtb4 $\quad 10.06$

$\begin{array}{lll}\text { Safb } & 10.05 & 10.52\end{array}$

Zbtb20 $\quad 10.03 \quad 10.66$

Hoxb7 I/I Hoxb8 $\quad 10.03 \quad 10.29$

Zfhx3 $\quad 10.03 \quad 10.52$

Nab1 $\quad 10.02 \quad 10.49$

$\begin{array}{lll}\text { Cnot4 } & 9.99 & 10.46\end{array}$

$\begin{array}{lll}\text { Zfp251 } & 9.98 & 10.64\end{array}$

$\begin{array}{lll}\text { Glis2 } & 9.97 & 10.74\end{array}$

$\begin{array}{llll}\text { retinoblastoma binding protein } 8 & \text { Rbbp8 } & 9.96 & 10.23\end{array}$

MAD homolog 4 (Drosophila) $\quad$ Smad4 $\quad 9.95 \quad 10.54$

zinc finger protein $809 \quad$ Zfp809 $\quad 9.95 \quad 10.43$

chromatin modifying protein 4B /// similar to zinc finger protein 341 $\quad$ Chmp4b /// LOCl $\quad 9.95 \quad 10.55$

GLIS family zinc finger 3

forkhead box Q1

$\mathrm{AE}$ binding protein 2

zinc finger $\mathrm{CCCH}$ type containing $11 \mathrm{~A}$

RIKEN cDNA 2010315B03 gene

THO complex 2

CCAAT/enhancer binding protein (C/EBP), gamma

zinc finger protein 664

homeo box C10

microphthalmia-associated transcription factor

trans-acting transcription factor 1

RIKEN cDNA 0610009B22 gene

nuclear factor $\mathrm{I} / \mathrm{X}$

methyltransferase like 14

ring finger protein 4

polymerase (RNA) II (DNA directed) polypeptide G

expressed sequence C80913

suppressor of Ty 16 homolog (S. cerevisiae)

zinc fingers and homeoboxes 3

Glis3

Foxq1

$9.94 \quad 10.57$

$9.93 \quad 9.48$

$\begin{array}{lll}\text { Aebp2 } & 9.93 & 10.67\end{array}$

Zc3h11a $\quad 9.91 \quad 10.49$

2010315B03Rik $\quad 9.91 \quad 10.05$

$\begin{array}{lll}\text { Thoc2 } & 9.91 & 10.49\end{array}$

$\begin{array}{lll}\text { Cebpg } & 9.90 & 10.42\end{array}$

$\begin{array}{lll}\text { Zfp664 } & 9.90 & 10.68\end{array}$

Hoxc10 $\quad 9.89 \quad 5.53^{\star}$

$\begin{array}{lll}\text { Mitf } & 9.89 & 10.30\end{array}$

$\begin{array}{lll}\text { Sp1 } & 9.88 & 10.99\end{array}$

0610009B22Rik $\quad 9.87 \quad 10.38$

$\begin{array}{lll}\text { Nfix } & 9.87 & 11.35\end{array}$

Mettl14 $\quad 9.87 \quad 10.46$

$\begin{array}{lll}\text { Rnf4 } & 9.86 & 10.39\end{array}$

$\begin{array}{lll}\text { Polr2g } & 9.84 & 10.08\end{array}$

$\begin{array}{llr}\mathrm{C} 80913 & 9.84 & 9.92\end{array}$

Supt16h $\quad 9.84 \quad 10.35$

$\begin{array}{lll}\text { Zhx3 } & 9.84 & 10.48\end{array}$

$\begin{array}{lll}\text { Zfp358 } & 9.83 & 10.18\end{array}$

$\begin{array}{llll}\text { Shwachman-Bodian-Diamond syndrome homolog (human) } & \text { Sbds } & 9.82 & 10.12 \\ \text { zinc finger protein } 161 & \text { Zfp161 } & 9.82 & 10.28\end{array}$

RUN and FYVE domain containing 3

structure specific recognition protein 1

SAP domain containing ribonucleoprotein

nuclear receptor subfamily 2 , group $F$, member 2

Rufy3

Ssrp1

$9.81 \quad 9.98$

$9.81 \quad 10.40$

Sarnp $\quad 9.81 \quad 9.61$

Nr2f2 $\quad 9.79 \quad 10.14$

Rnf14 $\quad 9.79 \quad 10.10$

$\begin{array}{llrr}\text { AT rich interactive domain 4A (RBP1-like) } & \text { Arid4a } & 9.79 & 9.84\end{array}$

YEATS domain containing 4

Yeats4

$9.77 \quad 10.04$ 
cell division cycle 5 -like (S. pombe)

nuclear transcription factor, X-box binding 1

Cdc5

$9.77 \quad 10.05$

zinc finger with KRAB and SCAN domains 1

$\mathrm{Nfx} 1$

$9.77 \quad 9.87$

signal transducer and activator of transcription 6

Zkscan1

$9.77 \quad 10.28$

C1D nuclear receptor co-repressor

Stat6

$9.75 \quad 10.03$

activating transcription factor 6

C1d

$9.75 \quad 9.91$

TEA domain family member 1

Atf6

$9.75 \quad 9.82$

zinc finger protein 219

high mobility group box transcription factor 1

Tead1

$9.73 \quad 10.79$

Zfp219

$9.70 \quad 10.13$

BAT2 domain containing 1

activating transcription factor 1

Hbp1

Bat2d

Atf1

XPA binding protein 2

Xab2

TAF15 RNA polymerase II

family with sequence similarity 48 , member $A$

Taf15

Fam48a

$9.69 \quad 10.34$

$9.68 \quad 10.49$

$9.66 \quad 10.76$

speckle-type POZ protein

interferon regulatory factor 6

CAMP responsive element binding protein 1

Spop

$9.66 \quad 10.17$

$9.65 \quad 9.52$

$9.64 \quad 10.05$

$9.61 \quad 10.10$

Irf6

$9.59 \quad 10.84$

CCR4-NOT transcription complex, subunit 1

Creb1

$9.59 \quad 10.32$

LIM domain binding 1

CCR4-NOT transcription complex, subunit 2

Cnot1

$9.59 \quad 10.63$

Ldb1

$9.59 \quad 9.93$

nuclear receptor subfamily 2 , group $\mathrm{C}$, member 2

Cnot2

$9.57 \quad 10.40$

$\mathrm{C}$-terminal binding protein 2

$\mathrm{Nr} 2 \mathrm{c} 2$

$9.57 \quad 10.35$

Max interacting protein 1

Ctbp2

$9.55 \quad 9.86$

Mxi1

$9.54 \quad 9.80$

purine rich element binding protein $A$

Pura

$9.53 \quad 10.03$

enhancer of rudimentary homolog (Drosophila)

Erh

zinc finger protein 329

Zfp329

Jumonji domain containing 3, mRNA (cDNA clone IMAGE:1378940)

myeloid/lymphoid or mixed-lineage leukemia 3

Kdm6b

$9.53 \quad 10.28$

$9.51 \quad 9.44$

$9.50 \quad 10.39$

ZXD family zinc finger $C$

MII3

nuclear factor I/B

Zxdc

9.50

9.88

$9.48 \quad 10.01$

E74-like factor 2

Nfib

$9.48 \quad 10.86$

bromodomain containing 1

Elf2

Brd1

$9.47 \quad 9.88$

myoneurin

Mynn

$9.47 \quad 10.04$

transcription factor 20

similar to Zinc finger BED domain containing protein 4

kelch-like $\mathrm{ECH}$-associated protein 1

upstream binding transcription factor, RNA polymerase I

Tcf20

LOC667118

$9.46 \quad 10.14$

$9.45 \quad 10.55$

Keap1

Ubtf

$9.45 \quad 9.97$

suppressor of Ty 5 homolog (S. cerevisiae)

Max dimerization protein 3

RAR-related orphan receptor gamma

empty spiracles homolog 2 (Drosophila)

Supt5h

9.44

9.83

$9.44 \quad 10.51$

9.69

Mxd3

$9.43 \quad 9.35$

Rorc

$9.42 \quad 9.93$

transcriptional regulator, SIN3A (yeast)

Emx2

$9.42 \quad 10.90$

core binding factor beta

RIKEN cDNA 5830417I10 gene

UTP6, small subunit (SSU) processome component, homolog

interleukin enhancer binding factor 2

zinc finger and SCAN domain containing 21

transducin-like enhancer of split 3, homolog of Drosophila E(spl)

MYST histone acetyltransferase (monocytic leukemia) 3

Sin $3 a$

Cbfb

9.41

9.78

5830417I10Rik

9.41

9.66

Utp6

9.40

9.48

IIf2

9.40

Zscan21

9.39

10.31

Tle3

9.39

10.20

Myst3

9.38

10.46

zinc finger protein 217

homeo box B4

inhibitor of DNA binding 3

nuclear receptor subfamily 1 , group $D$, member 2

Zfp217

9.38

9.78

$9.37 \quad 10.13$

Hoxb4

9.37

9.98

Id3

$9.36 \quad 10.15$

$\mathrm{Nr} 1 \mathrm{~d} 2$

9.35

9.39

Zfp187

9.35

zinc finger protein 191

Zfp191

10.41

dachshund 1 (Drosophila)

Dach1

$9.34 \quad 10.18$

$9.34 \quad 9.08$ 
transcription factor AP-2 beta

RE1-silencing transcription factor

predicted gene, EG382639

TAF9 RNA polymerase II

GATA binding protein 3

scaffold attachment factor B2

homeo box B5

family with sequence similarity 164 , member A

cyclin L1

TSC22 domain family, member 2

ring finger protein 1

zinc finger, ZZ domain containing 3

anaphase promoting complex subunit 11

SERTA domain containing 1

remodeling and spacing factor 1

zinc finger protein 553

zinc finger protein 644

paternally expressed 3

grainyhead-like 2 (Drosophila)

general transcription factor II A, 1

LIM domains containing 1

transcription factor Dp 2

zinc finger protein 263

zinc and ring finger 2

ras responsive element binding protein 1

sprouty homolog 2 (Drosophila)

MAD homolog 5 (Drosophila)

transcription factor $\mathrm{Dp} 1$

ets variant gene 3

forkhead box K2

PHD finger protein 10

Dr1 associated protein 1 (negative cofactor 2 alpha)

CCAAT/enhancer binding protein (C/EBP), alpha

ataxin 3

zinc finger protein 260

zinc finger protein 629

zinc finger protein 408

SRY-box containing gene 4

fos-like antigen 2 /// similar to fos-like antigen 2

zinc finger and BTB domain containing 1

programmed cell death 2-like

vascular endothelial zinc finger 1

paired box gene 8

myeloid/lymphoid or mixed-lineage leukemia

$\mathrm{X}$-box binding protein 1 , mRNA

thyrotroph embryonic factor

zinc finger, MYND-type containing 8

nucleus accumbens associated 2

D4, zinc and double PHD fingers family 2

ski sarcoma viral oncogene homolog (avian)

serum response factor

ring finger protein, LIM domain interacting

polycomb group ring finger 2

down-regulator of transcription 1

pre B-cell leukemia transcription factor 2

cut-like homeobox 1

\begin{tabular}{|c|c|c|}
\hline Tcfap2b & 9.34 & 9.4 \\
\hline Rest & 9.33 & 10.2 \\
\hline EG382639 & 9.33 & 10.0 \\
\hline Taf9 & 9.32 & 9. \\
\hline Gata3 & 9.32 & 10.5 \\
\hline Safb2 & 9.32 & 9.9 \\
\hline Hoxb5 & 9.31 & 9. \\
\hline Fam164a & 9.31 & 10.2 \\
\hline Ccnl1 & 9.30 & 9.8 \\
\hline $\mathrm{Tsc} 22 \mathrm{~d} 2$ & 9.30 & 9.2 \\
\hline Ring1 & 9.29 & 9. \\
\hline Zzz3 & 9.29 & 9.5 \\
\hline Anapc11 & 9.28 & 9.1 \\
\hline Sertad1 & 9.27 & 9. \\
\hline Rsf1 & 9.27 & 9. \\
\hline Zfp553 & 9.26 & 9. \\
\hline Zfp644 & 9.26 & 9. \\
\hline Peg3 & 9.24 & 8. \\
\hline Grhl2 & 9.24 & 9. \\
\hline Gtf2a1 & 9.24 & 9. \\
\hline Limd1 & 9.23 & 10. \\
\hline Tfdp2 & 9.23 & 9. \\
\hline Zfp263 & 9.23 & 9. \\
\hline Znrf2 & 9.23 & 9.8 \\
\hline Rreb1 & 9.22 & 9.8 \\
\hline Spry2 & 9.22 & 10.5 \\
\hline Smad5 & 9.21 & 9. \\
\hline Tfdp1 & 9.20 & 9. \\
\hline Etv3 & 9.19 & 9. \\
\hline Foxk2 & 9.18 & 9. \\
\hline Phf10 & 9.18 & 9. \\
\hline Drap1 & 9.18 & 9. \\
\hline Cebpa & 9.17 & 9. \\
\hline Atxn3 & 9.17 & 9. \\
\hline Zfp260 & 9.17 & 9. \\
\hline Zfp629 & 9.16 & 9. \\
\hline Zfp408 & 9.16 & 9. \\
\hline Sox4 & 9.15 & 10. \\
\hline Fosl2 & 9.15 & 10 \\
\hline Zbtb1 & 9.13 & 10. \\
\hline Pdcd2I & 9.13 & 9. \\
\hline Vezf1 & 9.13 & 9.8 \\
\hline Pax8 & 9.12 & 10 \\
\hline Mllt3 & 9.12 & 9. \\
\hline Xbp1 & 9.11 & 10. \\
\hline Tef & 9.11 & $9 .($ \\
\hline Zmynd8 & 9.11 & 9. \\
\hline Nacc2 & 9.11 & 9. \\
\hline Dpf2 & 9.10 & 9. \\
\hline Ski & 9.10 & 9. \\
\hline Srf & 9.09 & 9. \\
\hline Rlim & 9.09 & 9. \\
\hline Pcgf2 & 9.08 & \\
\hline Dr1 & 9.07 & \\
\hline $\mathrm{Pbx} 2$ & 9.07 & \\
\hline & 9.07 & \\
\hline
\end{tabular}


zinc finger and BTB domain containing 43

MAD homolog 3 (Drosophila)

RIKEN cDNA 1810007M14 gene

ring finger protein 2

zinc finger protein 768

nuclear receptor subfamily 3 , group $C$, member 2

delta-like 1 (Drosophila)

zinc finger protein 397

RING1 and YY1 binding protein

RIKEN cDNA 5730601F06 gene

CCR4-NOT transcription complex, subunit 7

cyclin T2

sal-like 1 (Drosophila)

zinc finger protein 740

tripartite motif-containing 28

ring finger protein 5

zinc finger and BTB domain containing 6

MAF1 homolog (S. cerevisiae) (Maf1), mRNA

jumonji, AT rich interactive domain 2

lysine (K)-specific demethylase 5D

MAD homolog 2 (Drosophila)

nuclear transcription factor- $Y$ beta

circadian locomoter output cycles kaput

serum response factor binding protein 1

zinc finger protein 516

HLA-B associated transcript 2-like

SKI-like

prostate tumor over expressed gene 1

transcription factor 12

inhibitor of growth family, member 2

myeloid/lymphoid or mixed-lineage leukemia

nuclear receptor interacting protein 1

transcription factor 4

RIKEN cDNA 1700023B02 gene

zinc finger protein 617

bromodomain and PHD finger containing, 3

RAR-related orphan receptor alpha

general transcription factor IIB

T-box 2

hairy and enhancer of split 6 (Drosophila)

upstream binding protein 1

lysine (K)-specific demethylase 5B

zinc finger protein 398

nuclear factor of activated T-cells 5

nuclear receptor coactivator 3

zinc finger, RAN-binding domain containing 2

zinc finger protein 445

ELK3, member of ETS oncogene family

thyroid hormone receptor alpha

AS42 oncogene homolog

nuclear factor of activated T-cells, cytoplasmic

Kruppel-like factor 10

homeodomain leucine zipper-encoding gene

zinc finger protein 281

TAF1 RNA polymerase II

Zbtb43

$9.06 \quad 9.65$

Smad3

$9.06 \quad 9.07$

1810007M14Rik $\quad 9.04 \quad 10.02$

$\begin{array}{lll}\text { Rnf2 } & 9.04 & 9.62\end{array}$

$\begin{array}{lll}\text { Zfp768 } & 9.03 & 8.57\end{array}$

$\begin{array}{lll}\mathrm{Nr} 3 \mathrm{c} 2 & 9.03 & 9.53\end{array}$

DII1 $\quad 9.02 \quad 9.92$

$\begin{array}{lll}\text { Zfp397 } & 9.00 & 9.31\end{array}$

$\begin{array}{lll}\text { Rybp } & 8.99 & 9.13\end{array}$

5730601F06Rik $\quad 8.99 \quad 9.60$

$\begin{array}{lll}\text { Cnot7 } & 8.97 & 9.46\end{array}$

$\begin{array}{lll}\text { Ccnt2 } & 8.97 & 9.58\end{array}$

Sall1 $\quad 8.97 \quad 5.57^{\star}$

$\begin{array}{lll}\text { Zfp740 } & 8.95 & 9.27\end{array}$

$\begin{array}{lll}\text { Trim28 } & 8.93 & 9.75\end{array}$

$\begin{array}{lll}\text { Rnf5 } & 8.93 & 9.69\end{array}$

$\begin{array}{lll}\text { Zbtb6 } & 8.93 & 9.47\end{array}$

$\begin{array}{lll}\text { Maf1 } & 8.92 & 9.87\end{array}$

$\begin{array}{lll}\text { Jarid2 } & 8.92 & 9.50\end{array}$

$\begin{array}{lll}\text { Kdm5d } & 8.92 & 9.25\end{array}$

$\begin{array}{lll}\text { Smad2 } & 8.91 & 9.84\end{array}$

$\begin{array}{lll}\text { Nfyb } & 8.90 & 9.50\end{array}$

$\begin{array}{lll}\text { Clock } & 8.89 & 9.48\end{array}$

$\begin{array}{lll}\text { Srfbp1 } & 8.89 & 9.08\end{array}$

$\begin{array}{lll}\text { Zfp516 } & 8.89 & 9.31\end{array}$

Bat2l $\quad 8.88 \quad 9.64$

$\begin{array}{lll}\text { Skil } & 8.88 & 9.71\end{array}$

$\begin{array}{lll}\text { Ptov1 } & 8.87 & 9.17\end{array}$

$\begin{array}{lll}\text { Tcf12 } & 8.87 & 9.56\end{array}$

$\begin{array}{lll}\text { Ing2 } & 8.86 & 9.36\end{array}$

$\begin{array}{lll}\text { Mllt6 } & 8.86 & 9.67\end{array}$

$\begin{array}{lll}\text { Nrip1 } & 8.86 & 9.42\end{array}$

$\begin{array}{lll}\text { Tcf4 } & 8.85 & 9.34\end{array}$

1700023B02Rik $\quad 8.85 \quad 8.75$

$\begin{array}{lll}\text { Zfp617 } & 8.85 & 9.42\end{array}$

$\begin{array}{lll}\text { Brpf3 } & 8.85 & 8.61\end{array}$

$\begin{array}{lll}\text { Rora } & 8.83 & 9.69\end{array}$

$\begin{array}{lll}\text { Gtf2b } & 8.83 & 9.47\end{array}$

$\begin{array}{lll}\text { Tbx2 } & 8.82 & 9.07\end{array}$

$\begin{array}{lll}\text { Hes6 } & 8.82 & 9.30\end{array}$

$\begin{array}{lll}\text { Ubp1 } & 8.82 & 9.24\end{array}$

$\begin{array}{lll}\mathrm{Kdm} 5 \mathrm{~b} & 8.81 & 9.41\end{array}$

$\begin{array}{lll}\text { Zfp398 } & 8.81 & 9.51\end{array}$

$\begin{array}{lll}\text { Nfat5 } & 8.81 & 9.76\end{array}$

$\begin{array}{lll}\text { Ncoa3 } & 8.80 & 9.67\end{array}$

$\begin{array}{lll}\text { Zranb2 } & 8.80 & 9.14\end{array}$

$\begin{array}{lll}Z \text { Zfp445 } & 8.80 & 9.23\end{array}$

Elk3 $\quad 8.79 \quad 8.83$

$\begin{array}{lll}\text { Thra } & 8.79 & 9.62\end{array}$

$\begin{array}{lll}\text { Maf } & 8.79 & 9.02\end{array}$

Nfatc3 $\quad 8.77 \quad 9.16$

KIf10 $\quad 8.76 \quad 9.63$

Homez $\quad 8.76 \quad 8.86$

$\begin{array}{lll}\text { Zfp281 } & 8.75 & 8.70\end{array}$

$\begin{array}{lll}\text { Taf1 } & 8.75 & 9.37\end{array}$

zinc finger protein 687

Zfp687

$8.74 \quad 8.26$ 
RIKEN cDNA 4930529C04 gene

polyhomeotic-like 1 (Drosophila)

expressed sequence Al987944 /// expressed sequence AW146154

SRY-box containing gene 6

inhibitor of growth family, member 1

zinc finger protein 606

zinc finger and BTB domain containing 2

TOX high mobility group box family member 4

HNF1 homeobox B

homeo box A10

zinc finger protein 3

interferon regulatory factor 1

zinc finger protein 292

myocyte enhancer factor $2 \mathrm{~A}$

cullin associated and neddylation disassociated 1

zinc finger protein 507

regulatory factor $X, 1$ (influences HLA class II expression)

general transcription factor II A, 2

single-minded homolog 1 (Drosophila)

Scm-like with four mbt domains 1

AT hook containing transcription factor 1

RIKEN cDNA 5730507C01 gene

ash2 (absent, small, or homeotic)-like (Drosophila)

retinoblastoma-like 2

TOX high mobility group box family member 3

zinc finger protein 467

suppressor of Ty 6 homolog (S. cerevisiae)

retinoid $X$ receptor alpha

regulatory factor $X, 5$ (influences HLA class II expression)

nuclear receptor coactivator 1

mediator complex subunit 14

zinc finger protein 707

SAP30 binding protein

SRY-box containing gene 12

4lysine (K)-specific demethylase 6A

transcription factor E3

zinc finger and BTB domain containing 38

nuclear factor I/A

human immunodeficiency virus type I enhancer binding protein 2

mediator of RNA polymerase II transcription, subunit 4 homolog

hepatoma-derived growth factor, related protein 2

retinoid $X$ receptor beta

activating transcription factor 3

transcription factor AP-2, alpha

$\mathrm{N}$-myc (and STAT) interactor

activating transcription factor 5

general transcription factor III A

RIKEN cDNA 1300003B13 gene

inhibitor of growth family, member 5

$\mathrm{N}$-acetylglucosamine-1-phosphate transferase, alpha and beta

castor homolog 1, zinc finger (Drosophila)

cyclin T1

zinc finger protein 821

GA repeat binding protein, beta 2

RB1-inducible coiled-coil 1

chromobox homolog 4 (Drosophila Pc class)

\begin{tabular}{|c|c|c|}
\hline 4930529C04Rik & 8.74 & 8.59 \\
\hline Phc1 & 8.73 & 9.25 \\
\hline Al987944 & 8.73 & 9.40 \\
\hline Sox6 & 8.72 & 9.66 \\
\hline Ing1 & 8.72 & 9.15 \\
\hline Zfp606 & 8.71 & 9.00 \\
\hline Zbtb2 & 8.70 & 9.39 \\
\hline Tox4 & 8.69 & 9.02 \\
\hline Hnf1b & 8.68 & 9.56 \\
\hline Hoxa10 & 8.67 & 6.66 \\
\hline Zfp3 & 8.67 & 9.11 \\
\hline Irf1 & 8.67 & 9.37 \\
\hline Zfp292 & 8.66 & 9.05 \\
\hline Mef2a & 8.65 & 9.50 \\
\hline Cand1 & 8.65 & 9.63 \\
\hline Zfp507 & 8.65 & 8.88 \\
\hline Rfx1 & 8.65 & 9.66 \\
\hline Gtf2a2 & 8.64 & 9.66 \\
\hline Sim1 & 8.64 & 9.56 \\
\hline Sfmbt1 & 8.64 & 8.77 \\
\hline Ahctf1 & 8.62 & 8.67 \\
\hline 5730507C01Rik & 8.62 & 8.27 \\
\hline Ash2l & 8.61 & 9.14 \\
\hline Rbl2 & 8.61 & 9.16 \\
\hline Tox3 & 8.61 & 9.20 \\
\hline Zfp467 & 8.61 & 8.57 \\
\hline Supt6h & 8.60 & 9.54 \\
\hline Rxra & 8.60 & 8.84 \\
\hline Rfx5 & 8.59 & 9.00 \\
\hline Ncoa1 & 8.59 & 9.08 \\
\hline Med14 & 8.59 & 9.50 \\
\hline Zfp707 & 8.59 & 9.28 \\
\hline Sap30bp & 8.59 & 9.03 \\
\hline Sox12 & 8.58 & 8.81 \\
\hline Kdm6a & 8.57 & 9.30 \\
\hline Tcfe3 & 8.57 & 8.75 \\
\hline Zbtb38 & 8.57 & 8.77 \\
\hline Nfia & 8.56 & 10.65 \\
\hline Hivep2 & 8.55 & 9.37 \\
\hline Med4 & 8.54 & 8.72 \\
\hline Hdgfrp2 & 8.53 & 9.20 \\
\hline Rxrb & 8.53 & 8.65 \\
\hline Atf3 & 8.53 & 8.87 \\
\hline Tcfap2a & 8.52 & 9.18 \\
\hline $\mathrm{Nmi}$ & 8.52 & 9.31 \\
\hline Atf5 & 8.52 & 9.13 \\
\hline Gtf3a & 8.52 & 8.97 \\
\hline 1300003B13Rik & 8.52 & 8.39 \\
\hline Ing5 & 8.52 & 8.74 \\
\hline Gnptab & 8.52 & 9.14 \\
\hline Casz1 & 8.52 & 8.56 \\
\hline Ccnt1 & 8.50 & 9.43 \\
\hline Zfp821 & 8.49 & 9.08 \\
\hline Gabpb2 & 8.49 & 8.57 \\
\hline Rb1cc1 & 8.49 & 9.12 \\
\hline Cbx4 & 8.48 & 9.61 \\
\hline
\end{tabular}


zinc finger protein 672

empty spiracles homolog 1 (Drosophila)

homeo box A3

apoptosis antagonizing transcription factor

zinc finger protein 384

deltex 2 homolog (Drosophila)

PHD finger protein 12

zinc finger protein 775

BTB and CNC homology 1

RIKEN cDNA 6720457D02 gene

zinc finger protein 763

K(lysine) acetyltransferase 5

transducin-like enhancer of split 4, homolog of Drosophila E(spl)

neural proliferation, differentiation and control gene 1

TAF2 RNA polymerase II

forkhead box $\mathrm{J} 2$

staphylococcal nuclease and tudor domain containing 1

lysine (K)-specific demethylase 5C

nuclear receptor subfamily 3, group C, member 1

PWP1 homolog (S. cerevisiae)

transcription factor $E B$

MAX gene associated

zinc finger protein 62

mastermind like 1 (Drosophila)

zinc finger protein 560

Kruppel-like factor 15

Pbx/knotted 1 homeobox

thyroid hormone receptor interactor 4

zinc fingers and homeoboxes 1

zinc finger protein 787

zinc finger protein 827

zinc finger protein 148

Bmi1 polycomb ring finger oncogene

WW domain containing transcription regulator 1

MYST histone acetyltransferase 2

regulatory factor $\mathrm{X}, 7$

general transcription factor IIF, polypeptide 2

zinc finger protein 369

E2F transcription factor 3

RIKEN cDNA 9130019022 gene

transcription elongation factor A (SII)-like 1

signal transducer and activator of transcription 1

lysine (K)-specific demethylase 5A

RIKEN cDNA D330038006 gene

zinc finger, BED domain containing 4

ets variant gene 6 (TEL oncogene)

CREB/ATF bZIP transcription factor

cyclin $\mathrm{D}$ binding myb-like transcription factor 1

mediator complex subunit 21

cDNA sequence BC049349

core-binding factor, runt domain, alpha subunit 2, translocated to, 2

period homolog 1 (Drosophila)

zinc finger and BTB domain containing 41 homolog

transcription elongation factor A (SII)-like 3

zinc and ring finger 1

cAMP responsive element modulator

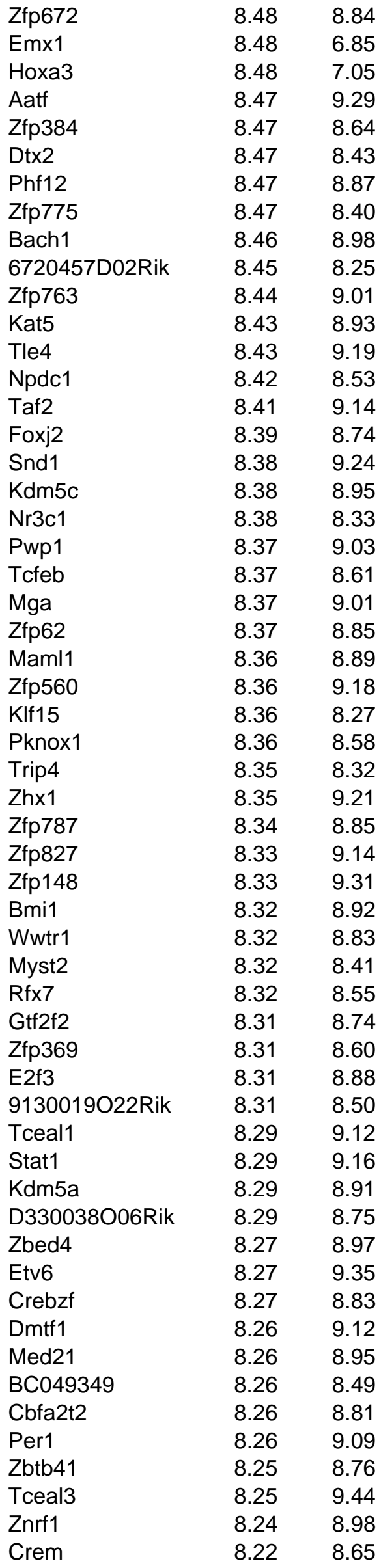


nuclear transcription factor-Y alpha

zinc finger and BTB domain containing 40

interferon regulatory factor 3

zinc finger and SCAN domain containing 12

period homolog 2 (Drosophila)

zinc finger protein 362

mbt domain containing 1

general transcription factor II E, polypeptide 2 (beta subunit)

RuvB-like protein 2

jumonji domain containing $1 \mathrm{C}$

zinc finger protein 612

hepatic leukemia factor

CCR4-NOT transcription complex, subunit 3

RIKEN cDNA 5730403B10 gene

human immunodeficiency virus type I enhancer binding protein 1

PHD finger protein 20-like 1

heat shock factor 1

v-maf musculoaponeurotic fibrosarcoma oncogene family, protein G

zinc finger protein 46

YY1 associated factor 2

menage a trois 1

Sp2 transcription factor

zinc finger protein 655

TAF5-like RNA polymerase II

homeo box $\mathrm{C} 9$

estrogen related receptor, alpha

recombination signal binding protein for immunoglobulin kappa J

PHD finger protein 20

TAF11 RNA polymerase II

expressed sequence AW146020

peroxisome proliferative activated receptor, gamma

coactivator 1 beta

POU domain, class 6 , transcription factor 1

zinc finger protein 367

programmed cell death 2

zinc finger with KRAB and SCAN domains 6

zinc finger protein 746

zinc finger protein 592

zinc finger protein 704

RIKEN cDNA $2310001 \mathrm{H} 12$ gene

metal response element binding transcription factor 2

zinc finger protein 764

transcription elongation factor B (SIII), polypeptide 3

Zinc finger protein 212

myocyte enhancer factor 2D

nuclear receptor subfamily 4, group A, member 1

pleckstrin homology domain containing, family $\mathrm{F}$ member 2

transcription elongation regulator 1 (CA150)

$\mathrm{V}$-maf musculoaponeurotic fibrosarcoma oncogene family, protein $\mathrm{K}$

zinc finger protein 111

zinc finger protein 84

MYC-associated zinc finger protein

zinc finger protein 661

activating transcription factor 7

TSC22 domain family, member 3

glucocorticoid modulatory element binding protein 1
Nfya

Zbtb40

Irf3

Zscan12

Per2

Zfp362

Mbtd1

Gtf2e2

Ruvbl2

Jmjd1c

Zfp612

HIf

Cnot3

5730403B10Rik

Hivep1

Phf20l1

Hsf1

Mafg

Zfp46

Yaf2

Mnat1

Sp2

Zfp655

Taf5I

Hoxc9

Esrra

Rbpj

Phf20

Taf11

AW146020

Ppargc1b

Pou6f1

Zfp367

Pdcd2

Zkscan6

Zfp746

Zfp592

Zfp704

2310001H12Rik

Mtf2

Zfp764

Tceb3

Zfp212

Mef2d

Nr4a1

Plekhf2

Tcerg1

Mafk

Zfp111

Zfp84

Maz

Zfp661

Atf7

Tsc22d3

Gmeb1
$8.22 \quad 8.43$

$8.22 \quad 8.65$

$8.21 \quad 8.85$

$8.21 \quad 9.00$

$8.20 \quad 8.27$

$8.19 \quad 8.54$

$8.19 \quad 8.61$

$8.19 \quad 8.61$

$8.18 \quad 9.23$

$8.18 \quad 8.76$

$8.18 \quad 8.64$

$8.18 \quad 7.14$

$8.18 \quad 8.64$

$8.18 \quad 8.65$

$8.17 \quad 8.67$

$8.17 \quad 8.82$

$8.16 \quad 8.49$

$8.16 \quad 8.32$

$8.15 \quad 8.81$

$8.15 \quad 8.60$

$8.15 \quad 8.86$

$8.14 \quad 7.96$

$8.14 \quad 8.57$

$8.14 \quad 8.18$

$8.14 \quad 6.70$

$8.14 \quad 8.59$

$8.13 \quad 8.19$

$8.13 \quad 8.78$

$8.13 \quad 8.75$

$8.12 \quad 8.29$

$8.12 \quad 8.61$

$8.12 \quad 8.59$

$8.11 \quad 9.00$

$8.10 \quad 7.97$

$8.10 \quad 8.62$

$8.09 \quad 8.83$

$8.09 \quad 8.53$

$8.08 \quad 8.29$

$8.08 \quad 8.46$

$8.07 \quad 8.76$

$8.07 \quad 8.43$

$8.07 \quad 8.69$

$8.07 \quad 8.58$

$8.06 \quad 8.25$

$8.05 \quad 9.19$

$8.05 \quad 8.79$

$8.05 \quad 8.78$

$8.04 \quad 8.56$

$8.04 \quad 8.64$

$8.04 \quad 8.34$

$8.04 \quad 8.66$

$8.04 \quad 7.69$

$8.04 \quad 8.53$

$8.01 \quad 8.79$

$8.01 \quad 8.78$ 
I(3)mbt-like 2 (Drosophila)

trichorhinophalangeal syndrome I (human)

zinc fingerprotein 618

zinc finger protein 651

PC4 and SFRS1 interacting protein 1

tripartite motif-containing 33

E74-like factor 3

nuclear receptor co-repressor 2

RuvB-like protein 1

Max dimerization protein 4

predicted gene, EG631624

zinc finger matrin type 3

zinc finger protein 688

RRN3 RNA polymerase I transcription factor homolog (yeast)

Zinc finger protein 498 , mRNA

retinoblastoma 1

upstream transcription factor 2

CCAAT/enhancer binding protein (C/EBP), beta

nuclear factor of kappa light polypeptide gene enhancer in B-cells 2

zinc fingers and homeoboxes 2

signal transducer and activator of transcription $5 B$

RUN and FYVE domain containing 1

IKAROS family zinc finger 5

v-maf musculoaponeurotic fibrosarcoma oncogene family, protein $B$

homeo box B6

RIKEN cDNA 2810021G02 gene

metal response element binding transcription factor 1

zinc finger protein 7

sterol regulatory element binding factor 2

deformed epidermal autoregulatory factor 1 (Drosophila)

deoxynucleotidyltransferase, terminal, interacting protein 1

zinc finger and BTB domain containing 24

cDNA sequence BC018101 /// zinc finger protein 97

zinc finger protein 236

Kruppel-like factor 4 (gut)

v-maf musculoaponeurotic fibrosarcoma oncogene family, protein $\mathrm{F}$

AT rich interactive domain 5B (MRF1-like)

zinc finger protein 639

membrane-bound transcription factor peptidase, site 2

POU domain, class 2, transcription factor 1

cut-like homeobox 2

general transcription factor II I repeat domain-containing 1

H6 homeo box 2

nuclear factor related to kappa B binding protein

zinc finger protein 192

zinc finger with KRAB and SCAN domains 3

teashirt zinc finger family member 1

PR domain containing 4

zinc finger and BTB domain containing 17

zinc finger protein 146

elongation factor RNA polymerase II 2

RUN and FYVE domain-containing 2

timeless interacting protein

zinc finger and BTB domain containing 33

zinc finger protein 317

polymerase I and transcript release factor

\begin{tabular}{|c|c|c|}
\hline L3mbtl2 & 8.01 & 8.74 \\
\hline Trps1 & 8.01 & 7.68 \\
\hline Zfp618 & 8.01 & 8.57 \\
\hline Zfp651 & 8.00 & 8.21 \\
\hline Psip1 & 7.99 & 8.60 \\
\hline Trim33 & 7.99 & 8.11 \\
\hline Elf3 & 7.97 & 8.92 \\
\hline Ncor2 & 7.97 & 8.58 \\
\hline Ruvbl1 & 7.96 & 8.78 \\
\hline Mxd4 & 7.96 & 8.45 \\
\hline EG631624 & 7.95 & 8.11 \\
\hline Zmat3 & 7.95 & 7.95 \\
\hline Zfp688 & 7.95 & 7.79 \\
\hline Rrn3 & 7.94 & 8.56 \\
\hline Zfp498 & 7.94 & 8.12 \\
\hline Rb1 & 7.93 & 8.10 \\
\hline Usf2 & 7.93 & 8.35 \\
\hline Cebpb & 7.93 & 8.34 \\
\hline Nfkb2 & 7.93 & 7.80 \\
\hline Zhx2 & 7.92 & 9.01 \\
\hline Stat5b & 7.91 & 7.82 \\
\hline Rufy1 & 7.91 & 8.16 \\
\hline Ikzf5 & 7.91 & 8.14 \\
\hline Mafb & 7.91 & 7.89 \\
\hline Hoxb6 & 7.90 & 9.07 \\
\hline 2810021G02Rik & 7.89 & 8.38 \\
\hline Mtf1 & 7.89 & 8.46 \\
\hline Zfp7 & 7.89 & 8.74 \\
\hline Srebf2 & 7.89 & 8.15 \\
\hline Deaf1 & 7.88 & 8.44 \\
\hline Dnttip1 & 7.87 & 8.24 \\
\hline Zbtb24 & 7.87 & 7.91 \\
\hline ВС018101 & 7.87 & 8.48 \\
\hline Zfp236 & 7.87 & 8.09 \\
\hline Klf4 & 7.86 & 7.60 \\
\hline Maff & 7.86 & 8.65 \\
\hline Arid5b & 7.86 & 8.47 \\
\hline Zfp639 & 7.86 & 7.91 \\
\hline Mbtps2 & 7.86 & 7.89 \\
\hline Pou2f1 & 7.85 & 7.89 \\
\hline Cux2 & 7.85 & 8.10 \\
\hline Gtf2ird1 & 7.85 & 8.14 \\
\hline $\mathrm{Hm} \times 2$ & 7.84 & 8.47 \\
\hline Nfrkb & 7.84 & 8.11 \\
\hline Zfp192 & 7.84 & 8.49 \\
\hline Zkscan3 & 7.83 & 8.36 \\
\hline Tshz1 & 7.83 & 7.96 \\
\hline Prdm4 & 7.83 & 8.86 \\
\hline Zbtb17 & 7.81 & 7.66 \\
\hline Zfp146 & 7.81 & 8.26 \\
\hline Ell2 & 7.81 & 8.52 \\
\hline Rufy2 & 7.81 & 8.11 \\
\hline Tipin & 7.80 & 8.32 \\
\hline Zbtb33 & 7.80 & 8.73 \\
\hline Zfp317 & 7.80 & 8.61 \\
\hline Ptrf & 7.78 & 888 \\
\hline
\end{tabular}


nuclear receptor subfamily 1 , group $D$, member 1

zinc finger protein $322 \mathrm{~A}$

sex determining region of $\mathrm{Chr} Y$

KDM3B lysine (K)-specific demethylase 3B

E2F transcription factor 6

zinc finger protein 512

cyclin C

transcriptional adaptor 3 (NGG1 homolog, yeast)-like

purine-rich element binding protein $\mathrm{G}$

E74-like factor 1

zinc finger protein 26

Homeo box B2 (Hoxb2), mRNA

zinc finger protein 810

gene trap locus 3

transcription factor $\mathrm{CP} 2$

suppressor of Ty 3 homolog (S. cerevisiae)

zinc fingr protein 551

LIM domain only 4

retinoblastoma binding protein 5

SERTA domain containing 2

GTF2I repeat domain containing 2

CCAAT/enhancer binding protein (C/EBP), delta

avian erythroblastosis virus E-26 (v-ets) oncogene related

YEATS domain containing 2

TSC22 domain family, member 4

RIKEN cDNA 2810021J22 gene

sterol regulatory element binding transcription factor 1

zinc finger, ZZ-type with EF hand domain 1

nuclear respiratory factor 1

activating transcription factor 6 beta

zinc finger protein ( $\mathrm{C} 2 \mathrm{H} 2$ type) 276

mediator of RNA polymerase II transcription, subunit 25 homolog

RIKEN cDNA C920016K16 gene

four and a half LIM domains 1

trans-acting transcription factor 3

B-cell leukemia/lymphoma 6

zinc finger protein 410

E26 avian leukemia oncogene 1, 5' domain

expressed sequence Al854703

putative homeodomain transcription factor 1

PR domain containing 2, with ZNF domain

trans-acting transcription factor 4

zinc finger protein 68

upstream transcription factor 1

MyoD family inhibitor domain containing

ring finger protein 25

zinc finger protein 30

zinc finger, HIT domain containing 2

zinc finger protein 710

ring finger protein 138

LIM domain only 2

RB-associated KRAB repressor

transducin-like enhancer of split 1, homolog of Drosophila $E(s p l)$

$M L X$ interacting protein

zinc finger and BTB domain containing $7 C$

zinc finger and BTB domain containing 16

Nr1d1

Zfp322a

Sry

$\mathrm{Kdm} 3 \mathrm{~b}$

E2f6

Zfp512

Ccnc

Tada3l

Purg

Elf1

Zfp26

Hoxb2

Zfp810

Gtl3

Tcfcp2

Supt3h

Zfp551

Lmo4

Rbbp5

Sertad2

Gtf2ird2

Cebpd

Erg

Yeats2

Tsc22d4

2810021J22Rik

Srebf1

Zzef1

Nrf1

Atf6b

Zfp276

Med25

C920016K16Rik

Fhl1

Sp3

Bcl6

Zfp410

Ets1

Al854703

Phtf1

Prdm2

Sp4

Zfp68

Usf1

Mdfic

Rnf25

Zfp30

Znhit2

Zfp710

Rnf138

Lmo2

Rbak

Tle1

Mlxip

Zbtb7c

Zbtb16 $\begin{array}{ll}7.78 & 8.80\end{array}$

$\begin{array}{ll}7.78 & 7.87\end{array}$

$\begin{array}{ll}7.77 & 7.48\end{array}$

$\begin{array}{ll}7.76 & 8.18\end{array}$

$\begin{array}{ll}7.76 & 7.75\end{array}$

$\begin{array}{ll}7.76 & 8.64\end{array}$

$\begin{array}{ll}7.76 & 8.04\end{array}$

$\begin{array}{ll}7.75 & 8.38\end{array}$

$\begin{array}{ll}7.75 & 7.40\end{array}$

$\begin{array}{ll}7.74 & 8.68\end{array}$

$\begin{array}{ll}7.74 & 8.48\end{array}$

$7.74 \quad 7.61$

$\begin{array}{ll}7.74 & 8.52\end{array}$

$\begin{array}{ll}7.74 & 8.19\end{array}$

$\begin{array}{ll}7.73 & 8.75\end{array}$

$\begin{array}{ll}7.73 & 7.76\end{array}$

$\begin{array}{ll}7.73 & 8.35\end{array}$

$\begin{array}{ll}7.72 & 9.44\end{array}$

$\begin{array}{ll}7.71 & 7.79\end{array}$

$7.70 \quad 8.36$
7.70

$\begin{array}{ll}7.70 & 7.91\end{array}$

$\begin{array}{ll}7.70 & 7.67\end{array}$

$7.70 \quad 7.64$

$\begin{array}{ll}7.70 & 7.74\end{array}$

$\begin{array}{ll}7.70 & 8.33\end{array}$

$\begin{array}{ll}7.70 & 7.93\end{array}$

$\begin{array}{ll}7.69 & 8.00\end{array}$

$\begin{array}{ll}7.69 & 7.72\end{array}$

$\begin{array}{ll}7.68 & 9.22\end{array}$

$\begin{array}{ll}7.66 & 8.12\end{array}$

$\begin{array}{ll}7.66 & 7.50\end{array}$

$\begin{array}{ll}7.66 & 8.62\end{array}$

$\begin{array}{ll}7.66 & 7.80\end{array}$

$\begin{array}{ll}7.65 & 7.63\end{array}$

$7.65 \quad 8.13$

$7.64 \quad 8.54$
7.64

$7.64 \quad 8.16$

$\begin{array}{ll}7.63 & 7.80\end{array}$

$\begin{array}{ll}7.63 & 7.27\end{array}$

$\begin{array}{ll}7.63 & 7.94\end{array}$

$\begin{array}{ll}7.63 & 7.90\end{array}$

$\begin{array}{ll}7.62 & 8.45\end{array}$

$\begin{array}{ll}7.62 & 8.31\end{array}$

$\begin{array}{ll}7.62 & 7.83\end{array}$

$\begin{array}{ll}7.61 & 9.09\end{array}$

$\begin{array}{ll}7.61 & 8.22\end{array}$

$\begin{array}{ll}7.61 & 7.42\end{array}$

$7.60 \quad 8.26$

$\begin{array}{ll}7.60 & 7.96\end{array}$

$\begin{array}{ll}7.60 & 8.05\end{array}$

$\begin{array}{ll}7.59 & 7.97\end{array}$

$\begin{array}{ll}7.59 & 8.03\end{array}$

$7.58 \quad 8.13$

$\begin{array}{ll}7.58 & 8.02\end{array}$

$\begin{array}{ll}7.58 & 7.79\end{array}$

$7.58 \quad 8.36$ 
lin-9 homolog (C. elegans)

nuclear receptor binding factor 2

interferon activated gene 203

ELK1, member of ETS oncogene family

transcriptional adaptor 2 (ADA2 homolog, yeast)-like

nuclear receptor subfamily 1 , group $\mathrm{H}$, member 2

zinc finger protein 715

zinc finger, FYVE domain containing 19

zinc finger protein 652

Melanin concentrating hormone receptor interacting zinc finger protein

sal-like 2 (Drosophila)

polymerase (RNA) II (DNA directed) polypeptide D

zinc finger protein 59

peroxisome proliferator activated receptor alpha

MAD homolog 7 (Drosophila)

general transcription factor II $\mathrm{H}$, polypeptide 4

MMS19 (MET18 S. cerevisiae)

Zinc finger protein 458 (Zfp458), mRNA

RIKEN cDNA 6720487G11 gene

transcription factor $\mathrm{E} 2 \mathrm{a}$

core-binding factor, runt domain, alpha subunit 2, translocated to, 3

zinc finger protein 1

BRF2, subunit of RNA polymerase III transcription initiation factor

RIKEN cDNA C330011K17 gene

zinc finger with KRAB and SCAN domains 14

RIKEN cDNA 5830417I10 gene /// similar to Dingo protein isoform 2

ankyrin repeat, family A (RFXANK-like), 2

tumor suppressor candidate 4

mediator complex subunit 17

early growth response 2

zinc finger protein 574

zinc finger protein 386 (Kruppel-like)

myeloid/lymphoid or mixed-lineage leukemia 1

zinc finger protein 784

snail homolog 2 (Drosophila)

SCAN domain-containing 1

zinc finger protein 35

transformation related protein 53

ring finger protein 166

hairy/enhancer-of-split related with YRPW motif-like

zinc finger protein 277

TAF5 RNA polymerase II

zinc finger protein 235

zinc finger protein 110

TAF6 RNA polymerase II

predicted gene, EG240038

DCP1 decapping enzyme homolog A (S. cerevisiae)

zinc finger protein 12

RIKEN cDNA 4933403003 gene /// predicted gene, EG245263

regulatory factor $X$-associated ankyrin-containing protein

signal transducer and activator of transcription 5A

LIM homeobox protein 1

TGFB-induced factor homeobox 1

zinc finger protein $\mathrm{X}$-linked

sine oculis-related homeobox 4 homolog (Drosophila)

mediator complex subunit 27
Ling

Nrbf2

Ifi203

Elk1

Tada2l

Nr1h2

Zfp715

Zfyve19

Zfp652

Zmynd19

Sall2

Polr2d

Zfp59

Ppara

Smad7

Gtf2h4

Mms19

Zfp458

6720487G11Rik

Tcfe2a

Cbfa2t3

Zfp1

Brf2

C330011K17Rik

Zkscan14

5830417I10Rik

Ankra2

Tusc4

Med17

Egr2

Zfp574

Zfp386

MII1

Zfp784

Snai2

Scand1

Zfp35

Trp53

Rnf166

Heyl

Zfp277

Taf5

Zfp235

Zfp110

Taf6

EG240038

Dcp1a

Zfp12

4933403003Rik

Rfxank

Stat5a

Lhx1

Tgif1

Zfx

Six4

Med27
7.57

7.57

7.57

7.54

7.54

7.53

7.53

7.53

7.53

7.51

7.50

7.50

7.50

7.50

7.49

7.49

7.48

7.48

7.47

7.47

7.47

7.46

7.46

7.46

7.45

7.45

7.45

7.43

7.43

7.43

7.43

7.43

7.41

7.41

7.41

7.41

7.40

7.40

7.40

7.39

7.38

7.38

7.37

7.37

7.36

7.36

7.35

7.35

7.35

7.34

7.34

7.34

7.34

7.34

7.33

7.33
7.72

7.40

7.34

7.86

7.66

7.94

7.59

8.05

8.31

7.36

7.48

8.27

7.67

7.97

8.67

7.98

8.03

8.39

7.79

7.53

7.69

7.96

7.26

8.28

7.62

8.00

7.34

8.03

8.07

8.31

8.04

8.38

8.73

7.64

6.90

7.58

7.67

7.63

7.05

8.23

8.12

7.90

8.07

8.00

8.07

7.67

7.69

6.95

6.17

7.51

8.35

7.81

7.81

8.07

7.98

7.76 
peroxisome proliferative activated receptor, gamma

rearranged L-myc fusion sequence

Pp

RIKEN cDNA 1200003107 gene

homeo box $A 7$

RIf

7.32

7.45

zinc finger protein 426

1200003I07Rik

7.32

7.64

Hoxa7

7.32

7.94

BRF1 homolog, subunit

Zfp426

7.32

6.59

7.31

7.98

special AT-rich sequence binding protein 1

zinc finger protein 87

TAF9B RNA polymerase II

estrogen receptor 1 (alpha)

zinc finger protein 383

polymerase (DNA directed), epsilon 3 ( $p 17$ subunit)

POZ (BTB) and AT hook containing zinc finger 1

Brf1

7.30

7.56

$7.29 \quad 8.05$

$7.29 \quad 7.64$

Zfp87

$7.29 \quad 7.84$

Taf9b

$7.295 .63^{*}$

Esr1

Zfp383

7.29

7.39

Pole3

7.28

Patz1 $\quad 7.28$

7.68

TGFB-induced factor homeobox 2

Tgif2

8.39

transducin-like enhancer of split 2, homolog of Drosophila E(spl)

homeo box B9

SET and MYND domain containing 2

speckle-type POZ protein-like

myeloid/lymphoid or mixed-lineage leukemia

zinc finger protein $280 \mathrm{C}$

myeloid/lymphoid or mixed-lineage leukemia

RIKEN cDNA 9430025M13 gene

HNF1 homeobox A

zinc finger protein 790

homeo box $\mathrm{C} 6$

zinc finger protein, autosomal /// zinc finger protein $\mathrm{X}$-linked

B-cell CLL/lymphoma 6, member B

sine oculis-related homeobox 5 homolog (Drosophila)

mediator of RNA polymerase II transcription, subunit 12 homolog

zinc finger protein 579

zinc finger protein 799

MAX dimerization protein 1

zinc finger protein 454

bromodomain and PHD finger containing, 1

hairy and enhancer of split 1 (Drosophila)

zinc finger protein 90

zinc finger protein 282

CCR4-NOT transcription complex, subunit 8

RIKEN cDNA 1700049 G17 gene

suppressor of hairy wing homolog 4 (Drosophila)

RIKEN cDNA 6430526N21 gene

zinc finger protein 646

RIKEN CDNA 9630025I21 gene

I(3)mbt-like 3 (Drosophila)

mediator complex subunit 26

ubiquitin-like, containing PHD and RING finger domains, 1

zinc finger protein $385 \mathrm{~B}$

tripartite motif-containing 24

zinc finger protein 316

general transcription factor II $\mathrm{H}$, polypeptide 1

mediator of RNA polymerase II transcription, subunit 6 homolog

zinc finger protein 39

zinc finger with KRAB and SCAN domains 17

SET and MYND domain containing 3

zinc finger protein 788

Tle2

7.28

7.51

Hoxb9 $\quad 7.28$

7.83

$\begin{array}{lll}\text { Smyd2 } & 7.27 & 8.19\end{array}$

Spopl $\quad 7.27$

Mllt10

Zfp280c

7.26

7.26

Mllt1 $\quad 7.25$

9430025M13Rik $\quad 7.25$

7.24
7.24

Hnf1a

Zfp790

7.24

Hoxc6

Zfa I/I Zfx

7.24

7.23

Bcl6b

Six5

Med12

7.23

7.22

Zfp579

7.22

Zfp799

7.22

Mxd1

Zfp454

Brpf1

Hes1

Zfp90

Zfp282

Cnot8

1700049G17Rik

Suhw4

6430526N21Rik

Zfp646

9630025I21Rik

L3mbtl3

Med26

Uhrf1

Zfp385b

Trim24

Zfp316

Gtf2h1

Med6

Zfp39

Zkscan17

Smyd3

7.22

7.22

7.22

7.21

7.21

7.20

7.20

7.19

7.18

7.18

7.18

7.18

7.17

7.17

7.16

7.16

7.15

7.15

7.15

7.13

7.13

7.13

7.13

Zfp788

7.12

2810047C21Rik]

7.12

8.05

7.96

7.74

8.32

7.43

6.94

8.11

6.12

7.64

7.39

7.94

8.14

7.56

7.96

7.75

7.72

7.86

8.44

7.28

7.46

8.22

7.87

8.04

7.69

7.38

7.49

7.48

7.08

7.49

7.24

7.74

7.23

7.44

7.86

7.87

6.99

8.00

7.71

RIKEN cDNA 2810047C21 gene 1 /// predicted gene, EG665577 
IKAROS family zinc finger 4

zinc finger protein 2

peroxisome proliferator activator receptor delta

zinc finger and BTB domain containing 26

zinc finger protein 512B

forkhead box N2

zinc finger protein 93

expressed sequence Al894139

PHD finger protein 15

WT1-interacting protein

zinc finger protein 319

zinc finger protein 691

zinc finger protein 182

zinc finger protein 113

ubiquitin-like, containing PHD and RING finger domains 2

AT rich interactive domain $3 \mathrm{~A}$ (BRIGHT-like)

zinc finger protein 64

polycomb group ring finger 6

CREB regulated transcription coactivator 2

Jun-B oncogene

transcription elongation factor A (SII), 3

zinc finger protein 532

Kruppel-like factor 13

cDNA sequence D10627

Inhibitor of DNA binding 4 (Id4), mRNA

zinc finger like protein 1

interferon regulatory factor 9

homeo box $\mathrm{C} 4$

lysine (K)-specific demethylase $3 \mathrm{~A}$

RIKEN cDNA 2810047C21 gene 1

zinc finger protein 451

zinc finger, HIT type 3

expressed sequence AA987161

MAX-like protein $X$

zinc finger protein 623

RIKEN cDNA 2610008E11 gene

aryl-hydrocarbon receptor

zinc finger protein 637

general transcription factor $\mathrm{IIH}$, polypeptide 3

GDNF-inducible zinc finger protein 1

predicted gene, OTTMUSG00000010657

zinc finger protein 462

putative homeodomain transcription factor 2

MYST histone acetyltransferase 1

interferon regulatory factor 2

period homolog 3 (Drosophila)

RIKEN cDNA 4930422107 gene

neuronal PAS domain protein 2

nuclear factor of activated T-cells, cytoplasmic

zinc finger protein 180

zinc finger, FYVE domain containing 1

predicted gene, EG330503

SRY-box containing gene 18

Flt3 interacting zinc finger protein 1

forkhead box P4

Ets2 repressor factor

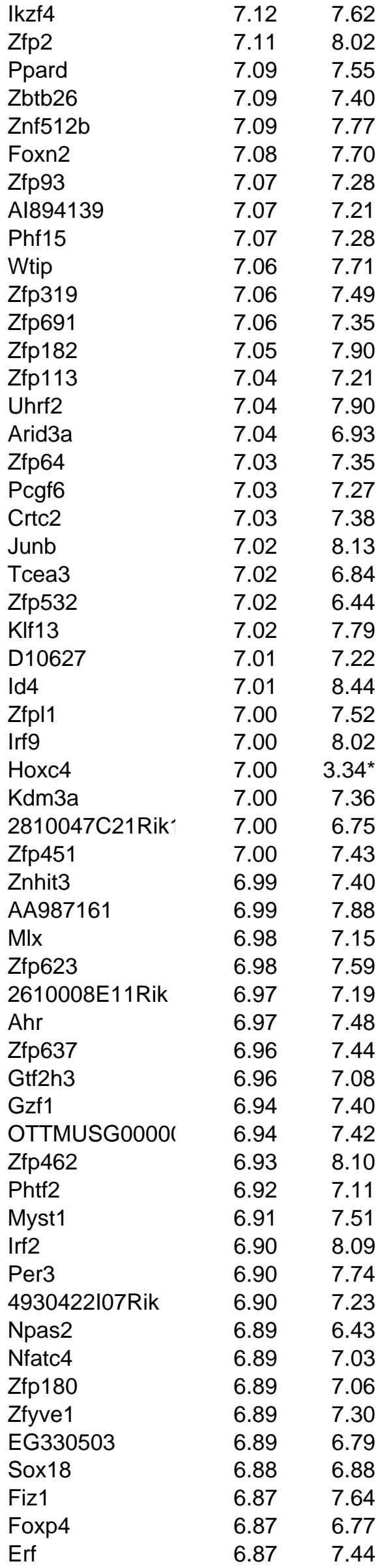


zinc finger protein 395

RIKEN cDNA 4930422107 gene

RIKEN cDNA 4933426121 gene

MKL (megakaryoblastic leukemia)/myocardin-like 1

pleiomorphic adenoma gene-like 2

cDNA sequence BC023179

forkhead box $\mathrm{P} 3$

zinc finger protein $518 \mathrm{~B}$

E4F transcription factor 1

zinc finger protein 518

general transcription factor II H, polypeptide 2

RIKEN cDNA 6330416L07 gene

calmodulin binding transcription activator 2

SET and MYND domain containing 5

ubiquitously transcribed tetratricopeptide repeat gene

progesterone receptor

cell division cycle associated 4

Kruppel-like factor 11

homeo box D3

zinc finger protein 668

nuclear receptor subfamily 5 , group A, member 1

candidate tumor suppressor in ovarian cancer 2

cDNA sequence BC066028

zinc finger protein 74

zinc finger E-box binding homeobox 1

thyroid hormone receptor beta

DCP1 decapping enzyme homolog b (S. cerevisiae)

mesenchyme homeobox 1

NK6 homeobox 2

ring finger protein 125

POU domain, class 4, transcription factor 1

inhibitor of growth family, member 4

brain expressed myelocytomatosis oncogene

zinc finger protein 667

IKAROS family zinc finger 2

human immunodeficiency virus type I enhancer binding protein 3

calmodulin binding transcription activator 1

CREB regulated transcription coactivator 1

RIKEN cDNA 5730403M16 gene

zinc finger protein 563

retinoic acid induced 1

nuclear factor of kappa light polypeptide gene enhancer in B-cells 1

SRY-box containing gene 5

zinc finger protein 41

heat shock factor 2

v-rel reticuloendotheliosis viral oncogene homolog A (avian)

MKL/myocardin-like 2

E1A binding protein $\mathrm{p} 300$

RIKEN cDNA A530054K11 gene

zinc finger protein 692

homeo box D4

zinc finger protein 109

polycomb group ring finger 3

zinc finger protein 748

nuclear receptor subfamily 4 , group A, member 2

trafficking protein particle complex 2

\begin{tabular}{|c|c|}
\hline Zfp395 & 6.87 \\
\hline 4930422I07Rik & 6.87 \\
\hline 4933426I21Rik & 6.86 \\
\hline Mkl1 & 6.86 \\
\hline Plagl2 & 6.85 \\
\hline BC023179 & 6.84 \\
\hline Foxp3 & 6.84 \\
\hline Zfp518b & 6.83 \\
\hline E4f1 & 6.83 \\
\hline Zfp518 & 6.82 \\
\hline Gtf2h2 & 6.82 \\
\hline 6330416L07Rik & 6.81 \\
\hline Camta2 & 6.81 \\
\hline Smyd5 & 6.81 \\
\hline Uty & 6.79 \\
\hline Pgr & 6.79 \\
\hline Cdca4 & 6.78 \\
\hline Klf11 & 6.78 \\
\hline Hoxd3 & 6.78 \\
\hline Zfp668 & 6.78 \\
\hline Nr5a1 & 6.76 \\
\hline RP23-143A14.5 & 6.76 \\
\hline BC066028 & 6.76 \\
\hline Zfp74 & 6.76 \\
\hline Zeb1 & 6.75 \\
\hline Thrb & 6.75 \\
\hline Dcp1b & 6.75 \\
\hline Meox1 & 6.74 \\
\hline Nkx6-2 & 6.73 \\
\hline Rnf125 & 6.73 \\
\hline Pou4f1 & 6.73 \\
\hline Ing4 & 6.73 \\
\hline Bmyc & 6.72 \\
\hline Zfp667 & 6.71 \\
\hline Ikzf2 & 6.70 \\
\hline Hivep3 & 6.70 \\
\hline Camta1 & 6.70 \\
\hline Crtc1 & 6.70 \\
\hline 5730403M16Rik & 6.69 \\
\hline Zfp563 & 6.69 \\
\hline Rai1 & 6.69 \\
\hline Nfkb1 & 6.68 \\
\hline Sox5 & 6.68 \\
\hline Zfp41 & 6.67 \\
\hline Hsf2 & 6.66 \\
\hline Rela & 6.65 \\
\hline Mkl2 & 6.63 \\
\hline Ep300 & 6.63 \\
\hline A530054K11Rik & 6.62 \\
\hline Zfp692 & 6.61 \\
\hline Hoxd4 & 6.61 \\
\hline Zfp109 & 6.60 \\
\hline Pcgf3 & 6.60 \\
\hline Zfp748 & 6.60 \\
\hline Nr4a2 & 6.60 \\
\hline $\mathrm{pc}$ & 6.59 \\
\hline
\end{tabular}


zinc finger protein 213

zinc finger protein 128

Zfp213

6.59

6.70

RIKEN cDNA A630033E08 gene

Zfp128

6.59

6.81

zinc finger protein 157

A630033E08Rik

6.59

6.47

polycomb group ring finger 5

Zfp157

6.59

Pcgf5

6.59

6.83

zinc finger protein 94

Zfp94

6.59

7.08

RIKEN CDNA 9230108I15 gene

heart and neural crest derivatives expressed transcript 1

PR domain containing 15

zinc finger E-box binding homeobox 2

zinc finger protein 142

mastermind like 2 (Drosophila)

zinc finger protein 825

9230108115Rik

6.58

6.82

Hand1

6.58

6.11

Prdm15

6.58

6.41

Zeb2

Zfp142

Maml2

Zfp825

6.57

7.50

transformation related protein 63

Zinc finger protein 120, mRNA (cDNA clone IMAGE:4222737)

Trp63

Zfp844

6.57

6.18

nuclear receptor subfamily 2 , group $C$, member 1

nuclear factor of activated T-cells, cytoplasmic

GA repeat binding protein, beta 1

zinc finger protein 760

SRY-box containing gene 13

zinc finger protein 143

TAF7 RNA polymerase II

homeo box A5

four and a half LIM domains 2

teashirt zinc finger family member 2

zinc finger protein 295

zinc finger protein 324

Kruppel-like factor 16

retinoic acid receptor, gamma

zinc finger protein 628

RIKEN cDNA E430024I08 gene

Kruppel-like factor 2 (lung)

interferon activated gene 205

glucocorticoid modulatory element binding protein 2

Jun dimerization protein 2

RIKEN cDNA 4930452B06 gene

expressed sequence AU041133

transcription elongation factor $\mathrm{A}(\mathrm{SII}), 2$

predicted gene, ENSMUSG00000053512

general transcription factor II E, polypeptide 1 (alpha subunit)

myocyte enhancer factor $2 \mathrm{C}$

RNA binding motif protein 38

zinc finger protein 346

zinc finger protein 697

Nr2c1

Nfatc2

Gabpb1

Zfp760

Sox13

Zfp143

6.57

6.57

6.69

6.68

$6.57 \quad 7.45$

$6.57 \quad 6.59$

$6.56 \quad 7.38$

$\begin{array}{ll}6.56 & 6.29\end{array}$

$6.56 \quad 7.50$

$6.56 \quad 6.79$

Taf7

Hoxa5

6.56

6.68

$6.55 \quad 6.93$

$6.55 \quad 6.62$

$5.14^{*}$

Tshz2

$6.53 \quad 6.31$

Zfp295

Zfp324

Klf16

Rarg

Zfp628

6.53

6.17

$6.52 \quad 7.30$

$6.52 \quad 6.88$

$6.50 \quad 7.24$

$6.49 \quad 7.36$

$\begin{array}{lll}\text { Klf2 } & 6.47 & 6.84\end{array}$

Ifi205 //I Mnda $\quad 6.46 \quad 5.74^{*}$

Gmeb2

Jdp2

$6.46 \quad 6.84$

4930452B06Rik $\quad 6.43 \quad 6.94$

$\begin{array}{lll}\text { AU041133 } & 6.43 & 7.00\end{array}$

$\begin{array}{lll}\text { Tcea2 } & 6.42 & 7.13\end{array}$

ENSMUSG00001 $\quad 6.42 \quad 6.40$

$\begin{array}{lll}\text { Gtf2e1 } & 6.42 & 6.92\end{array}$

$\begin{array}{lll}\text { Mef2c } & 6.42 & 6.31\end{array}$

$\begin{array}{lll}\mathrm{Rbm} 38 & 6.42 & 6.12\end{array}$

Zfp346 $\quad 6.41 \quad 6.65$

$\begin{array}{lll}Z \text { Zfp697 } & 6.40 & 6.61\end{array}$

$\begin{array}{lll}\text { Zfp280b } & 6.40 & 7.13\end{array}$

RIKEN CDNA A630033E08 gene

transducin-like enhancer of split 6, homolog of Drosophila $E(s p l)$

sex comb on midleg homolog 1

A630033E08Rik $\quad 6.40 \quad 6.88$

$\begin{array}{lll}\text { Tle6 } & 6.39 & 6.40\end{array}$

$\begin{array}{lll}\text { Scmh1 } & 6.38 & 7.14\end{array}$

$\begin{array}{llll}\text { zinc finger and BTB domain containing 39 } & \text { Zbtb39 } & 6.38 & 7.35 \\ \text { zinc finger protein 273 /// zinc finger protein 85, related sequence 1 } & \text { Zfp273 } & 6.38 & 6.88\end{array}$

zinc finger protein 334

zinc finger protein 169

Zfp334

Zfp169

6.37

6.35

Bnc2

6.36

6.90

Zfp28

6.35

6.35

zinc finger protein 28

Snapc4

6.35

6.87

Hey2

6.34

7.06

hairy/enhancer-of-split related with YRPW motif 2

6.33 
E2F transcription factor 5

zinc finger protein 444

zinc finger and BTB domain containing 3

zinc finger protein 37

AT rich interactive domain 3B (BRIGHT-like)

zinc finger protein 653

Ngfi-A binding protein 2

teashirt zinc finger family member 3

MYST histone acetyltransferase monocytic leukemia 4

inhibitor of DNA binding 1

atonal homolog 7 (Drosophila)

NK2 transcription factor related, locus 6 (Drosophila)

RIKEN cDNA 4930432021 gene

RAR-related orphan receptor beta

Meis homeobox 3

zinc finger protein 418

zinc finger protein

scratch homolog 2, zinc finger protein (Drosophila)

T-box 3

zinc finger protein 108

zinc finger and BTB domain containing 48

RIKEN CDNA 6720489N17 gene, mRNA

RIKEN cDNA A430033K04 gene

basic helix-loop-helix family, member e22

elongation factor RNA polymerase II

SRY-box containing gene 11

zinc finger protein 101

regulatory factor $\mathrm{X}, 2$ (influences HLA class II expression)

zinc finger and SCAN domain containing 4F

occludin/ELL domain containing 1

zinc finger protein 341

transcription factor AP4

Friend leukemia integration 1

retinoblastoma-like 1 ( $p 107$ )

zinc finger protein 689

CDNA sequence BC038328, mRNA (cDNA clone IMAGE:1531884)

predicted gene, OTTMUSG00000003825

delta-like 4 (Drosophila)

nuclear factor of activated T-cells, cytoplasmic

zinc finger protein 120

pleckstrin homology domain containing, family $\mathrm{F}$ member 1

zinc finger protein 446

LIM domain binding 2

nuclear receptor subfamily 1 , group $\mathrm{H}$, member 4

forkhead box P2

Kruppel-like factor 7 (ubiquitous)

caspase 8 associated protein 2

ets variant gene 5

zinc finger protein 597

zinc finger and BTB domain containing 5

nuclear receptor interacting protein 2

zinc finger protein 287

SET and MYND domain containing 4

zinc finger protein 709

PHD finger protein 1

Meis homeobox 2

\begin{tabular}{|c|c|c|}
\hline E2f5 & 6.33 & 6.96 \\
\hline Zfp444 & 6.32 & 6.24 \\
\hline Zbtb3 & 6.32 & 6.17 \\
\hline Zfp37 & 6.32 & 7.21 \\
\hline Arid3b & 6.32 & 6.25 \\
\hline Zfp653 & 6.32 & 6.65 \\
\hline Nab2 & 6.31 & 7.38 \\
\hline Tshz3 & 6.31 & 7.28 \\
\hline Myst4 & 6.30 & 6.86 \\
\hline Id1 & 6.30 & 7.77 \\
\hline Atoh7 & 6.30 & 6.53 \\
\hline Nkx2-6 & 6.30 & 5.88 \\
\hline 4930432O21Rik & 6.28 & 6.23 \\
\hline Rorb & 6.28 & 8.23 \\
\hline Meis3 & 6.26 & 6.54 \\
\hline Zfp418 & 6.25 & 6.68 \\
\hline Zfp229 & 6.25 & 6.62 \\
\hline Scrt2 & 6.25 & 6.30 \\
\hline Tbx3 & 6.25 & 8.29 \\
\hline Zfp108 & 6.25 & 6.54 \\
\hline Zbtb48 & 6.23 & 6.26 \\
\hline 6720489N17Rik & 6.23 & 7.27 \\
\hline A430033K04Rik & 6.23 & 6.90 \\
\hline Bhlhe22 & 6.22 & 8.22 \\
\hline Ell & 6.22 & 6.59 \\
\hline Sox11 & 6.21 & 5.41 \\
\hline Zfp101 & 6.21 & 6.56 \\
\hline $\mathrm{Rf} \times 2$ & 6.20 & 6.06 \\
\hline Zscan4f & 6.20 & $4.24^{\star}$ \\
\hline Ocel1 & 6.20 & 6.54 \\
\hline Zfp341 & 6.20 & 6.61 \\
\hline Tcfap4 & 6.19 & 6.15 \\
\hline Fli1 & 6.18 & 5.84 \\
\hline Rbl1 & 6.18 & 7.17 \\
\hline Zfp689 & 6.18 & 6.49 \\
\hline Zfp708 & 6.18 & 6.87 \\
\hline OTTMUSG & 6.18 & 6.11 \\
\hline DII4 & 6.17 & 6.89 \\
\hline Nfatc1 & 6.17 & 6.55 \\
\hline Zfp120 & 6.14 & 6.60 \\
\hline Plekhf1 & 6.13 & 6.69 \\
\hline Zfp446 & 6.13 & 6.24 \\
\hline Ldb2 & 6.12 & 5.89 \\
\hline Nr1h4 & 6.11 & 6.10 \\
\hline Foxp2 & 6.11 & $4.96^{\star}$ \\
\hline Klf7 & 6.10 & 8.52 \\
\hline Casp8ap2 & 6.10 & 7.20 \\
\hline Etv5 & 6.10 & $4.90^{*}$ \\
\hline Zfp597 & 6.09 & 6.34 \\
\hline Zbtb5 & 6.09 & 6.33 \\
\hline Nrip2 & 6.09 & $5.09^{*}$ \\
\hline Zfp287 & 6.08 & 6.67 \\
\hline Smyd4 & 6.08 & 6.53 \\
\hline Zfp709 & 6.08 & 7.37 \\
\hline Phf1 & 6.05 & 6.16 \\
\hline Meis2 & 6.05 & 6.25 \\
\hline
\end{tabular}


ethanol induced 1

E2F transcription factor 2

zinc finger protein 248

cDNA sequence AB182283

zinc finger protein $354 \mathrm{C}$

transcription factor EC

zinc finger and BTB domain containing 7B

transcription elongation factor A (SII)

CREB regulated transcription coactivator 3

ets variant gene 4 (E1A enhancer binding protein, E1AF)

zinc finger and AT hook domain containing

jagged 2

transcription factor 15

zinc finger protein 60

zinc finger protein 493

nucleus accumbens associated 1

E74-like factor 5

SERTA domain containing 3

nuclear receptor subfamily 6 , group A, member 1

zinc finger protein 654

zinc finger protein 595

zinc finger protein 160

zinc finger protein 407

runt related transcription factor 1

zinc finger protein 52

H6 homeo box 3

RIKEN cDNA A830023I12 gene

Zinc finger protein 40 (Zfp40), mRNA

interferon regulatory factor 5

aryl hydrocarbon receptor nuclear translocator-like

zinc finger protein $385 \mathrm{C}$

nuclear receptor subfamily 0 , group $B$, member 2

ovo-like 2 (Drosophila)

hypermethylated in cancer 2

zinc finger protein 275

zinc finger protein 568

RIKEN cDNA 1700029101 gene

expressed sequence AI987944

zinc finger, FYVE domain containing 26

zinc finger with KRAB and SCAN domains 5

zinc finger protein 711

similar to SRF-dependent transcription regulation associated protein

TEA domain family member 3

signal transducer and activator of transcription 2

zinc finger and SCAN domain containing 22

CDNA sequence BC062115, mRNA

zinc finger protein 53

avian reticuloendotheliosis viral (v-rel) oncogene related $B$

E2F transcription factor 1

zinc finger protein 11

MAD homolog 6 (Drosophila)

ets variant gene 1

interferon regulatory factor 8

predicted gene, 380850

zinc finger protein 61

zinc finger protein 758

\begin{tabular}{|c|c|c|}
\hline Etohi1 & 6.05 & 6.33 \\
\hline E2f2 & 6.05 & 7.65 \\
\hline Zfp248 & 6.05 & 6.67 \\
\hline AB182283 & 6.05 & 6.05 \\
\hline Zfp354c & 6.04 & 6.86 \\
\hline Tcfec & 6.03 & $5.59^{*}$ \\
\hline Zbtb7b & 6.03 & 6.51 \\
\hline Tceanc & 5.99 & 6.31 \\
\hline Crtc3 & 5.99 & 6.09 \\
\hline Etv4 & 5.97 & $5.00^{*}$ \\
\hline Zfat & 5.96 & 6.11 \\
\hline Jag2 & 5.94 & $5.76^{*}$ \\
\hline Tcf15 & 5.94 & $5.73^{*}$ \\
\hline Zfp60 & 5.93 & 5.95 \\
\hline Zfp493 & 5.93 & 6.29 \\
\hline Nacc1 & 5.92 & $5.76^{*}$ \\
\hline Elf5 & 5.91 & 9.57 \\
\hline Sertad3 & 5.90 & 6.75 \\
\hline Nr6a1 & 5.90 & 6.84 \\
\hline Zfp654 & 5.90 & 6.49 \\
\hline Zfp595 & 5.90 & 6.67 \\
\hline Zfp160 & 5.89 & 6.34 \\
\hline Zfp407 & 5.89 & 6.88 \\
\hline Runx1 & 5.87 & 5.81 \\
\hline Zfp52 & 5.87 & 6.18 \\
\hline $\mathrm{Hm} \times 3$ & 5.86 & 7.50 \\
\hline A830023I12Rik & 5.86 & 5.85 \\
\hline Zfp40 & 5.86 & 6.20 \\
\hline Irf5 & 5.86 & 5.87 \\
\hline Arntl & 5.85 & 6.17 \\
\hline Zfp385c & 5.84 & $5.44^{\star}$ \\
\hline NrOb2 & 5.84 & 6.25 \\
\hline Ovol2 & 5.83 & 6.43 \\
\hline Hic2 & 5.81 & $5.50^{*}$ \\
\hline Zfp275 & 5.80 & 5.92 \\
\hline Zfp568 & $5.79^{\star}$ & 6.25 \\
\hline 1700029I01Rik & $5.79^{*}$ & 6.69 \\
\hline Al987944 & $5.78^{\star}$ & 6.71 \\
\hline Zfyve26 & $5.75^{\star}$ & 6.79 \\
\hline Zkscan5 & $5.70^{*}$ & 6.42 \\
\hline Zfp711 & $5.70^{*}$ & 7.66 \\
\hline LOC636713 & $5.68^{*}$ & 6.31 \\
\hline Tead3 & $5.63^{\star}$ & 5.92 \\
\hline Stat2 & $5.63^{*}$ & 6.06 \\
\hline Zscan22 & $5.62^{\star}$ & 5.90 \\
\hline ВС062115 & $5.62^{\star}$ & 5.84 \\
\hline Zfp53 & $5.6^{*}$ & 6.77 \\
\hline Relb & $5.59^{*}$ & 6.10 \\
\hline E2f1 & $5.59^{\star}$ & 6.22 \\
\hline Zfp11 & $5.55^{\star}$ & 5.82 \\
\hline Smad6 & $5.54^{*}$ & 6.26 \\
\hline Etv1 & $5.53^{\star}$ & 5.99 \\
\hline Irf8 & $5.49^{\star}$ & 5.91 \\
\hline 380850 & $5.48^{*}$ & 6.05 \\
\hline Zfp61 & $5.46^{*}$ & 6.06 \\
\hline Zfp758 & $5.46^{*}$ & 6.19 \\
\hline
\end{tabular}


RIKEN cDNA 3110052M02 gene

zinc finger protein 472

zinc finger protein 202

OVO homolog-like 1 (Drosophila)

myelocytomatosis oncogene

zinc finger protein 51

zinc finger protein 719

zinc finger protein 513

zinc finger protein 429

zinc finger protein 239

cAMP responsive element binding protein 3-like 4

general transcription factor IIIC, polypeptide 3

zinc finger and BTB domain containing 34

scleraxis

v-myc myelocytomatosis viral related oncogene

filamin binding LIM protein 1

predicted gene, EG434179

zinc finger protein 335

pre B-cell leukemia transcription factor 3

cDNA sequence BC066107

zinc finger protein 438

twist homolog 1 (Drosophila)

cullin-associated and neddylation-dissociated 2 (putative)

RIKEN cDNA 2210010B09 gene

expressed sequence Al449175

Kruppel-like factor 5

3110052M02Rik
Zfp472
Zfp202
Ovol1
Myc
Zfp51
Zfp719
Zfp513
Zfp429
Zfp239
Creb314
Gtf3c3
Zbtb34
Scx
Mycn
Fblim1
EG434179
Zfp335
Pbx3
BC066107
Zfp438
Twist1
Cand2
2210010B09Rik
Al449175
Klf5

$5.45^{\star} \quad 6.69$

$5.44^{\star} \quad 6.07$

$5.44^{\star} \quad 5.93$

$5.40^{*} \quad 6.24$

$5.36^{\star} \quad 6.92$

$5.35^{\star} \quad 6.32$

$5.33^{\star} \quad 6.20$

$5.33^{\star} \quad 6.17$

$5.31^{\star} \quad 6.41$

$5.30^{*} \quad 5.91$

$5.30^{*} \quad 5.82$

$5.30^{*} \quad 5.96$

$5.29^{\star} \quad 6.67$

$5.25^{\star} \quad 6.79$

$5.24^{\star} \quad 6.53$

$5.24^{\star} \quad 6.16$

$5.23^{*} \quad 6.00$

$5.19^{\star} \quad 6.36$

$5.15^{\star} \quad 7.30$

$5.13^{\star} \quad 5.90$

$5.13^{*} \quad 5.89$

$5.07^{*} \quad 6.34$

$4.92^{*} \quad 6.44$

$4.89 * \quad 5.84$

$4.86^{\star} \quad 6.17$

$4.6^{\star} \quad 6.46$

* - the A_value is below the cut-off level 
A

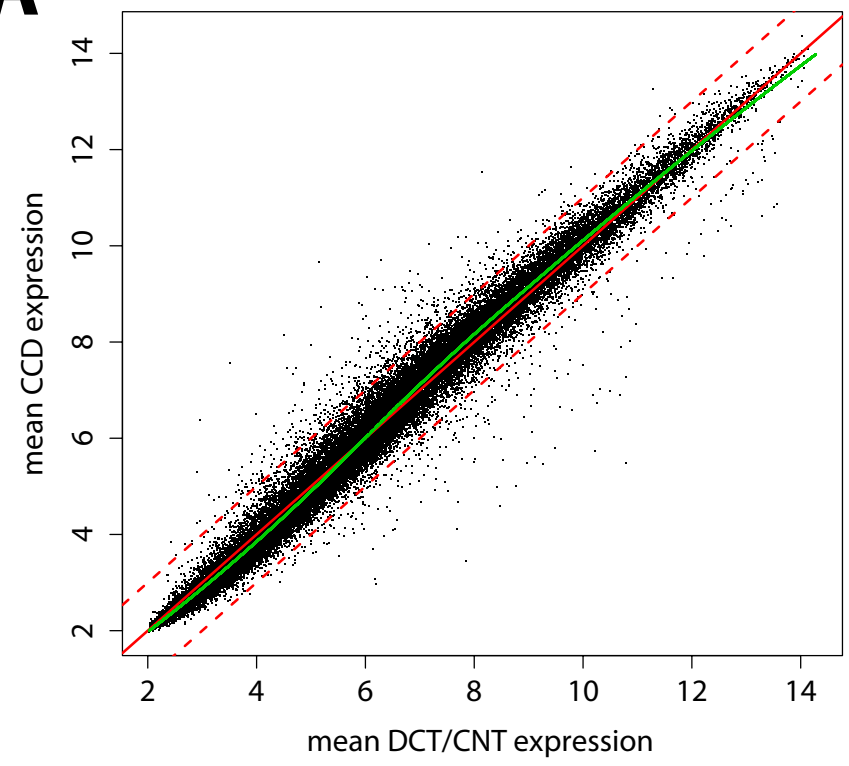

B

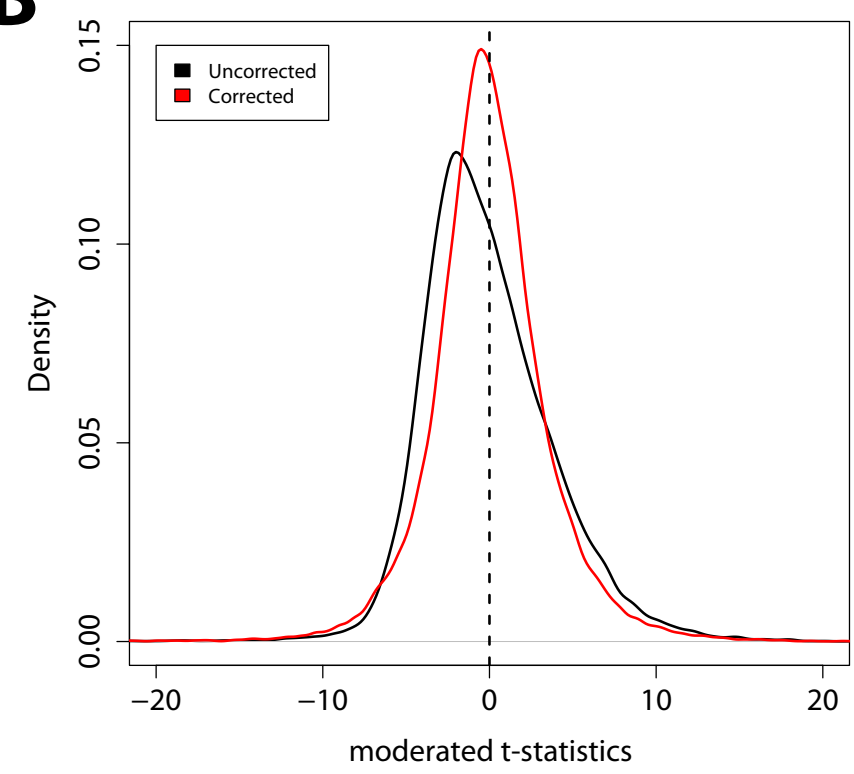

